Universidade de São Paulo

Escola Superior de Agricultura "Luiz de Queiroz"

Perda localizada de carga em conexões utilizadas em sistemas de microirrigação

Wagner Wilson Ávila Bombardelli

Dissertação apresentada para obtenção do título de Mestre em Ciências. Área de concentração: Engenharia de Sistemas Agrícolas

Piracicaba

2018 


\section{Wagner Wilson Ávila Bombardelli \\ Engenheiro Agrícola}

Perda localizada de carga em conexões utilizadas em sistemas de microirrigação versão revisada de acordo com a resolução CoPGr 6018 de 2011

Orientador:

Prof. Dr. JOSÉ ANTÔNIO FRIZZONE

Dissertação apresentada para obtenção do título de Mestre em Ciências. Área de concentração: Engenharia de Sistemas Agrícolas 
Dados Internacionais de Catalogação na Publicação DIVISÃO DE BIBLIOTECA - DIBD/ESALQ/USP

Bombardelli, Wagner Wilson Ávila

Perda localizada de carga em conexões utilizadas em sistemas de microirrigação / Wagner Wilson Ávila Bombardelli. - - versão revisada de acordo com a resolução CoPGr 6018 de 2011. - - Piracicaba, 2018.

$81 \mathrm{p}$.

Dissertação (Mestrado) - - USP / Escola Superior de Agricultura "Luiz de Queiroz".

1. Bancada automatizada 2. Hidráulica 3. Coeficientes experimentais 4. Modelagem de conexões I. Título 
DEDICATÓRIA

À minha avó Aparecida (in memoriam), Ao prof. Antonio Pires de Camargo, dedico... 


\section{AGRADECIMENTOS}

Não há evolução que se conduza solitariamente. Ela se mantém contínua através daqueles que nos indicam caminhos, nos orientam e nos dão o esteio para seguirmos o nosso. Para os quais registro meu singelo reconhecimento sobre o crescimento conquistado, dessa forma agradeço...

À Escola Superior de Agricultura "Luiz de Queiroz” (ESALQ/USP) e ao Programa de Pós-Graduação em Engenharia de Sistemas Agrícolas, por oferecer condições necessárias para as pesquisas e assumir essa responsabilidade com a sociedade;

À Coordenação de Aperfeiçoamento Pessoal de Nível Superior (CAPES) pela concessão de bolsa, que faz acontecer a expansão e consolidação da pós-graduação no país;

Ao Prof. José Antônio Frizzone, por suas sugestões, recomendações e confiança em mim depositada ao longo desse trabalho;

Ao Prof. Antonio Pires de Camargo, por quem dedico com prazer o fruto de nosso estudo, pois não caberiam palavras para atingir tanto conhecimento compartilhado com humildade e paciência. Um abraço fraterno!

Ao Prof. Giuliani do Prado, por me consolidar a base teórica necessária e me proporcionar ingressar no meio científico;

Ao Seu Sílvio, da RSB Plásticos, por seu importante apoio e confiança no saber, sem os quais estaríamos ainda mais longe de se atingir o suprassumo da excelência;

Aos funcionários e professores do Departamento de Engenharia de Biossistemas (LEB) pelo carinho, dedicação e compromisso com o setor público. Especialmente aos professores Tarlei A. Botrel e Sérgio Nascimento Duarte, dos quais zelarei os exemplos transmitidos;

Aos colegas Eric Alberto da Silva e Hermes Soares da Rocha por suas estimadas colaborações num estudo multidisciplinar; ao colega de faculdade Rogério Lavanholi pela irmandade, apoio e simulações; ao colega Luiz Sobenko pelo aprendizado compartilhado; aos estagiários Dante Chiaroni e Nathalia Horrana por suas significativas colaborações; aos demais colegas do LEMI: Ana Sátiro, Diego Sousa, Douglas Reis, Fabrício de Oliveira, Marcus Talamini Junior, Veronica Martins; à companheira Luma Dominical e demais colegas que fortaleceram a amizade e compartilharam de seus momentos, tais como Adriano Pacheco, Ailson de Almeida, Alex Nunes, Artur Carniato, Asdrubal Farias, Cleverson Freitas, Débora Pantojo, Éder Duarte, Elvis Felipe, Fernada Lameda, Hugo Ricardo, Jéfferson Costa, Jefferson Vieira, Jéssica Garcia, Luísa Lelis, Marcos Amaral, Nathalia Lopes, Oriel Figureira, Otávio Neto, Rony Sampaio, Tamires Teles, Thuane Barbosa, Timóteo Barros, Wagner Wolff et al. 


\section{SUMÁRIO}

RESUMO

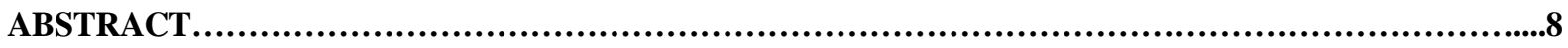

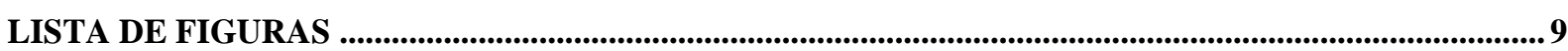

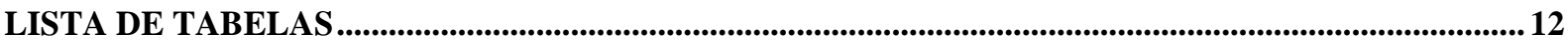

1. INTRODUÇÃ

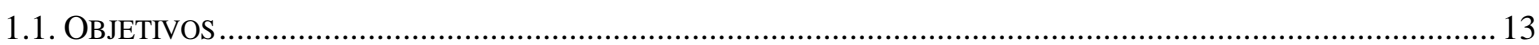

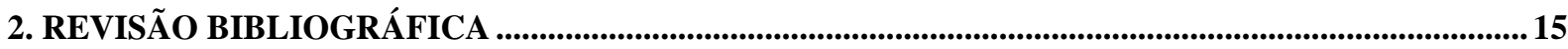

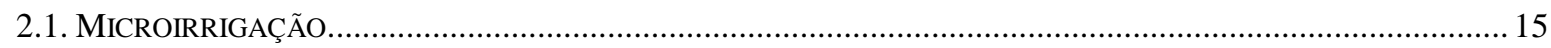

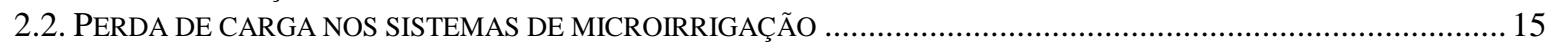

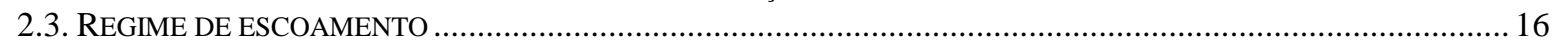

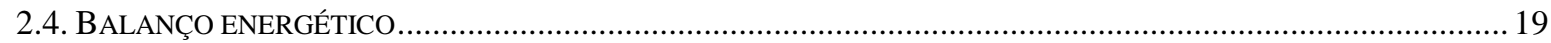

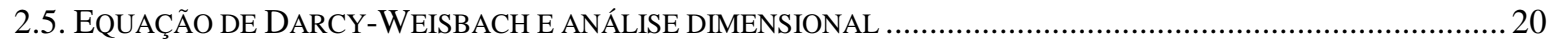

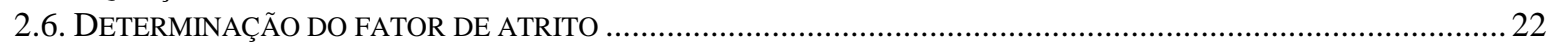

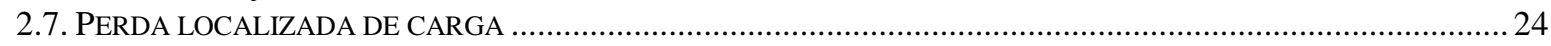

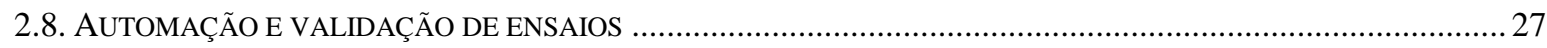

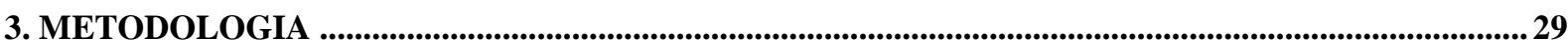

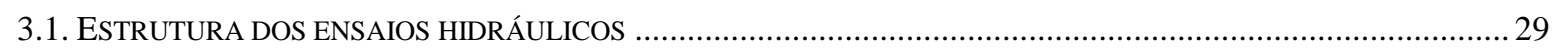

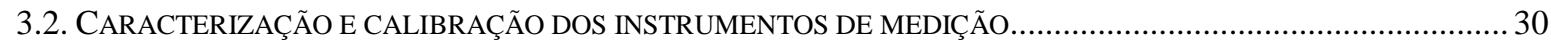

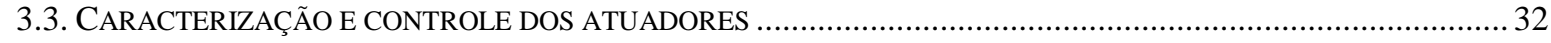

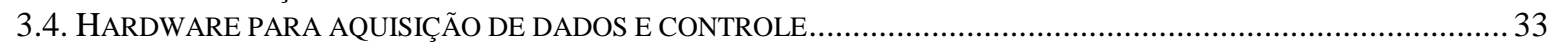

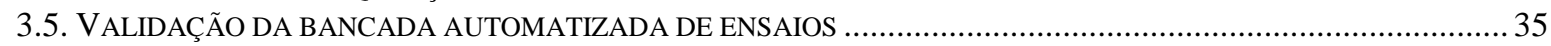

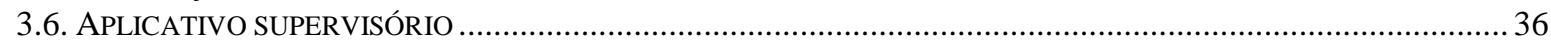

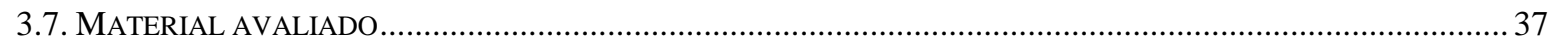

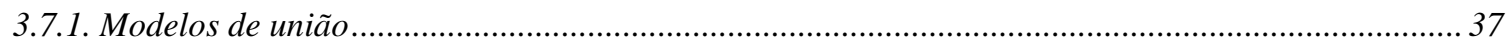

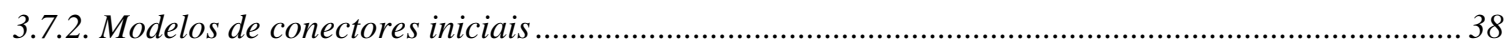

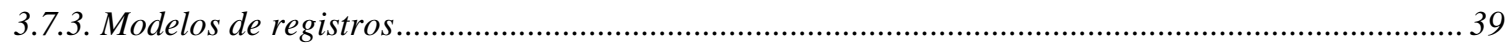

3.7.3.1. Registros de união ………………………………………………………………………………...39

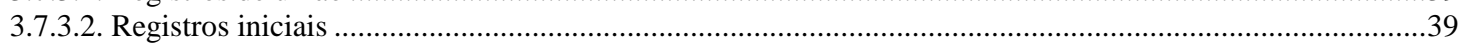

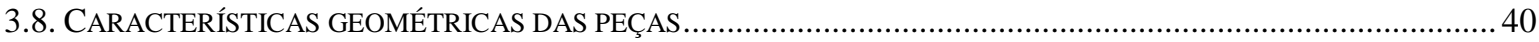

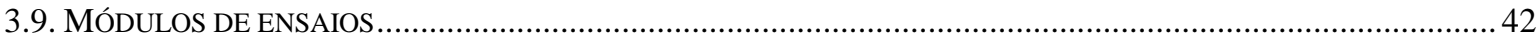

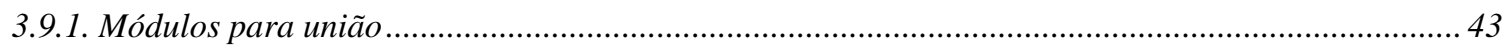

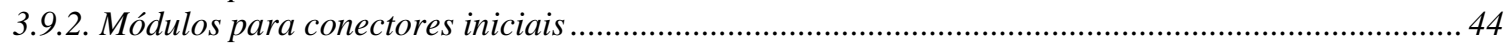

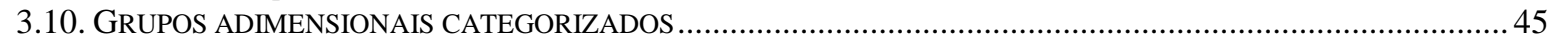

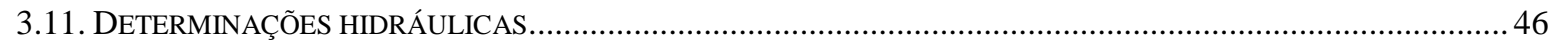

4. RESULTADOS E DISCUSSÃO

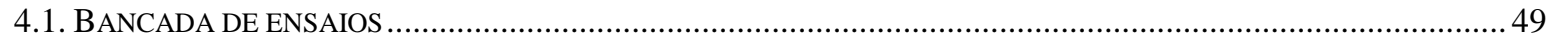

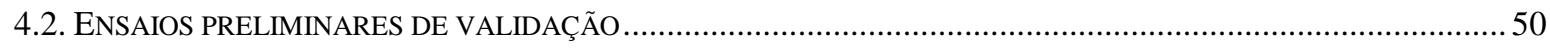

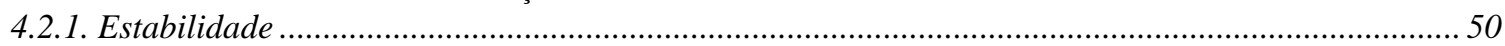

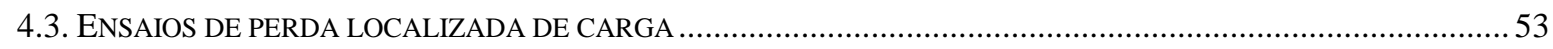

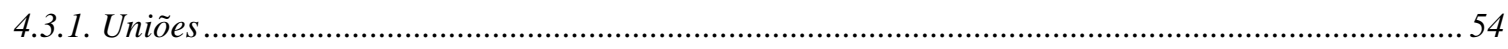

4.3.1.1. Diâmetro nominal de $13 \mathrm{~mm}$...…………………………………………………………………54

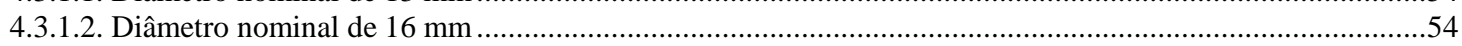

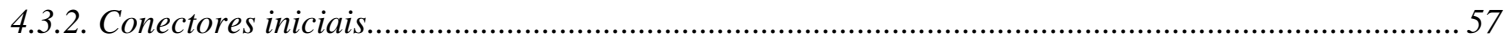

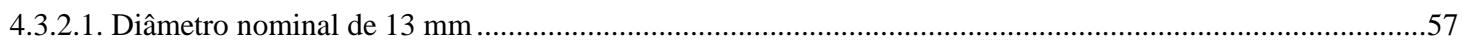

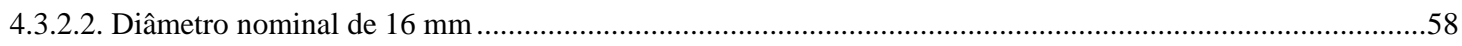

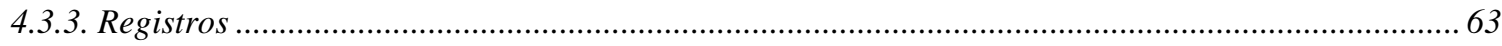

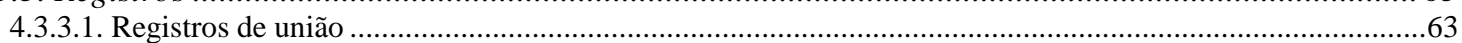

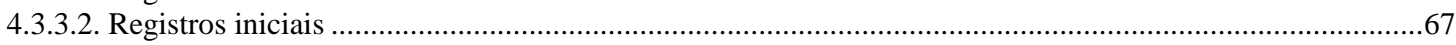

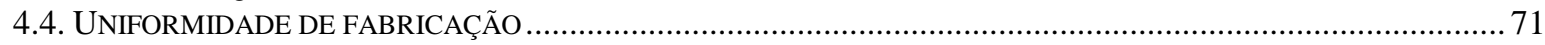

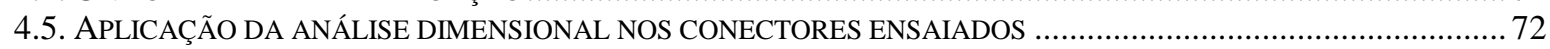




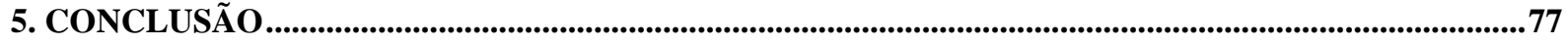

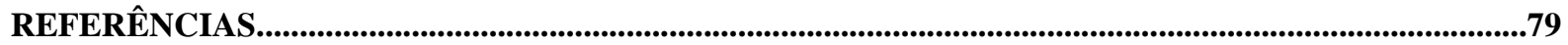


RESUMO

\title{
Perda localizada de carga em conexões utilizadas em sistemas de microirrigação
}

\begin{abstract}
Há pouca disponibilidade de informações de perda localizada de carga sobre conexões utilizadas em microirrigação. Diante disso, objetivou-se desenvolver e validar uma bancada automatizada para ensaios e determinar experimentalmente as perdas localizadas provocadas por conexões utilizadas em sistemas de microirrigação. Desenvolveu-se uma bancada automatizada utilizando um circuito eletrônico microcontrolado que dispõe de funcionalidades para aquisição e condicionamento de sinais de sensores; controle de inversor de frequência e válvula proporcional; controle Proporcional-Integral-Derivativo (PID); e, comunicação Modbus RTU com outros dispositivos através de rede RS-485. O firmware implementado no microcontrolador foi desenvolvido na linguagem C, enquanto que a interface gráfica do usuário (GUI) foi desenvolvida em C\#. A metodologia de ensaios foi elaborada combinando recomendações de normas técnicas internacionais. Os ensaios foram conduzidos sob pressão de entrada controlada em $150 \mathrm{kPa}$, sendo ensaiadas entre cinco e dez peças para cada modelo de conexão. As curvas relacionando vazão e perda localizada de carga foram construídas com, pelo menos, 15 valores de vazão, submetidos sob condição de incremento e decréscimo para incluir eventuais efeitos de histerese do sistema de medição. Foram coletados 30 pontos por condição de vazão, tendo sido realizado uma aquisição de 900 pontos por ensaio. Para cada modelo avaliado foram apresentados as seguintes informações: curva de perda localizada de carga em função de vazão, coeficiente de perda localizada de carga $\left(\mathrm{K}_{\mathrm{L}}\right)$ e comprimento equivalente (Leq). A bancada de ensaios automatizada permitiu a condução dos ensaios onde os sistemas de medição e controle operaram adequadamente, sendo capazes de atender a requisitos estabelecidos em normas técnicas. Os valores aproximados de $\mathrm{K}_{\mathrm{L}}$ se apresentaram entre 2,70 a 24,08. Em muitos dos casos, o coeficiente tendeu a uma constância após um número de Reynolds de 10000. Pôde-se verificar também a sensibilidade do coeficiente relacionada com a razão das seções internas nas conexões. Os expoentes da vazão assumem valores próximos do que é aplicado pela equação de Darcy-Weisbach $(\mathrm{m}=2)$.
\end{abstract}

Palavras-chave: Bancada automatizada; Hidráulica; Coeficientes experimentais; Modelagem de conexões 


\section{ABSTRACT \\ Minor losses caused by fittings used in microirrigation systems}

Information about minor losses caused by fittings employed in microirrigation systems are hard to be found in literature. The objective of this research was to develop and validate an automated bench for determine experimentally minor losses caused by fittings commonly installed in microirrigation. An automated bench was developed using a microcontrolled electronic circuit that has functionalities for data acquisition and signal conditioning; control of variable frequency drive and proportional valve; Proportional-Integral-Derivative Control (PID); and, Modbus RTU communication with other devices through a RS-485 network. The firmware implemented for the microcontroller was programmed in the $C$ language, while the graphical user interface (GUI) was developed in C\#. The methodology of tests was based on international standards. The tests were carried out under controlled inlet pressure, at $150 \mathrm{kPa}$, and five to ten units were tested for each fitting model. The curves relating flow and minor losses were drawn based on minimum of 15 flow values, obtained under conditions of increase and decrease of flow rate in order to take into account possible effects of hysteresis related to the measurement system. In each flow rate, 30 points were collected resulting in a sample size of 900 points in each test. For each model of fitting evaluated, the following information was presented: curves of minor losses as a function of flow rate, minor loss coefficient $\left(\mathrm{K}_{\mathrm{L}}\right)$ and minor losses expressed as an equivalent length (Leq). The automated test bench enabled to carry out the experiments properly, being able to meet the requirements established by technical standards. The values of $\mathrm{K}_{\mathrm{L}}$ presented ranged from 2.70 to 24.08 . Usually, that coefficient tended to become constant for Reynolds number higher than 10000. The sensitivity of the coefficient related to a ratio of the internal sections in the connections was also verified. The flow exponents presented values close to what is applied by the Darcy-Weisbach equation $(\mathrm{m}=2)$.

Keywords: Automated bench; Hydraulic; Experimental coefficients; Modeling of fittings 


\section{LISTA DE FIGURAS}

FIGURA 1. Representação da superfície hipotética sujeita às forças decompostas (adaptado de Brunetti, 2008).

FIGURA 2. Representação de expansão brusca abordada pelo teorema de Borda-Bélanger.

FIGURA 3. Ilustração da estrutura de ensaio: (1) reservatório de água; (2) conjunto motobomba; (3) inversor de frequência; (4) medidor eletromagnético de vazão; (5) transmissor de temperatura; (6) registro by-pass; (7) transmissor de pressão de entrada; (8) transmissor de pressão diferencial; (9) trecho de ensaio; (10) tomadas de pressão a montante (a) e a jusante (b); (11) válvula de retorno (sistema fechado).

FIGURA 4. Simulação dos vetores de velocidade ocasionados na seção do conduto pela passagem da singularidade.

FIGURA 5. Fluxograma de instrumentação da bancada de ensaios, em que: FT - medidor de vazão eletromagnético; TT- transmissor de temperatura; PT - transmissor de pressão; PDT - transmissor de pressão diferencial.

FIGURA 6. Calibração dos instrumentos de mensuração da vazão, pressão, temperatura da água e pressão diferencial; utilizados para determinação da curva vazão-perda de carga de cada peça...................................... 32

FIGURA 7. Diagrama de controle retroativo.

FIGURA 8. Diagrama em blocos das funções do hardware desenvolvido. Q - vazão; Pin - pressão de entrada; $\Delta \mathrm{p}$ - pressão diferencial; T - temperatura; V.P. - válvula proporcional; I.F. - inversor de frequência; ADC/DAC - canais de conversão.

FIGURA 9. Fotografia da placa desenvolvida para aquisição e condicionamento de sinais, controle de atuadores e transmissão de dados.

FIGURA 10. Representação da coleta de dados obtidas durante um ensaio para validação da bancada. ............. 35

FIGURA 11. Janela inicial do aplicativo supervisório para configuração dos parâmetros de ensaio. ..................36

FIGURA 12. Tela parcial de monitoramento apresentada pelo aplicativo supervisório ao término de um ensaio.

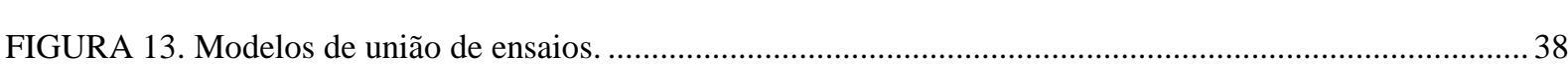

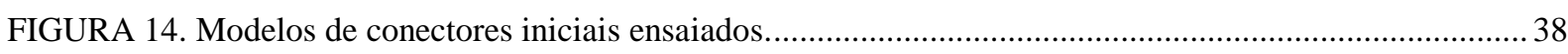

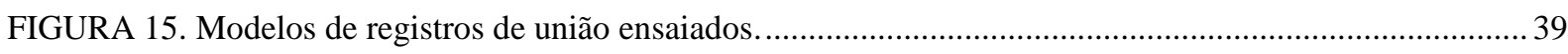

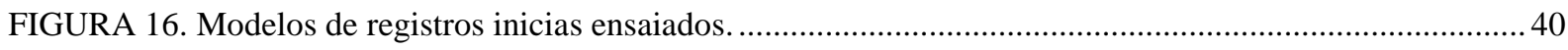

FIGURA 17. Corte longitudinal das uniões e conectores iniciais. .............................................................. 41

FIGURA 18. Corte longitudinal dos registros de união e registros iniciais ensaiados................................... 41

FIGURA 19. Projetor ótico Starret HB400 utilizado para determinação do diâmetro da garganta em registros sendo (a) peça regular caracterizada e (b) peça com irregularidade descartada do grupo...................................42

FIGURA 20. Arranjo dos trechos experimentais para uniões com diâmetros nominais de (a) 13 e (b) 16 milímetros; com sentido de fluxo da esquerda para direita.

FIGURA 21. Anéis de vedação bilabiais empregados para alocação dos conectores iniciais na linha de derivação.

FIGURA 22. Características dimensionais dos anéis de vedação (a) 0130 e (b) 0132.

FIGURA 23. Arranjo experimental instalado na bancada para ensaios de conexões de união (esquerda) e conexões iniciais (direita); em que, (1) painel de potência, (2) painel de comando, (3) conjunto motobomba, (4) transmissor de pressão, (5) transmissor de pressão diferencial, (6) registro de retorno, (7) medidor de vazão eletromagnético, (8) transmissor de temperatura e (9) ramificação para ensaios de perda distribuída..................49

FIGURA 24. Disposição dos painéis elétricos de (1) potência e (2) comando, instalados na bancada................50

FIGURA 25. Gráficos de controle para monitoramento da média e da variabilidade da pressão de ensaio (valor alvo $=1,5$ bar) sob duas vazões: (a) vazão baixa, $0,90 \mathrm{~m}^{3} \mathrm{~h}^{-1}$; (b) vazão elevada, $2,70 \mathrm{~m}^{3} \mathrm{~h}^{-1}$ 
FIGURA 26. Gráficos de controle para monitoramento da média e da variabilidade da vazão: (a) vazão baixa, $0,90 \mathrm{~m}^{3} \mathrm{~h}^{-1}$; (b) vazão elevada, $2,70 \mathrm{~m}^{3} \mathrm{~h}^{-1}$.

FIGURA 27. Gráficos de controle para monitoramento da média e da variabilidade da temperatura da água: (a) vazão baixa, $0,90 \mathrm{~m}^{3} \mathrm{~h}^{-1}$; (b) vazão elevada, $2,70 \mathrm{~m}^{3} \mathrm{~h}^{-1}$.

FIGURA 28. Gráficos de controle para monitoramento da média e da variabilidade da pressão diferencial: (a) vazão baixa, $0,90 \mathrm{~m}^{3} \mathrm{~h}^{-1}$; (b) vazão elevada, $2,70 \mathrm{~m}^{3} \mathrm{~h}^{-1}$....

FIGURA 29. Resultados experimentais da união 0081: (a) curva de queda de pressão em função de vazão; (b) perda localizada de carga em função de vazão; (c) perda localizada de carga em função de carga cinética; (d) coeficiente $\mathrm{K}_{\mathrm{L}}$ em função de Reynolds.

FIGURA 30. Resultados experimentais da união 0038: (a) curva de queda de pressão em função de vazão; (b) perda localizada de carga em função de vazão; (c) perda localizada de carga em função de carga cinética; (d) coeficiente $\mathrm{K}_{\mathrm{L}}$ em função de Reynolds.

FIGURA 31. Resultados experimentais da união 0082: (a) curva de queda de pressão em função de vazão; (b) perda localizada de carga em função de vazão; (c) perda localizada de carga em função de carga cinética; (d) coeficiente $\mathrm{K}_{\mathrm{L}}$ em função de Reynolds.

FIGURA 32. Resultados experimentais da união 0083: (a) curva de queda de pressão em função de vazão; (b) perda localizada de carga em função de vazão; (c) perda localizada de carga em função de carga cinética; (d) coeficiente $\mathrm{K}_{\mathrm{L}}$ em função de Reynolds..

FIGURA 33. Resultados experimentais do conector inicial 0057: (a) curva de queda de pressão em função de vazão; (b) perda localizada de carga em função de vazão; (c) perda localizada de carga em função de carga cinética; (d) coeficiente $\mathrm{K}_{\mathrm{L}}$ em função de Reynolds.

FIGURA 34. Resultados experimentais do conector inicial 0037: (a) curva de queda de pressão em função de vazão; (b) perda localizada de carga em função de vazão; (c) perda localizada de carga em função de carga cinética; (d) coeficiente $\mathrm{K}_{\mathrm{L}}$ em função de Reynolds.

FIGURA 35. Resultados experimentais do conector inicial 0046: (a) curva de queda de pressão em função de vazão; (b) perda localizada de carga em função de vazão; (c) perda localizada de carga em função de carga cinética; (d) coeficiente $\mathrm{K}_{\mathrm{L}}$ em função de Reynolds.

FIGURA 36. Resultados experimentais do conector inicial 0058: (a) curva de queda de pressão em função de vazão; (b) perda localizada de carga em função de vazão; (c) perda localizada de carga em função de carga cinética; (d) coeficiente $\mathrm{K}_{\mathrm{L}}$ em função de Reynolds.

FIGURA 37. Resultados experimentais do conector inicial 0059: (a) curva de queda de pressão em função de vazão; (b) perda localizada de carga em função de vazão; (c) perda localizada de carga em função de carga cinética; (d) coeficiente $\mathrm{K}_{\mathrm{L}}$ em função de Reynolds.

FIGURA 38. Resultados experimentais do conector inicial 0186: (a) curva de queda de pressão em função de vazão; (b) perda localizada de carga em função de vazão; (c) perda localizada de carga em função de carga cinética; (d) coeficiente $\mathrm{K}_{\mathrm{L}}$ em função de Reynolds.....

FIGURA 39. Resultados experimentais do registro de união 0153: (a) curva de queda de pressão em função de vazão; (b) perda localizada de carga em função de vazão; (c) perda localizada de carga em função de carga cinética; (d) coeficiente $\mathrm{k}_{\mathrm{l}}$ em função de reynolds.

FIGURA 40. Resultados experimentais do registro de união 0151: (a) curva de queda de pressão em função de vazão; (b) perda localizada de carga em função de vazão; (c) perda localizada de carga em função de carga cinética; (d) coeficiente $\mathrm{K}_{\mathrm{L}}$ em função de Reynolds.

FIGURA 41. Resultados experimentais dos registros de união 0212, 0213 e 0223: (a) curva de queda de pressão em função de vazão; (b) perda localizada de carga em função de vazão; (c) perda localizada de carga em função de carga cinética; (d) coeficiente $\mathrm{K}_{\mathrm{L}}$ em função de Reynolds. ...

FIGURA 42. Resultados experimentais do registro de união 0214: (a) curva de queda de pressão em função de vazão; (b) perda localizada de carga em função de vazão; (c) perda localizada de carga em função de carga cinética; (d) coeficiente $\mathrm{K}_{\mathrm{L}}$ em função de Reynolds.

FIGURA 43. Resultados experimentais do registro inicial 0152: (a) curva de queda de pressão em função de vazão; (b) perda localizada de carga em função de vazão; (c) perda localizada de carga em função de carga cinética; (d) coeficiente $\mathrm{K}_{\mathrm{L}}$ em função de Reynolds. 
FIGURA 44. Resultados experimentais do registro inicial 0150: (a) curva de queda de pressão em função de vazão; (b) perda localizada de carga em função de vazão; (c) perda localizada de carga em função de carga cinética; (d) coeficiente $\mathrm{K}_{\mathrm{L}}$ em função de Reynolds

FIGURA 45. Resultados experimentais dos registros iniciais 0182 e 0183: (a) curva de queda de pressão em função de vazão; (b) perda localizada de carga em função de vazão; (c) perda localizada de carga em função de carga cinética; (d) coeficiente $\mathrm{K}_{\mathrm{L}}$ em função de Reynolds.

FIGURA 46. Resultados experimentais do registro inicial 0184: (a) curva de queda de pressão em função de vazão; (b) perda localizada de carga em função de vazão; (c) perda localizada de carga em função de carga cinética; (d) coeficiente $\mathrm{K}_{\mathrm{L}}$ em função de Reynolds.

FIGURA 47. Representação do desvio entre valores estimados e observados através do modelo desenvolvido para conectores iniciais, em que (a) valores estimados versus observado, e (b) análise gráfica do erro confrontando o erro relativo presente em dada frequência acumulada 74

FIGURA 48. Representação do desvio entre valores estimados e observados através do modelo desenvolvido para uniões, em que (a) valores estimados versus observado, e (b) análise gráfica do erro confrontando o erro relativo máximo por frequência acumulada.

FIGURA 49. Representação do desvio entre valores estimados e observados através do modelo desenvolvido para registros de união, em que (a) valores estimados versus observado, e (b) análise gráfica do erro confrontando o erro relativo máximo por frequência acumulada.

FIGURA 50. Representação do desvio entre valores estimados e observados através do modelo desenvolvido para registros iniciais, em que (a) valores estimados versus observado, e (b) análise gráfica do erro confrontando o erro relativo máximo por frequência acumulada.

FIGURA 51. Representação da (a) perda localizada de carga nos conetores iniciais, estimado pelo modelo desse estudo e pelo modelo de Vilaça et al. (2017), com a perda localizada observada, e; (b) análise gráfica do erro confrontando o erro relativo máximo por frequência acumulada 


\section{LISTA DE TABELAS}

TABELA 1. Análise dimensional das variáveis intrínsecas ao fenômeno de perda de carga.

TABELA 2. Características dimensionais (médias e desvio padrão) das uniões e conectores iniciais, em milímetros

TABELA 3. Características dimensionais (médias e desvio padrão) dos registros de união e registros iniciais, em milímetros

TABELA 4. Indicação das características dimensionais (média e desvio padrão) dos anéis de vedação reportados, em milímetros.

TABELA 5. Média e medidas de dispersão dos dados obtidos do coeficiente $\mathrm{K}_{\mathrm{L}}$ entre peças dos modelos de conexão a partir de uma velocidade de referência acima de $1,50 \mathrm{~m} \mathrm{~s}^{-1}$.

TABELA 6. Coeficientes ajustados para a modelagem da perda localizada de carga para as categorias de (1) união; (2) conectores iniciais; (3) registros de união, e; (4) registros de conexões iniciais. 


\section{INTRODUÇÃO}

As linhas laterais de um sistema de microirrigação são condutos pressurizados que distribuem a água através dos emissores, os quais mantém uma uniformidade de distribuição em função da variação de pressão na linha. Para que se atinjam os níveis apropriados de uniformidade, faz-se necessário quantificar a perda de carga que ocorre ao longo da linha, incluindo as perdas localizadas de carga nos emissores e conexões; haja visto que a análise hidráulica relaciona-se diretamente com a qualidade de um sistema de microirrigação (YILDIRIM; AGIRALIOGLU, 2004).

Como demonstram os estudos na área, há relevantes impactos a serem considerados, bem como o acréscimo de 5\% a 32\% sob as perdas totais de energia devido à protrusão on-line em tubos de polietileno de 13 e 25 mm (AL-AMOUD, 1995). Relatou-se, também, que negligenciar o efeito das perdas localizadas de carga pode induzir a erros de $25 \%$ na estimação de diâmetros e 7\% no comprimento máximo das linhas laterais (YILDIRIM, 2007). Considerando em simulações dois modelos de tubos com emissores integrados, as perdas localizadas de carga contribuíram entre $6,4 \%$ e $49,5 \%$ das perdas totais de energia no projeto de linhas laterais (PROVENZANO; PUMO, 2004). Noutro estudo, a perda de carga total aumentou de $24,5 \%$ para $50,8 \%$, devido a perdas localizadas causadas por gotejadores não coaxiais integrados a tubos de polietileno (RETTORE NETO et al., 2009). Percebe-se que tais omissões no dimensionamento acabam por comprometer a qualidade do sistema.

Há uma proporção aproximadamente direta entre a perda localizada e a carga cinética do escoamento, e isso se expressa através de um coeficiente. Seu valor pode ser obtido experimentalmente para cada peça, o que vem sendo realizado, há vários anos, por engenheiros interessados no assunto, por fabricantes de conexões e válvulas e laboratórios. No entanto, as informações técnicas de conexões utilizadas quando não disponíveis, encontram-se desatualizadas aos que considerem o aprimoramento contínuo de sua tecnologia de produção (KOTOWSKI; SZEWCZYK; CIEZAK, 2011; TSAKIRIS; TSAKIRIS, 2012).

A informatização nos dias atuais vem permitindo que operações computacionais executem rotinas com menores esforços e demanda de tempo, com cálculos mais abrangentes e próximos das condições reais (RETTORE NETO et al., 2013). Isso também ocorre na condução dos ensaios, pois o incremento da observação, da experiência e a necessidade de verificação prática em estudos da hidráulica proporcionou modelos mais concisos com a realidade que fomentam ainda mais o avanço da tecnologia para a aquisição dos dados (VALLE, 2015). Os ensaios hidráulicos para obtenção de informações técnicas de irrigação constituem tarefas repetitivas que estão sujeitas às mais diversas imperfeições. Acima disso, o uso de sistemas automatizados adequadamente projetados e validados para a execução de tarefas dessa natureza assegura maior estabilidade nas condições de ensaio, otimização do tempo de operação, redução das falhas ou imperfeições humanas e, consequentemente, oferecendo mais qualidade ao ensaio.

\subsection{Objetivos}

- Desenvolver e validar uma bancada automatizada para ensaios de perda localizada de carga;

- Determinar experimentalmente perdas localizadas de carga em conexões utilizadas em sistemas de microirrigação através da bancada desenvolvida;

- Propor modelos matemáticos a partir do teorema de Buckingham para as classes de conexões ensaiadas. 


\section{REVISÃO BIBLIOGRÁFICA}

Poucas são as informações técnicas de fabricantes que quantificam as perdas localizadas de carga ocasionadas pelas conexões utilizadas nos sistemas de microirrigação. Os dados que representam a perda localizada de carga, quando não disponíveis, encontram-se desatualizados com a tecnologia de produção do mercado. Há uma discrepância entre manuais técnicos de perda localizada de carga (KOTOWSKI; SZEWCZYK; CIEZAK, 2011), quando não há uma ausência de dados técnicos atualizados referentes a conexões e peças especiais disponíveis atualmente no mercado (PRADO, 2015). Desse modo, os ensaios de laboratório para a obtenção desses dados atualizados são de grande importância para o correto dimensionamento de sistemas de irrigação.

\subsection{Microirrigação}

O método consiste na aplicação de água em alta frequência e baixo volume, na superfície do solo ou na subsuperfície, mantendo com alto grau de umidade um pequeno volume de solo que contém o sistema radicular das plantas (FRIZZONE et al., 2012; MANTOVANI; BERNARDO; PALARETTI, 2012).

Geralmente, os sistemas de microirrigação são definidos por seus dispositivos de emissão de água (KELLER; BLIESNER, 1990). Utilizam-se emissores instalados ao longo de uma tubulação paralela com a linha de plantas, os quais variam desde simples orifícios em tubos plásticos de parede fina, emissores de fluxo laminar de longo percurso, até os mais elaborados e mais eficientes emissores de fluxo turbulento e compensadores de pressão (EVANS; WU; SMAJSTRALA, 2007; FRIZZONE et al., 2012). Tipicamente, a água é aplicada na forma de gotas, na superfície ou subsuperfície do solo, denominada por gotejamento; ou então aspergida, conhecida por microaspersão.

O grande interesse pela microirrigação foi despertado principalmente pelos resultados de economia de água e energia que o sistema pode oferecer, aliado ao grande potencial para oferecer condições ótimas de manejo para o desenvolvimento e produtividades das plantas; uma vez que o objetivo final de qualquer atividade agrícola é atingir o máximo retorno econômico líquido. A uniformidade de irrigação, as práticas de manejo da irrigação, o custo da água e o custo energético, o preço dos produtos, a redução da produtividade pelo déficit ou pelo excesso de água, incluindo possível contaminação das fontes de água, são fatores importantes que afetam o retorno econômico de um sistema de produção irrigado (GOMES, 2009; SCALOPPI, 1986). Uniformidade de distribuição da água depende basicamente da uniformidade de vazão dos emissores. No dimensionamento de um sistema de microirrigação, o critério mais adotado é permitir uma variação máxima de vazão dos emissores na subunidade na ordem de $10 \%$, reproduzindo uma variação de carga de pressão em emissores convencionais de até 21\% (FRIZZONE et al., 2012). Portanto, essa estratégia de dimensionamento do sistema deve estimar rigorosamente a perda de carga que ocorre num projeto hidráulico.

\subsection{Perda de carga nos sistemas de microirrigação}

Define-se perda de carga como a energia dissipada por unidade de peso de um fluido real quando este escoa (BRUNETTI, 2008). No escoamento de um fluido real, as partículas escoam numa velocidade crescente 
oposta ao contato da parede, que mantém uma camada com velocidade nula, mas que passam a influir nas partículas vizinhas, com um gradiente de velocidade expresso pela tensão de cisalhamento relacionado com a viscosidade do fluido. Além disso, considerando a turbulência, há de se expressar também o efeito que a rugosidade das paredes mantém ao seu movimento.

Pode-se classificar a perda de carga como perda contínua de carga (ou distribuída) e perdas localizadas de cargas (ou singulares). A perda contínua é resultante da dinâmica do fluido submetido ao escoamento em um meio, que, por fins práticos, admite-se como uniforme em qualquer trecho de uma canalização de dimensões constantes, conduzindo vazão constante, independentemente de sua posição em relação ao plano. Já na presença de singularidades, a energia dissipada é caracterizada pontualmente e está relacionada com a carga cinética do escoamento. Muitas vezes subestimada, essa perda possui grande importância em canalizações com alto número de peças especiais.

Nos sistemas de microirrigação há uma alta densidade de elementos pontuais, como os emissores, as conexões e acessórios (válvulas, registros, filtros, conectores, etc.), e seus impactos podem ser consideráveis nesses sistemas (AL-AMOUD, 1995; PROVENZANO; PUMO, 2004; YILDIRIM, 2007; RETTORE NETO, 2008). A uniformidade de distribuição de um sistema de irrigação é importante para o uso eficiente da água aplicada. Assim, diferenças de pressão em relação à necessária podem ser resultantes de projetos indaqueados das tubulações e da motobomba, da seleção inadequada dos dispositivos reguladores de pressão e obstrução do sistema de filtragem. O excesso de variação de pressão no sistema, causados por perda de carga e por variação da cota de um terreno decorre de um projeto mal dimensionado (FRIZZONE et al., 2012). Para que se atinjam níveis apropriados de uniformidade faz-se necessário quantificar a perda de carga que ocorre ao longo da linha, incluindo as perdas localizadas nos emissores e conexões. O estudo hidráulico relaciona-se diretamente com a qualidade de um sistema de microirrigação (YILDIRIM; AGIRALIOGLU, 2004). Alves et al. (2012) comprovaram ser necessário quantificar a perda localizada de carga para dimensionamento de sistemas de irrigação para alcançar uma maior exatidão.

A perda de carga em um sistema hidráulico implica no custo do projeto, pois quanto maior a perda de carga ocasionada por tubulações, peças especiais e acessórios, maiores serão os gastos com energia devido à necessidade de um conjunto motobomba de maior potência para conseguir manter a vazão de projeto. O diâmetro da canalização dependerá exclusivamente da perda de carga admitida pelo projetista. Enquanto o custo fixo de aquisição do sistema aumenta com o acréscimo do diâmetro, o custo operacional diminui e reduz a exigência de energia de bombeamento requerida (FRIZZONE et al., 2012; PRADO, 2015)

\subsection{Regime de escoamento}

Para melhor compreender o fenômeno de dissipação de energia, há de se descrever previamente os regimes de escoamento, pois suas equações determinísticas partem de um intervalo pressuposto. Osborne Reynolds, em 1883, demonstrou que os líquidos escoam sob os regimes distintos: o regime laminar, uma zona crítica e o regime turbulento (AZEVEDO NETTO; FERNANDEZ Y FERNANDEZ, 2015). Por homenagem ao mérito, estabelecese um adimensional para classificação do escoamento comumente conhecido por número de Reynolds (Re); apresentando-se como solução aos problemas tradicionais de mecânica dos fluidos. 
Para adentrar nesse raciocínio, será descrito inicialmente o conceito de tensão de cisalhamento. Considerando uma força $\vec{F}$ aplicada sobre uma superfície de área $\mathrm{A}$, tal força pode ser decomposta segundo a direção normal à superfície e a da tangente (Figura 1).

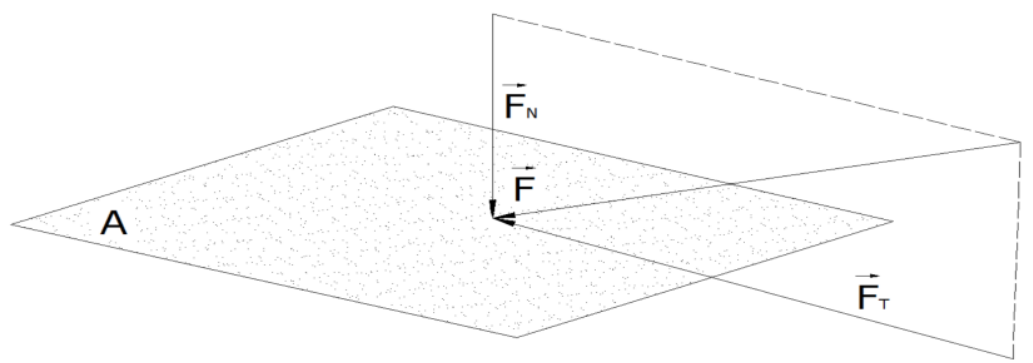

Figura 1. Representação da superfície hipotética sujeita às forças decompostas (adaptado de BRUNETTI, 2008).

A tensão de cisalhamento média $(\tau)$ é o quociente entre o módulo da força tangencial $\left(\mathrm{F}_{\mathrm{T}}\right)$ pela área $(\mathrm{A})$ sobre a qual está sendo aplicada (eq. 1).

$$
\tau=\frac{F_{T}}{A}
$$

A lei de Newton da viscosidade afirma que certos fluídos possuem uma proporcionalidade entre a tensão de cisalhamento e o gradiente de velocidade (dv/dy) entre camadas de uma seção genérica (eq. 2). Esses são conhecidos como fluídos newtonianos, e a água se inclui nessa categoria. O coeficiente de proporcionalidade nada mais é do que a viscosidade absoluta ou dinâmica $(\mu)$, que representa a resistência de um fluido ao escoamento. Tal grandeza é uma propriedade do fluído e de suas condições, como, por exemplo, a temperatura (BRUNETTI, 2008).

$$
\tau=\mu \frac{d v}{d y}
$$

Através da segunda lei de Newton, conhecida por princípio fundamental da dinâmica, a força de inércia num fluído pode assim ser apresentada pela forma direta (eq. 3d) considerando a massa específica ( $\rho$ ), a vazão (Q) como produto da velocidade média de escoamento $(V)$ pela área da seção $(A)$ e a aceleração como uma taxa de variação da velocidade $(\mathrm{dV})$ num intervalo de tempo (dt).

$$
\begin{gathered}
\vec{F}=m \vec{a} \\
F_{\text {inércia }}=\rho \cdot V o l \cdot \frac{d V}{d t} \\
F_{\text {inércia }}=\rho \cdot Q \cdot d V \\
F_{\text {inércia }}=\rho \cdot V \cdot A \cdot d V
\end{gathered}
$$


O número de Reynolds classifica o escoamento e é obtido através do quociente de ambas as forças: a força de inércia e a força tangente da tensão de cisalhamento de um fluído newtoniano (eq. 4). Num conduto de seção circular a dimensão linear característica (dy) é o próprio diâmetro interno (D) do tubo (PERES, 2015).

$$
\operatorname{Re}=\frac{F_{\text {inércia }}}{F_{T}}=\frac{\rho \cdot V \cdot A \cdot d V}{A \cdot \mu \cdot \frac{d V}{d y}}=\frac{\rho V D}{\mu}
$$

em que: Re - número de Reynolds (adimensional);

$\rho$ - massa específica do fluido $\left(\mathrm{kg} \mathrm{m}^{-3}\right)$;

$\mathrm{V}$ - velocidade média do escoamento $\left(\mathrm{m} \mathrm{s}^{-1}\right)$;

$\mathrm{D}$ - diâmetro do tubo (m); e,

$\mu$ : viscosidade dinâmica do fluido $\left(\mathrm{kg} \mathrm{m}^{-1} \mathrm{~s}^{-1}\right)$.

Vale mencionar que essa aplicação de Reynolds é restrita tão somente para condutos de seção circular, cuja dimensão linear característica é seu diâmetro interno. No caso de seções não circulares, a dimensão linear característica é o raio hidráulico $\left(\mathrm{R}_{\mathrm{H}}\right)$. Pode-se descrever o raio hidráulico como sendo a relação entre a área molhada e o perímetro molhado.

Quanto maior for o número de Reynolds, mais importantes serão as forças de inércia e menos relevantes as tensões viscosas do fluído. Por questões práticas, adota-se para alguns casos a expressão da viscosidade cinemática (U), como razão entre a viscosidade dinâmica $(\mu)$ pela correspondente massa específica $(\rho)$, retornando uma área por unidade de tempo (eq. 5). Pode-se expressar o número de Reynolds em função da viscosidade cinemática. (eq. 6).

$$
\begin{gathered}
v=\frac{\mu}{\rho} \\
\operatorname{Re}=\frac{V \cdot D}{v}=\frac{4 Q}{\pi D v}
\end{gathered}
$$

em que: $\nu$ - viscosidade cinemática $\left(\mathrm{m}^{2} \mathrm{~s}^{-1}\right)$; $\mathrm{e}$

$$
\mathrm{Q}-\text { vazão }\left(\mathrm{m}^{3} \mathrm{~s}^{-1}\right) \text {. }
$$

Há autores que apresentam a massa específica e a viscosidade da água estimadas em função de sua temperatura (t). Tanaka et al. (2001) modelaram a massa específica da água (eq. 7) para temperaturas entre $0{ }^{\circ} \mathrm{C}$ e 40 ${ }^{\circ} \mathrm{C}$ sob pressão atmosférica no nível do mar. Pinto et al. (2014) aplicaram os dados empíricos apresentados por Azevedo Netto \& Fernandez (2015) com o modelo matemático sugerido por Likhachev (2003), obtendo uma função da viscosidade cinemática sob domínio da temperatura e da massa específica (eq. 8). 


$$
\begin{gathered}
\rho=999,974950 \cdot\left[1-\frac{(t-3,983035)^{2}(t+301,797)}{522528,9(t+69,34881)}\right] \\
v=\frac{32,025666 \cdot 10^{-6}}{\rho} \cdot \mathrm{e}^{\frac{482,134866}{t+119,886026}}
\end{gathered}
$$

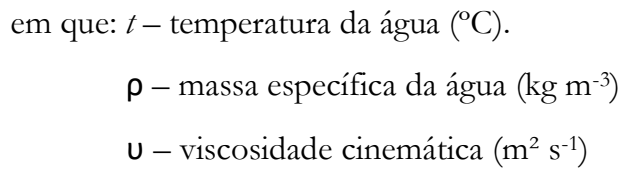

Em condutos, o escoamento em regime laminar ocorre para valores do número de Reynolds abaixo de 2000, em que as partículas se movem ao longo de trajetórias bem definidas, na forma de camadas ou de lâminas, em um movimento retilíneo e unidimensional, com todos os seus vetores de velocidade posicionados unicamente no sentido do escoamento; a perda de energia é bastante expressiva pela viscosidade. O tipo de escoamento que irá ocorrer quando o número de Reynolds variar entre 2000 a 4000 será ora laminar, ora turbulento, consolidando uma zona crítica. Os valores dessa faixa podem variar de acordo com cada autor, pois livros de mecânica dos fluídos não tratam exclusivamente da água. De qualquer forma, um Reynolds acima de 4000 está mais consolidado ao regime turbulento, onde o deslocamento sofre perturbações de velocidades transversais que conferem uma movimentação caótica; a perda de energia é função do efeito combinado das forças de inércia, tensões viscosas e rugosidade dos tubos (PORTO, 2006; AZEVEDO NETTO; FERNANDEZ Y FERNANDEZ, 2015; PERES, 2015).

\subsection{Balanço energético}

Um fluido está submetido às energias mecânicas (potencial, cinética e de pressão). Daniel Bernoulli, em 1738, propôs uma equação que permite relacionar cota, velocidade e pressão em duas seções do escoamento de um fluido ideal (incompressível e sem atrito interno); os termos da equação são comumente deduzidos às cargas (energia em relação ao peso), obtendo um conjunto contabilizado por carga hidráulica $(\mathrm{H})$, que é simplificado unicamente por dimensões lineares $\left(\mathrm{M}^{0} \mathrm{~L}^{1} \mathrm{~T}^{0}\right)$.

Nos fluidos ideais, as cargas totais se mantêm constantes ao longo das seções e essa equação seria enunciada como se, entre duas seções do escoamento, o fluido for incompressível, sem atrito interno, regime permanente, não houver máquina nem trocas de calor, então as cargas totais se manterão constantes em qualquer seção, não havendo nem ganhos nem perdas de carga. Contudo, como comentado anteriormente, nos fluidos reais há de se considerar a resistência do atrito interno entre dois pontos de um trecho. Com base no fato de que a energia não pode ser criada nem destruída, mas transformada, faz-se necessário construir uma equação que estabelece o balanço das energias, por meio da equação da continuidade. O conceito de perda de carga é introduzido para balancear essa equação, sem objetivo de explicar o destino dessa energia. Assim, a equação de Bernoulli para fluídos reais (eq. 9) pode ser representada considerando o atrito interno, e nela ainda são mantidas as hipóteses de regime permanente, fluido incompressível, propriedades uniformes na seção e sem trocas de calor induzidas (BRUNETTI, 2008). 


$$
Z_{1}+\frac{V_{1}^{2}}{2 g}+\frac{P_{1}}{\gamma}=Z_{2}+\frac{V_{2}^{2}}{2 g}+\frac{P_{2}}{\gamma}+h f
$$

em que: $Z$ - carga da cota $(\mathrm{m})$;

$\mathrm{P} / \gamma$ - carga de pressão $(\mathrm{m})$;

$\mathrm{V}^{2} / 2 \mathrm{~g}$ - carga cinética $(\mathrm{m})$;

hf - perda de carga (m).

\subsection{Equação de Darcy-Weisbach e análise dimensional}

Dentre os métodos para estimar a perda de carga, tem-se a equação de Darcy-Weisbach, de 1845, como sendo a mais aceita pela comunidade científica. A equação de Darcy-Weisbach, também conhecida como Fórmula Universal, foi deduzida através de investigações acerca da tensão da água sob as paredes da canalização e lei de semelhança, cujo princípio é baseado pela análise dimensional. Por conta disso, é considerada de base teórica.

Por experiência prática, foi observado que as variáveis que influenciam na perda de carga são: (i) diâmetro do tubo; (ii) comprimento; (iii) rugosidade do tubo; (iv) velocidade de escoamento; (v) viscosidade absoluta, e; (vi) massa específica. Diante disso existem 7 grandezas envolvidas que podem ser expressas a partir de 3 grandezas básicas: massa $(\mathrm{M})$; comprimento $(\mathrm{L})$ e tempo $(\mathrm{T})$. Para encontrar a relação entre as variáveis responsáveis seria necessário alterar gradualmente o valor de uma variável enquanto se mantém todas as outras variáveis constantes. $\mathrm{O}$ processo seria repetido para cada variável até que as relações fossem descobertas. Isso seria um procedimento difícil e, às vezes, até mesmo impossível de executar. Ao combinar os termos em grupos adimensionais para reduzir o número de variáveis, o processo torna-se menos complicado em sua execução. Esse tipo de abordagem é denominado de análise dimensional, e a base de aplicação dessa abordagem a uma ampla variedade de problemas é o teorema de Buckingham Pi (BUCKINGHAM, 1914; MUNSON; YONG; OKIISHI, 2004). No caso em questão, esse teorema afirma existir quatro grupos adimensionais possíveis, e as dimensões que se estabelecem no fenômeno são expressas pela Tabela 1 .

Tabela 1. Análise dimensional das variáveis intrínsecas ao fenômeno de perda de carga.

\begin{tabular}{lc}
\hline Variável & Dimensão \\
\hline Pressão diferencial $(\Delta \mathrm{P})$ & $\mathrm{M} \mathrm{L}^{-1} \mathrm{~T}^{-2}$ \\
Diâmetro $(\mathrm{D})$ & $\mathrm{L}$ \\
Comprimento $(\mathrm{L})$ & $\mathrm{L}$ \\
Rugosidade $(\varepsilon)$ & $\mathrm{L}$ \\
Velocidade $(\mathrm{V})$ & $\mathrm{L} \mathrm{T}^{-1}$ \\
Viscosidade $(\mu)$ & $\mathrm{M} \mathrm{L}^{-1} \mathrm{~T}^{-1}$ \\
Massa específica $(\rho)$ & $\mathrm{M} \mathrm{L}^{-3}$ \\
\hline
\end{tabular}

Dessa listagem, separam-se as variáveis repetidas, as quais são ordenadas em número igual ao das grandezas básicas. Nota-se que a pressão diferencial é a variável dependente primordial e a viscosidade possui apenas um grau de diferença do expoente no tempo. Além disso, o comprimento e a rugosidade possuem dimensões idênticas ao diâmetro. Portanto, dada sua distinção, é sensato agrupar $\rho, \mathrm{V}$ e D e alternar o quarto termo 
sequencialmente. Como se pretende determinar grupos adimensionais, os expoentes terão suas dimensões similares igualadas a zero.

$$
\begin{gathered}
\Pi_{1}=\rho^{A} V^{B} D^{C} \Delta p=M^{0} L^{0} T^{0} \\
\Pi_{2}=\rho^{D} V^{E} D^{F} \mu=M^{0} L^{0} T^{0} \\
\Pi_{3}=\rho^{G} V^{H} D^{I} L=M^{0} L^{0} T^{0} \\
\Pi_{4}=\rho^{J} V^{K} D^{L} \varepsilon=M^{0} L^{0} T^{0}
\end{gathered}
$$

Resolvendo o sistema dimensional, obtém-se os quatro termos Pi:

$$
\begin{gathered}
\Pi_{1}=\rho^{-1} V^{-2} D^{0} \Delta p=\frac{\Delta p}{\rho V^{2}} \\
\Pi_{2}=\rho^{-1} V^{-1} D^{-1} \mu=\frac{\mu}{\rho V D}=\frac{1}{R e} \\
\Pi_{3}=\rho^{0} V^{0} D^{-1} \mathrm{~L}=\frac{\mathrm{L}}{D} \\
\Pi_{4}=\rho^{0} V^{0} D^{-1} \varepsilon=\frac{\varepsilon}{D}
\end{gathered}
$$

O processo assegura que os quatro termos serão homogêneos e que há uma relação funcional expressa pela eq. 12 e 13. Verifica-se que o segundo termo (eq. 11b) é o inverso de Reynolds, porém basta que a função equivalente seja construída por número adimensionais independentes formado com as grandezas envolvidas no fenômeno. Qualquer operação que for efetuada sobre os adimensionais determinados será válida desde que eles continuem adimensionais (BRUNETTI, 2008).

$$
\begin{aligned}
& \Pi_{1}=f\left(\Pi_{2}, \Pi_{3}, \Pi_{4}\right) \\
& \frac{\Delta p}{\rho V^{2}}=\phi\left(\operatorname{Re}, \frac{\varepsilon}{D}, \frac{L}{D}\right)
\end{aligned}
$$

Experiências demonstram que hf é diretamente proporcional com a razão comprimento-diâmetro. Considerando uma coluna d'água correlacionada com a queda de pressão pelo seu peso específico ( $\Delta \mathrm{p}=\rho g h$ ), e ainda uma constante implícita nessa relação, tem-se a equação de Darcy-Weisbach (eq. 14). O termo que assimila o número de Reynolds e a rugosidade relativa do tubo é associado ao denominado fator de atrito $f$ que será detalhado a seguir.

$$
h f=f \frac{L}{D} \frac{V^{2}}{2 g}=0,08263 \cdot f \cdot L \cdot \frac{Q^{2}}{D^{5}}
$$

em que: $f$ - fator de atrito (adimensional);

$\mathrm{L}$ - comprimento da tubulação (m);

$\mathrm{D}$ - diâmetro interno do tubo (m);

$\mathrm{V}$ - velocidade média de escoamento na seção $\left(\mathrm{m} \mathrm{s}^{-1}\right)$; 
$\mathrm{Q}$ - vazão $\left(\mathrm{m}^{3} \mathrm{~s}^{-1}\right)$

$\mathrm{g}$ - aceleração gravitacional, tomada como $9,81\left(\mathrm{~m} \mathrm{~s}^{-2}\right)$.

\subsection{Determinação do fator de atrito}

O maior empecilho de aplicar a Equação Universal consiste na determinação do fator de atrito $f$. Essa resistência hidráulica constitui informação básica necessária ao projeto hidráulico (YOO; SINGH, 2005). Há métodos teóricos para sua determinação, mas aproximações empíricas são comumente empregadas (VON BERNUTH, 1990). O adimensional $f$ pode depender apenas do regime de escoamento ou ainda depender da altura de rugosidade do tubo (eq. 15).

$$
f=\varphi\left(\operatorname{Re}, \frac{\varepsilon}{D}\right)
$$

O termo de rugosidade relativa foi iniciado pelo experimento de Nikuradse realizado em 1933, considerando a altura da rugosidade em relação ao diâmetro (AZEVEDO NETTO; FERNANDEZ Y FERNANDEZ, 2015). Num estudo conduzido por meio de rugosímetro de bancada (ROCHA et al., 2017) foi observado uma rugosidade média de 8,116 $\mu \mathrm{m}$ para tubos de polietileno utilizados na irrigação.

Para escoamento laminar, o cálculo do fator de atrito é feito pela equação de Hagen-Poiseuille (eq. 16), cuja função depende tão apenas do número de Reynolds.

$$
f=\frac{64}{\operatorname{Re}}
$$

Entretanto, considerando um regime de escoamento permanente turbulento, a estimativa do fator de atrito se torna mais complexa, haja visto que $f$ torna-se, também, função da rugosidade relativa das paredes do tubo (ROMEO; ROYO; MONZÓN, 2002).

Para escoamento turbulento uniforme em tubos hidraulicamente rugosos, mistos e lisos, a equação (eq. 17) de Colebrook-White (1937) é largamente aplicada e mostra-se como método padrão de aproximação de $f$, sendo válida para regimes de transição e turbulentos $\left(2000 \leq \mathrm{Re} \leq 10^{8}\right)$ com rugosidade relativa de $0 \leq \varepsilon / \mathrm{D} \leq 0,05$ (ROMEO; ROYO; MONZÓN, 2002; PORTO, 2006; SONNAD; GOUDAR, 2006; FRIZZONE et al., 2012; VILAÇA, 2012).

$$
\frac{1}{\sqrt{f}}=-2 \log \left(\frac{\varepsilon / D}{3,71}+\frac{2,52}{\operatorname{Re} \sqrt{f}}\right)
$$

em que: $\varepsilon$ - altura média das rugosidades do tubo $(\mathrm{m})$;

$\mathrm{D}$ - diâmetro interno da seção (m). 
A equação de Colebrook-White é um arranjo inteiramente empírico, com coeficientes empiricamente determinados, que tem a vantagem de ser operacional (VON BERNUTH, 1990). É uma combinação entre a equação de Prandtl (eq. 18), para escoamento turbulento em tubos lisos, e a equação de Von Karman (eq. 19), para escoamento em tubos rugosos, sendo estas suas bases teóricas (YOO; SINGH, 2005; VILAÇA, 2012).

$$
\begin{aligned}
& \frac{1}{\sqrt{f}}=-2 \log \frac{2,51}{\operatorname{Re} \sqrt{f}} \\
& \frac{1}{\sqrt{f}}=-2 \log \frac{K}{3,71 D}
\end{aligned}
$$

Pela presença do fator $f$ de forma implícita nessas equações anteriores, há de se adotar processos iterativos para sua aproximação, como o método de Newton-Rhapson. Reconhecendo a exigência de cálculos numéricos, alguns autores propuseram aproximações explícitas. Swamee e Jain (1976) realizaram o desenvolvimento de uma aproximação explícita com alto grau de exatidão (eq. 20), válido aos intervalos $10^{-6}<\varepsilon / \mathrm{D}<10^{-2} \operatorname{com} 5 \cdot 10^{3}<\operatorname{Re}<$ $10^{8}$ (SWAMEE; JAIN, 1976; ROMEO; ROYO; MONZÓN, 2002; SONNAD; GOUDAR, 2006).

$$
f=\frac{0,25}{\left[\log \left(\frac{\varepsilon}{3,7 D}+\frac{5,74}{\operatorname{Re}^{0,9}}\right)\right]^{2}}
$$

Posteriormente, Swamee apresentou uma equação genérica (eq. 21) para o cálculo do fator de atrito, cujo uso não apresenta restrições quanto ao regime de escoamento, número de Reynolds e rugosidade relativa (SWAMEE, 1993). Andrade (2001), afirma que seu uso seja feito com cautela, pois há um aumento no desvio de $f$ quando se aumenta a rugosidade do tubo e uma redução de $f$ quando se aumenta o número de Reynolds, muito embora, o autor tenha encontrado valores de $f$ bastante próximos aos estimados pela equação de Colebrook-White em regime de transição e turbulência plena.

$$
f=\left\{\left(\frac{64}{\mathrm{Re}}\right)^{8}+9,5\left[\ln \left(\frac{\varepsilon}{3,7 D}+\frac{5,74}{\mathrm{Re}^{0,9}}\right)-\left(\frac{2500}{\mathrm{Re}}\right)^{6}\right]^{-16}\right\}^{0,125}
$$

Todavia, na irrigação localizada, o número de Reynolds nas linhas laterais normalmente é inferior a $10^{5}$ e $f$ pode ser calculado com boa precisão pela simples equação proposta por Blasius (eq. 22), desde que $4000 \leq \operatorname{Re} \leq 10^{5}$, e seja o escoamento considerado como hidraulicamente liso (VILAÇA, 2012). Os coeficientes dessa equação podem variar de acordo com a tecnologia de produção do tubo. Cardoso e Klar (2014) estimaram os coeficientes, respectivamente, como 0,300 e 0,25 , resultando numa pequena redução nos valores de $f$. De acordo com von Bernuth (1990), com a inserção do fator de atrito de Blasius na equação de Darcy- Weisbach, obtêm-se três vantagens: (i) possui base teórica e é dimensionalmente homogênea; (ii) apresenta boa exatidão para $4000 \leq \operatorname{Re} \leq$ 
105; (iii) é facilmente corrigida para variações na viscosidade da água. Salienta-se ainda que a equação de Blasius superestima $f$ quando $\operatorname{Re}<4000$.

$$
f=\frac{c}{\operatorname{Re}^{m}}
$$

Sendo proposto por Blasius: $\mathrm{c}=0,316$ e $\mathrm{m}=0,25$.

Por questões de simplicidade no cálculo, muitos projetistas de sistemas de irrigação dão preferência em adotar equações empíricas, como as de Hazen-Williams, Manning e Scobey, para determinar a perda contínua de carga nas tubulações. Contudo, a perda de carga calculada pelas equações empíricas podem diferir do valor retornado pela equação de Darcy-Weisbach, pois, nesta última não há restrições quanto às condições de escoamento (BOMBARDELLI; GARCÍA, 2003; PORTO, 2006).

\subsection{Perda localizada de carga}

A introdução de componentes adicionais, tais como conexões, válvulas, cotovelos, curvas, tês, emissores inseridos na linha lateral, e outras possíveis espécies de excentricidades, interferem numa perda de carga pontualizada na tubulação, com alterações bruscas na velocidade de escoamento do fluido, em módulo e direção. O alargamento brusco é um dos poucos casos (talvez o único) para o qual é possível obter o coeficiente de perda de carga a partir de uma análise simples. Para tanto, devem-se considerar as equações da continuidade, da conservação da quantidade de movimento para um volume de controle entre as duas seções e a equação da energia. Assumindo que o movimento é uniforme nas duas seções, obtem-se a equação do teorema de Borda-Bélanger (FRIZZONE et al., 2012). Por exemplo representado pela Figura 2, admitindo que a pressão em 2 seja medida a jusante da zona de turbilhão, considerando essas seções (1 e 2) e aplicando-se Bernoulli, tem-se a perda localizada de carga pelo alargamento brusco (eq. 23).

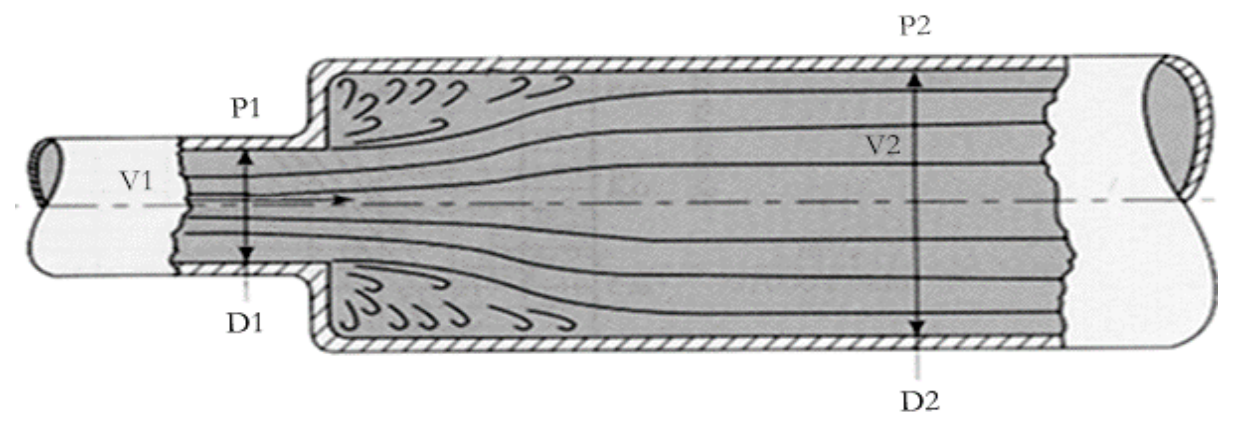

Figura 2. Representação de expansão brusca abordada pelo teorema de Borda-Bélanger.

$$
h f_{L}=\frac{V_{1}^{2}-V_{2}^{2}}{2 g}-\frac{P_{2}-P_{1}}{\rho g}
$$


Essa zona de turbilhão é a razão de se estudar o espaçamento adequado para a inserção de tomadas de pressão que disponham de uma estabilização satisfatória. A variação da quantidade de movimento deve igualar-se ao impulso das forças, assim as duas expressões de forças atuantes (inércia e pressão) são igualadas.

$$
\begin{gathered}
\rho Q\left(V_{1}-V_{2}\right)=\left(P_{2}-P_{1}\right) A_{2} \\
\frac{V_{2} A_{2}\left(V_{1}-V_{2}\right)}{A_{2}}=\frac{P_{2}-P_{1}}{\rho} \\
\frac{2 V_{2}\left(V_{1}-V_{2}\right)}{2 g}=\frac{P_{2}-P_{1}}{\rho g}
\end{gathered}
$$

Substituindo a eq. $24 \mathrm{c}$ na eq. 23 , tem-se:

$$
h f_{L}=\frac{\left(V_{1}-V_{2}\right)^{2}}{2 g}
$$

Essa expressão (eq. 25) é conhecida como o teorema de Borda-Bélanger, em homenagem a Borda, que deduziu essa expressão, em 1766, e Belanger, que retomou seus estudos e expôs essa teoria (AZEVEDO NETTO; FERNANDEZ Y FERNANDEZ, 2015). A expressão geral das perdas localizadas nessa condição é obtida considerando a equação da continuidade na expressão anterior, dado conforme a eq. 26.

$$
h f_{L}=\frac{V_{1}^{2}}{2 g}\left(1-\frac{A_{1}}{A_{2}}\right)^{2}
$$

Todavia, ainda não há uma análise teórica capaz de indicar os detalhes do escoamento de uma singularidade e possibilitar o cálculo exato da perda de carga provocada. Normalmente a perda de carga é determinada experimentalmente, uma vez que seu tratamento analítico é demasiadamente complexo, e, para maioria dos componentes hidráulicos os valores são fornecidos na forma adimensional (PORTO, 2006; FRIZZONE et al., 2012; AZEVEDO NETTO; FERNANDEZ Y FERNANDEZ, 2015). O método mais comum para determinar a perda localizada de carga $\left(\mathrm{hf}_{\mathrm{L}}\right)$ é baseado em sua proporção com a carga cinética, como expresso pela eq. 27, dado por um coeficiente adimensional $\left(\mathrm{K}_{\mathrm{L}}\right)$.

$$
h f_{L}=K_{L} \cdot \frac{V^{2}}{2 g}
$$

em que: $K_{L}$ - coeficiente de perda localizada de carga (adimensional);

$\mathrm{hf}_{\mathrm{L}}$ - perda localizada de carga $(\mathrm{m})$;

$\mathrm{V}$ - velocidade média de escoamento $\left(\mathrm{m} \mathrm{s}^{-1}\right)$. 
Diante disso, pode-se determinar o coeficiente $\mathrm{K}_{\mathrm{L}}$ (eq. 28). A princípio, o coeficiente depende das condições de escoamento e das características geométricas da peça. Porém esse coeficiente tende a uma constância quando o escoamento vai se tornando mais turbulento, tendo sido adotado no uso prático um número constante, que é tabelado e informado para cada peça e conexão. Percebe-se que essa informação é bastante útil para cálculos no dimensionamento de sistemas hidráulicos.

$$
K_{L}=\frac{2 g \cdot h f_{L}}{V^{2}}=\frac{2 \cdot \Delta p}{\rho V^{2}}
$$

em que: $\Delta \mathrm{p}$ - queda de pressão $\left(\mathrm{N} \mathrm{m}^{-2}\right)$;

$$
\begin{aligned}
& \rho \text { - massa específica da água }\left(\mathrm{kg} \mathrm{m}^{-3}\right) ; \\
& \mathrm{g} \text { - aceleração gravitacional }\left(\mathrm{m} \mathrm{s}^{-2}\right) ; \\
& \mathrm{hf} f_{\mathrm{L}} \text { - perda localizada de carga }(\mathrm{m}) ; \\
& \mathrm{V} \text { - velocidade média do escoamento }\left(\mathrm{m} \mathrm{s}^{-1}\right) .
\end{aligned}
$$

Uma forma de se determinar $\mathrm{K}_{\mathrm{L}}$ é através do coeficiente angular obtido pela regressão linear dos pontos experimentais de perda localizada sob o domínio da carga cinética no tubo, como sendo esse a reta tangente formada entre a dispersão dos pontos. Outra forma de se estimar é por meio de um gráfico, sendo plotado a nuvem de pontos obtidos de $K_{L}$ sob função do escoamento, onde o valor médio alcançado é o coeficiente aderido a uma constância.

Por praticidade, uma canalização que compreende diversas peças especiais e outras singularidades equivale, sob o ponto de vista das perdas de carga, a um encanamento retilíneo de comprimento maior. O comprimento equivalente (eq. 29b) é função de proporções diretas ao coeficiente $\mathrm{K}_{\mathrm{L}}$ e diâmetro, mas inverso ao coeficiente de atrito $f$. Cada peça corresponderá a um certo comprimento fictício e adicional, onde, contabilizado em sua totalidade, será denominado como comprimento virtual da canalização.

$$
\begin{gathered}
h f_{L}=K_{L} \cdot \frac{V^{2}}{2 g}=f \cdot \frac{L e q}{D} \cdot \frac{V^{2}}{2 g} \\
\text { Leq }=\frac{K_{L} \cdot D}{f}
\end{gathered}
$$

em que: $K_{L}$ - coeficiente de perda localizada de carga (adimensional);

$\mathrm{D}$ - diâmetro da tubulação (m);

$f$ - fator de atrito (adimensional);

Leq - comprimento equivalente (m).

Uma outra simplificação consiste em dividir esse comprimento equivalente pelo diâmetro das canalizações retilíneas, e expressar a perda de carga por número de diâmetros (AZEVEDO NETTO; FERNANDEZ Y FERNANDEZ, 2015). De acordo com o trabalho conduzido por Prado (2015), expressar a perda localizada em termos do número de diâmetros não apresentou constância em relação aos diâmetros estudados. 


\subsection{Automação e validação de ensaios}

A automação de ensaios para irrigação não é uma tentativa recente, como verifica-se nos ensaios para aspersores conduzidos por Fischer e Wallender (1988), Seginer et al. (1992), Tarjuelo et al. (1999) e Zanon et al. (2000). Os ensaios automatizados na área mantêm-se sob contínuo aperfeiçoamento, como exemplificado pela análise de incertezas de Saretta (2016). No campo de pesquisas relacionadas à obstrução de emissores, destaca-se a bancada automatizada desenvolvida por Niu, Liu e Chen (2012), a qual possibilitou realizar um grande número de avaliações de gotejadores, de longa duração e com diferentes qualidades de água. Perboni (2016) descreveu o desenvolvimento e validação de uma estrutura automatizada para o monitoramento contínuo da vazão de gotejadores, permitindo, além do monitoramento individualizado, a redução da mão de obra na condução dos ensaios. Conforme esse autor, a automatização dos processos assegura confiabilidade nos resultados desde que o sistema seja validado.

A instabilidade nos sistemas de controle e medição pode afetar diretamente a qualidade dos resultados dos ensaios. Causas de instabilidade podem agir naturalmente em qualquer sistema de medição, seja por interferência do operador, imperfeições em dispositivos mecânicos ou eletrônicos, oscilações na fonte de energia, vibrações mecânicas e ruídos elétricos (ROCHA et al., 2017). Uma quantificação da instabilidade pode ser obtida por meio de técnicas e ferramentas de controle estatístico de processos, para avaliar o grau de adequação de bancadas de ensaio. Desde o estudo anterior de Rocha (2014), foram utilizadas as cartas de controle de Shewhart para avaliar a estabilidade do instrumento de medição. Técnicas de controle estatístico de qualidade (CEP) foram desenvolvidas para avaliar a variabilidade de processos de produção ou sistemas de medição (MONTGOMERY, 2013). Seu propósito é exprimir a qualidade por meio de limites admissíveis de variância nos resultados de ensaios. 


\section{METODOLOGIA}

Os procedimentos experimentais para determinação das perdas localizadas de carga foram executados no Laboratório de Irrigação do Departamento de Engenharia de Biossistemas da Escola Superior de Agricultura "Luiz de Queiroz” - USP, município de Piracicaba, SP.

\subsection{Estrutura dos ensaios hidráulicos}

O arranjo dos instrumentos (Figura 3) baseia-se em normas técnicas (ISO, 2008; ISO TR, 2005). A estrutura consiste num circuito fechado alimentado por um reservatório de $4800 \mathrm{~L}$ conectado a um conjunto motobomba responsável pela pressurização do sistema. $\mathrm{O}$ volume assegura que a temperatura da água durante os ensaios não sofra variações significativas $\left( \pm 3^{\circ} \mathrm{C}\right)$ durante o ensaio (ISO, 2005). Circuito eletrônico microcontrolado foi desenvolvido e utilizado para facilitar a aquisição de dados e controle das condições de ensaio.

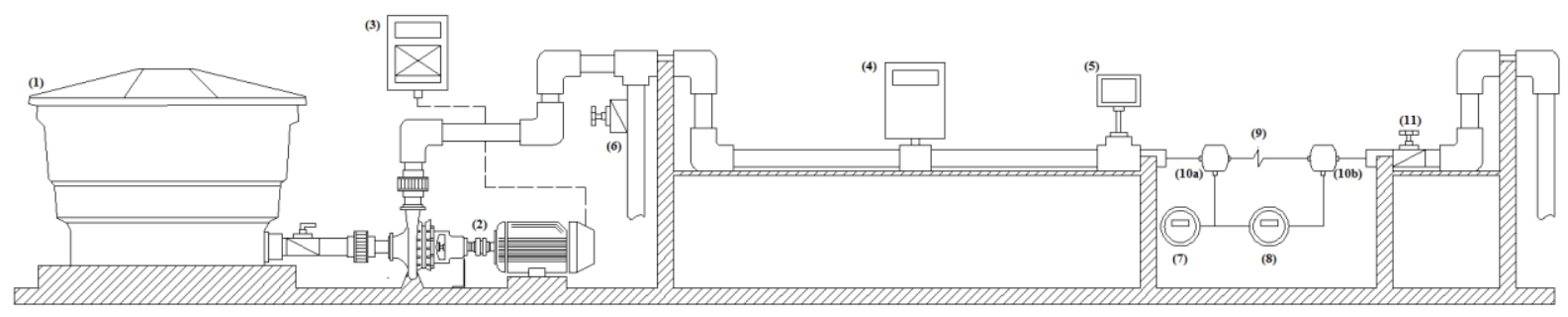

Figura 3. Ilustração da estrutura de ensaio: (1) reservatório de água; (2) conjunto motobomba; (3) inversor de frequência; (4) medidor eletromagnético de vazão; (5) transmissor de temperatura; (6) registro by-pass; (7) transmissor de pressão de entrada; (8) transmissor de pressão diferencial; (9) trecho de ensaio; (10) tomadas de pressão a montante (a) e a jusante (b); (11) válvula de retorno (sistema fechado).

Prezando versatilidade de ensaios, duas bombas centrífugas em paralelo foram incluídas na bancada, tendo seu acionamento definido pela demanda de operação singularmente. Uma motobomba utilizada é da marca KSB, modelo Hydrobloc C 1000N T, que admite vazões entre o intervalo de $0,50 \mathrm{~m}^{3} \mathrm{~h}^{-1}-11,00 \mathrm{~m}^{3} \mathrm{~h}^{-1}(303,92$ $225,49 \mathrm{kPa}$ ), condicionada pelo motor elétrico trifásico com potência nominal de $0,75 \mathrm{~kW}$ a 3470 RPM. Outra, também de marca KSB, modelo Hydrobloc MA 403, possui 3 estágios, e admite vazões de até 7,00 $\mathrm{m}^{3} \mathrm{~h}^{-1}(872,55$ $784,31 \mathrm{kPa}$ ), condicionado por motor elétrico trifásico com potência nominal de 3,0 kW a $3450 \mathrm{RPM}$. Um filtro de tela de malha 120 mesh foi alocado no ínicio do recalque, após registro das bombas. Há possibilidade de se conectar um registro adicional (by-pass) antes do trecho de monitoramento para possíveis ajustes na condição de ensaios que exija vazões muito baixas; mas sem necessidade para o específico estudo.

O tubo adotado no trecho experimentado é de polietileno de baixa densidade linear, de uso comum na prática de microirrigação, com diâmetros de 13 e $16 \mathrm{~mm}$. Vilela et al. (2003) estabeleceram um estudo de perda de carga em tubos de polietileno, variando-se a vazão para cada pressão estudada, de maneira a obter velocidades de escoamento entre 0,5 a 3,0 $\mathrm{m} \mathrm{s}^{-1}$. Mantovani et al. (2012) afirmaram o uso prático na irrigação de até 2,0 $\mathrm{m} \mathrm{s}^{-1}$. Frizzone et al. (2012) recomendam evitar velocidades acima de 2,0 $\mathrm{m} \mathrm{s}^{-1}$, adotando-se sistemas de segurança que previnam transientes hidráulicos, mas também recomendam velocidades mínimas de $0,3 \mathrm{~m} \mathrm{~s}^{-1}$ para evitar a 
sedimentação de materiais suspensos dentro das tubulações. Por ter um teor laboratorial os intervalos desses ensaios podem vir a extrapolar os limites recomendados.

A queda de pressão proporcionada pela perturbação da conexão é quantificada por dois pontos de tomadas de pressão acoplados por colares. O espaçamento das tomadas de pressão com a peça amostral pode vir a comprometer o valor retornado, pois demasiadamente curtos podem provocar instabilidade e excessivos atribuem uma perda distribuída desnecessária.

Diante disso, o fenômeno de escoamento proporcionado pela passagem na peça foi simulado por meio de análises computacionais de fluidodinâmica pelo programa COMSOL Multiphysics ${ }^{\circledR}$, $\operatorname{com}_{\text {o }}$ propósito de se observar qual a distância mínima para estabilização das tomadas de pressão (Figura 4). Simulou-se duas uniões (13 e $16 \mathrm{~mm}$ ) operando sob uma velocidade crítica de $3,50 \mathrm{~m} \mathrm{~s}^{-1}$.

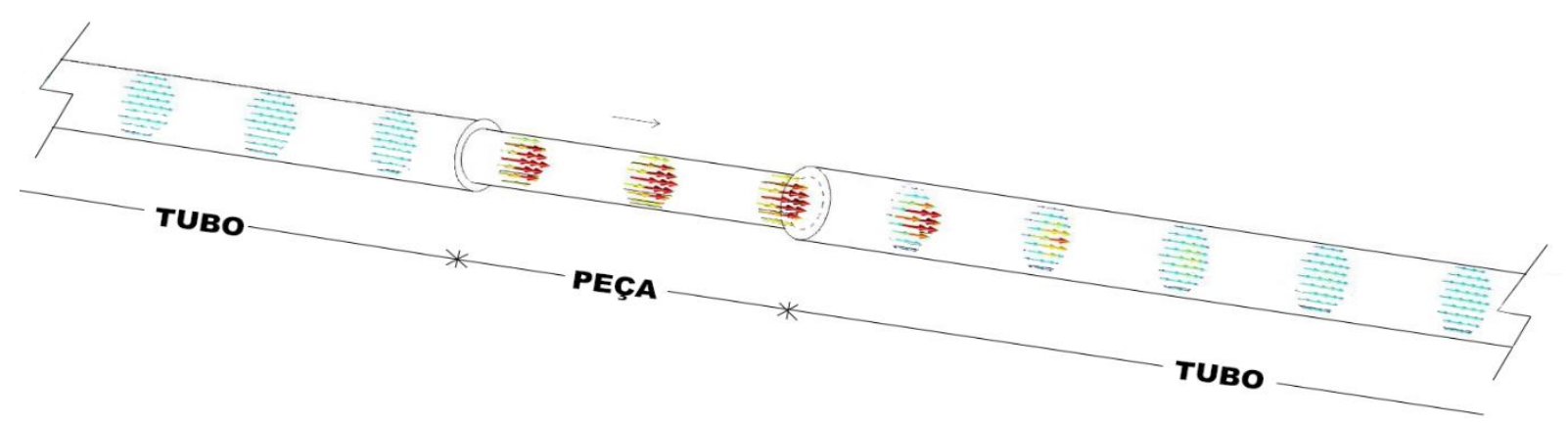

Figura 4. Simulação dos vetores de velocidade ocasionados na seção do conduto pela passagem da singularidade.

Diante disso, se propôs um espaçamento adequado como sendo equivalente a 2 diâmetros na entrada (a montante) e 10 diâmetros na saída (a jusante) para otimizar a posição das tomadas. Tais valores também são atribuídos pela normativa ISO 9644:2008 para o ensaio de válvulas de irrigação. Convém significar os cuidados na furação do tubo para alocação das tomadas de pressão, pois resíduos do tubo podem provocar zonas de baixa pressão, além de se pensar em soluções que impeçam possíveis vazamentos; procedimentos que serão descritos posteriormente.

\subsection{Caracterização e calibração dos instrumentos de medição}

Nos ensaios laboratoriais dos materiais de irrigação comumente são monitorados parâmetros como pressão relativa, vazão, pressão diferencial e temperatura da água (ROCHA, 2016). A qualidade dessas medições é crucial para o êxito e reprodução dos ensaios. O fluxograma de instrumentação da bancada de ensaios é apresentado na Figura 5. 


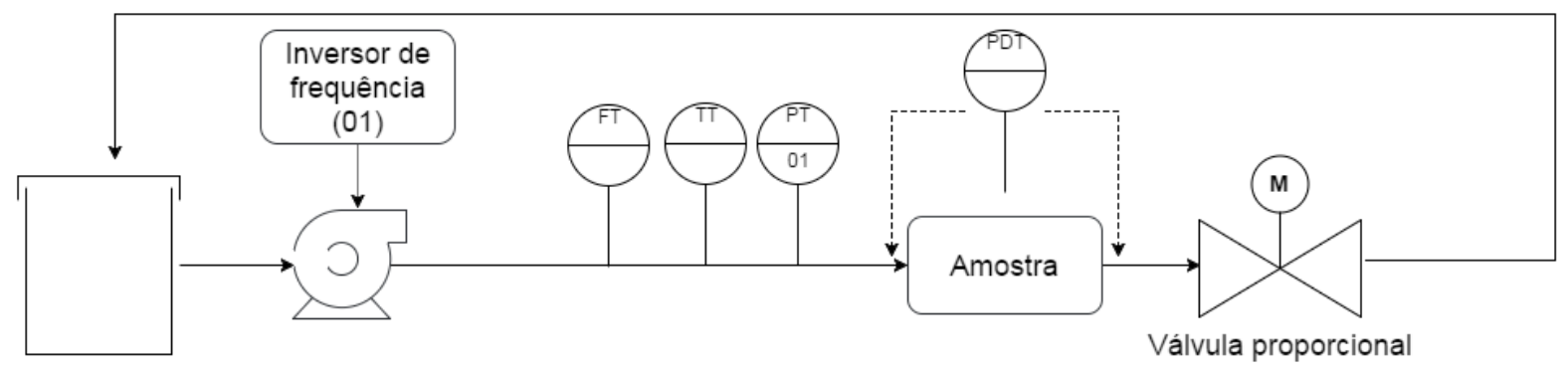

Reservatório

Figura 5. Fluxograma de instrumentação da bancada de ensaios, em que: FT - medidor de vazão eletromagnético; TT transmissor de temperatura; PT - transmissor de pressão; PDT - transmissor de pressão diferencial.

O monitoramento de vazão foi efetuado utilizando-se um transmissor eletromagnético de vazão, de marca Krohne ${ }^{\circledR}$, modelo IFC 010 D, com resolução de $1 \cdot 10^{-2} \mathrm{~m}^{3} \mathrm{~h}^{-1}$, conectado a montante do trecho ensaiado. O instrumento de medição foi calibrado para operação na faixa de vazão de 0 a $4 \mathrm{~m}^{3} \mathrm{~h}^{-1}$, com incerteza expandida de 0,5\% em relação ao fundo de escala. O sinal transmitido é de 4-20 mA. Os sifões invertidos alocados nas extremidades têm o intuito de preservar a integridade do equipamento, assegurando que a seção de medição de vazão sempre esteja completamente cheia de água.

O transmissor de pressão diferencial, de marca Novus ${ }^{\circledR}$, modelo NP800H, dispõe de um sensor capacitivo, alimentado por uma tensão de 24 VCC, com resolução de $1 \cdot 10^{-2} \mathrm{kPa}$, fornecendo um sinal de saída de 4 $20 \mathrm{~mA}$ a dois fios. O equipamento foi configurado para operar sob uma faixa de pressão diferencial de 1-100 kPa. Uma vez que sua rangeabilidade é de 100:1, valores fora de tal faixa podem vir a extrapolar a incerteza de medição do fabricante. De acordo com o mesmo, o produto oferece uma exatidão de 0,075\%.

A temperatura da água foi monitorada por um transmissor de temperatura, de marca Zürich ${ }^{\circledR}$, modelo TZD.420, com resolução de $0,1^{\circ} \mathrm{C}$, faixa de medição entre 0 a $50{ }^{\circ} \mathrm{C}$, precisão de $0,5 \%$, alimentado sob tensão de 24 VCC e com o sinal de saída de 4-20 mA. A temperatura é importante para corrigir a massa específica e viscosidade da água.

O monitoramento da pressão na entrada do trecho de ensaio é realizado por um transmissor de pressão, de marca Zürich ${ }^{\circledR}$, modelo Z.10.B.420, cuja mensuração ocorre através de um sensor piezoresistivo. O manômetro em uso transmite valores numa faixa de 0-5 bar com precisão do sinal de $0,1 \%$. Como os demais sensores, o sinal de saída é de 4-20 mA. Sobretudo, a pressão de operação pode influenciar no diâmetro de tubos de polietileno (RETTORE NETO, 2011). Diante disso, essa variável é controlada durante todo o ensaio e será mais detalhado a seguir.

A norma ISO 9644:2008 é aplicada para determinações de perda de carga em válvulas de irrigação, sendo a referência normativa mais próxima do problema tratado nesse trabalho. A referida norma especifica que o desvio admissível entre a leitura indicada nos aparelhos de medição e o valor real deve ser, no máximo, 2\% para medições de vazão, pressão e pressão diferencial, e $1{ }^{\circ} \mathrm{C}$ para a temperatura da água.

Por regressão linear foram ajustadas equações que correlacionassem os sinais digitais dos instrumentos descritos com suas respectivas unidades físicas. Por se tratarem de transmissores, os valores de medição são informados pelo próprio instrumento; os quais já se encontram calibrados. Os gráficos a seguir (Figura 6) representam os pares de pontos obtidos, com as respectivas equações dos instrumentos de medição. 

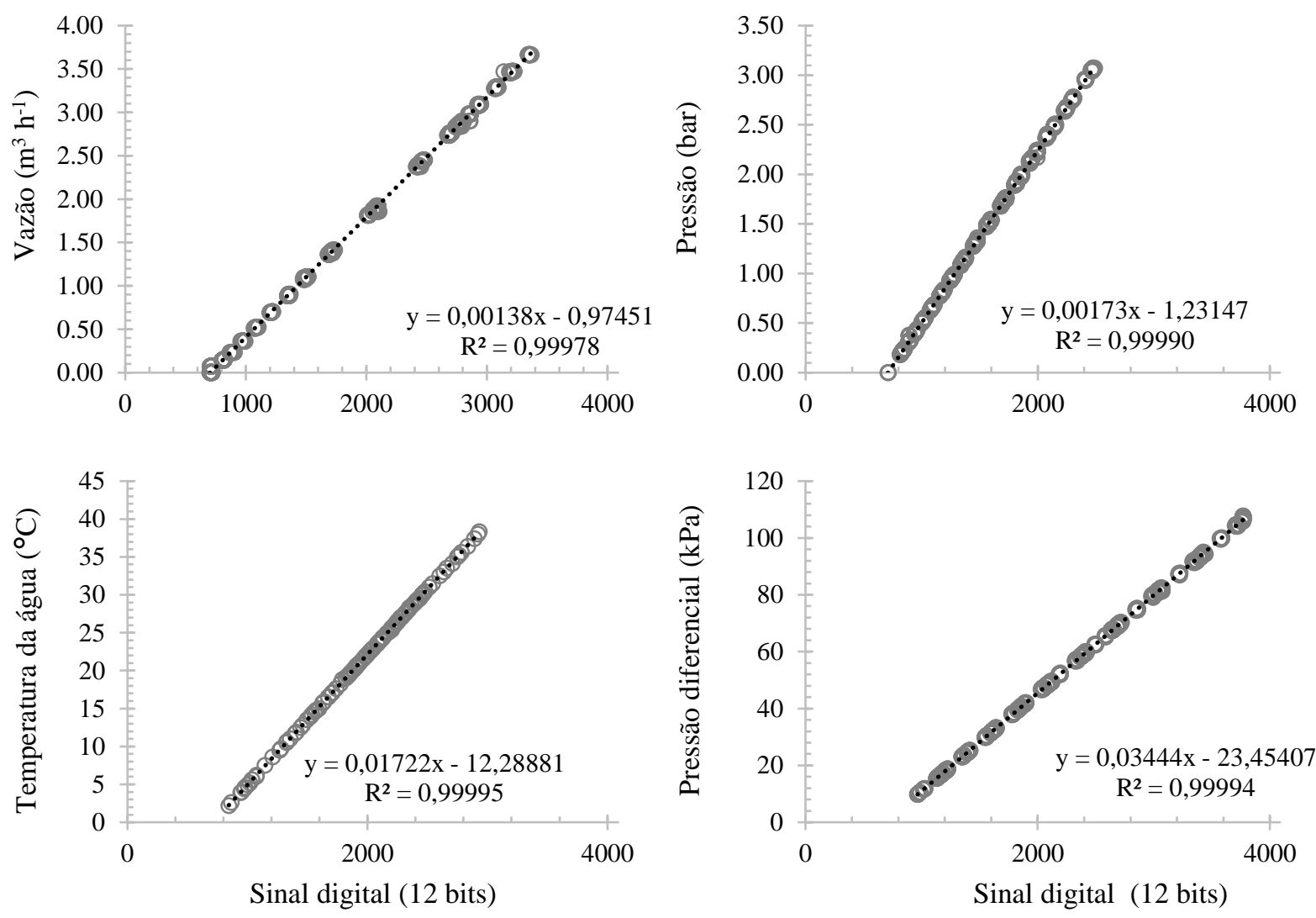

Figura 6. Calibração dos instrumentos de mensuração da vazão, pressão, temperatura da água e pressão diferencial; utilizados para determinação da curva vazão-perda de carga de cada peça.

\subsection{Caracterização e controle dos atuadores}

O ajuste de vazão de ensaio é obtido pelo controle elétrico da válvula proporcional Belimo® LRB24-3, com passagem interna de $1 / 2$ ”, instalada a jusante da amostra sob teste. A válvula é alimentada com tensão de 24 VCC. O comando é operado através da entrada de sinais elétricos numa faixa de 2-10 VCC. Conforme ISO 9644:2008, não há restrições quanto o tamanho ou tipo da válvula.

O inversor de frequência utilizado é da marca Weg, modelo CFW-08. Na configuração em estado remoto, converte a faixa de tensão recebida $(0-10 \mathrm{~V})$ em uma frequência para alimentação do motor, conferindo a velocidade de rotação da bomba e, consequentemente, a pressurização do sistema. Os limites de frequência operam entre $15 \mathrm{~Hz}$ (ajustado previamente) a $60 \mathrm{~Hz}$.

O controle da pressão de ensaio opera em malha fechada (Figura 7), utilizando-se a lógica de controle Proporcional-Integrativo-Derivativo (PID). Os sinais de pressão de entrada (Pin) são comparados ao parâmetro da pressão desejada (setpoint), definido previamente ao ensaio. Seu processamento é retornado analogicamente ao inversor de frequência (IF), que confere a regulagem necessária de rotação para a motobomba (MB). 


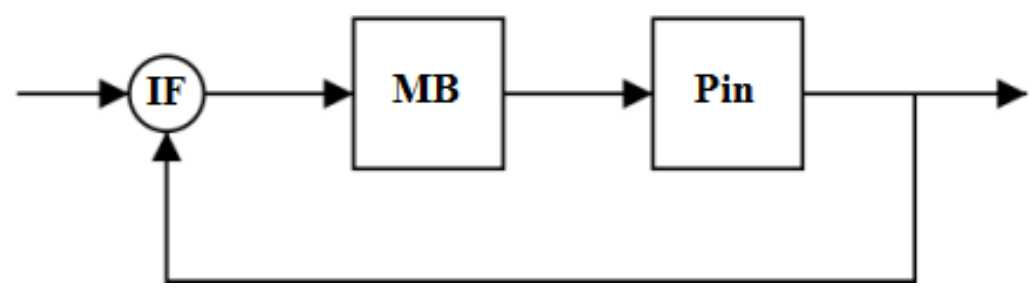

Figura 7. Diagrama de controle retroativo.

O uso de controlador PID visa assegurar acurácia no controle das pressões de ensaio. Recomenda-se um índice de acurácia na regulação da pressão de $\pm 1 \%$ aos ensaios (ISO TR, 2005).

\subsection{Hardware para aquisição de dados e controle}

Haja visto o monitoramento e controle das condições de ensaio, faz-se interessante reportar tais quantificações num banco de dados para posterior análise. Um hardware - com núcleo no microcontrolador dsPIC30F4013 - foi desenvolvido para a aquisição, controle de operações e transmissão de dados para plataforma PC com características funcionais ilustradas conforme Figura 8.

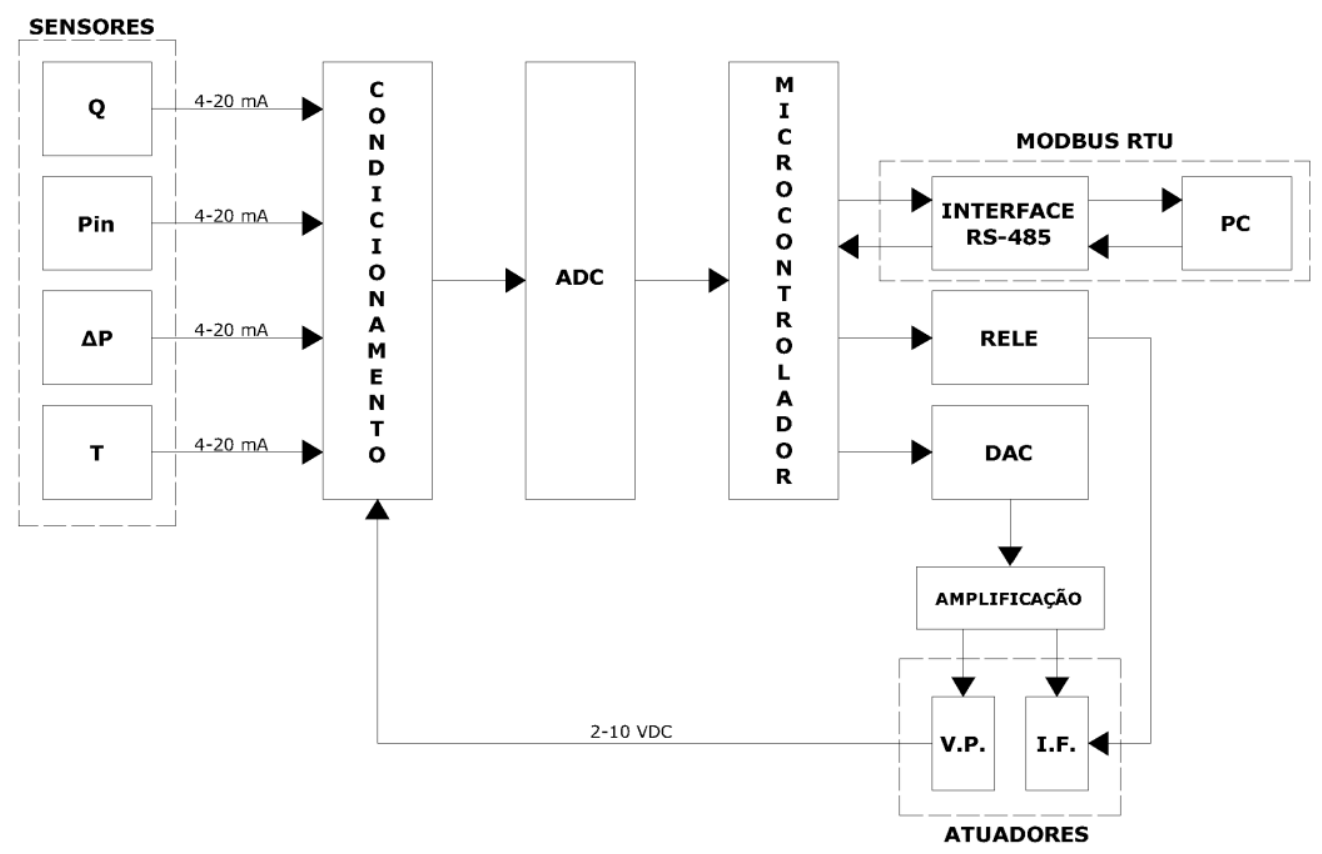

Figura 8. Diagrama em blocos das funções do hardware desenvolvido. Q - vazão; Pin - pressão de entrada; $\Delta \mathrm{P}$ - pressão diferencial; T - temperatura; V.P. - válvula proporcional; I.F. - inversor de frequência; ADC/DAC - canais de conversão.

Os sensores operam com sinais analógicos de 4-20 mA que são convertidos para uma faixa de tensão contínua (0-5 VCC). A placa dispõe de 8 entradas analógicas dedicadas para esse fim.

O condicionamento desses sinais é obtido com a associação de amplificadores operacionais (AOP). O circuito subtrator permite que se obtenha na saída uma tensão igual a diferença entre os sinais aplicados, 
multiplicados por um ganho, enquanto o circuito seguidor atua como isolador de estágios e reforçador de correntes. Um circuito resistor-capacitor (RC) presente entre eles atua como filtro.

A placa também dispõe de outras 8 entradas analógicas para aquisição e condicionamento de sinais de tensão entre 0 e 5 VCC. Um destes reserva-se para monitoramento da posição em que se encontra a válvula proporcional (feedback), com uma divisão de tensão prévia pois o sinal de retorno da válvula proporcional é maior que 5 VCC.

Adicionalmente, dois canais são exclusivos para conversão digital-analógico (Digital-to-Analog Converter) 12-bit, com controles PID individualizados, permitindo obter um ajuste dos atuadores para domínio das condições de ensaio. Após essa conversão proporcionada pelo DAC, os sinais são amplificados para uma faixa de até 10 VCC. Um dos canais foi dedicado com uso da lógica PID ao controle do inversor de frequência e outro para ajuste da válvula proporcional. Embora fosse possível, não foi empregado controle PID para controle da válvula proporcional e, por consequência, da vazão de ensaio.

Permite-se ainda, 16 entradas digitais (expandindo-se as portas I/O) e 3 saídas digitais a relés para controle de energização de dispositivos. Um relé encarrega-se pelo controle de energização do inversor de frequência para cada início e fim de ensaio. Por fim, a placa construída é apresentada na Figura 9. A alimentação é fornecida sob tensão de 12 VCC.

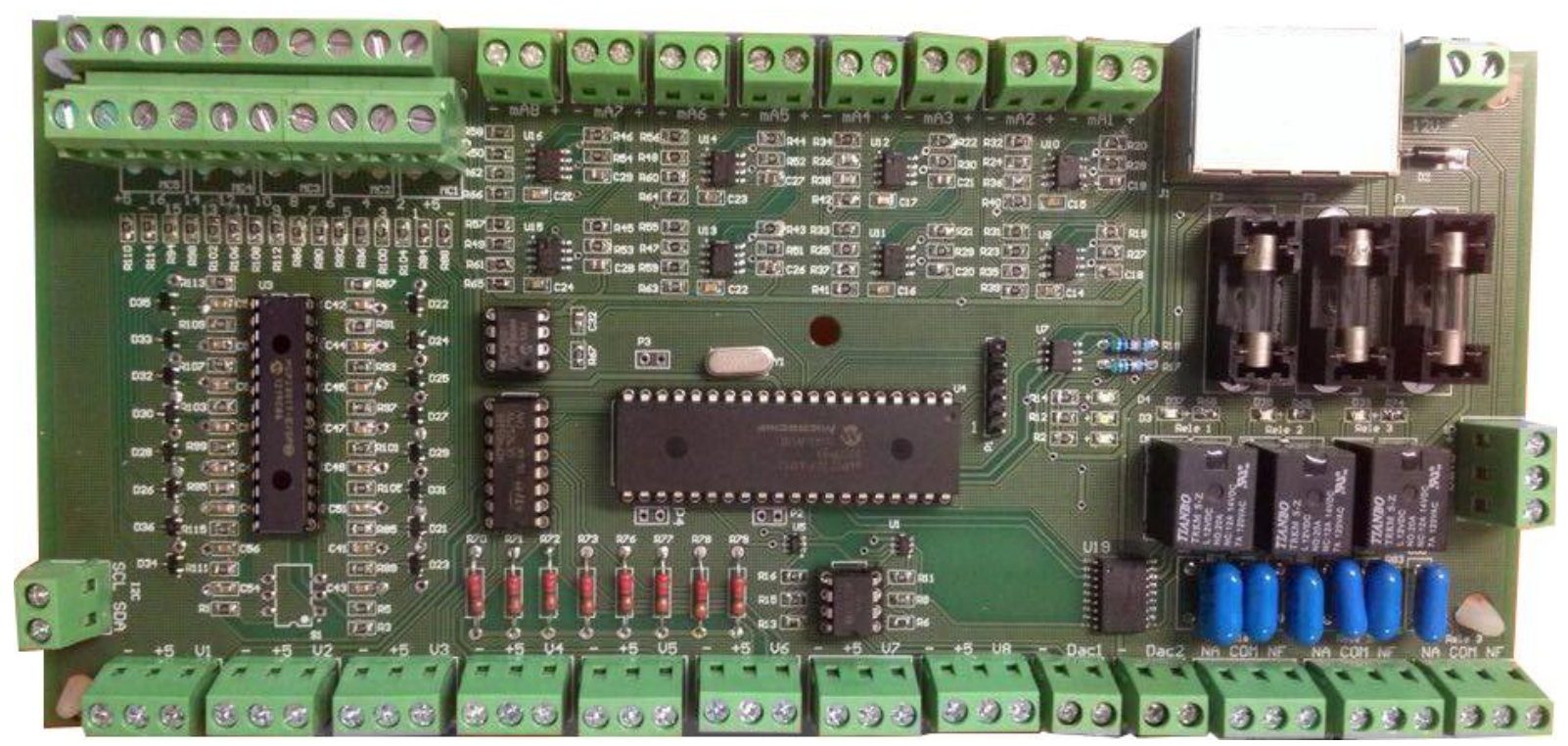

Figura 9. Fotografia da placa desenvolvida para aquisição e condicionamento de sinais, controle de atuadores e transmissão de dados.

O algoritmo incluso no microcontrolador foi programado em C, através do compilador $\mathrm{CCS}^{\circledR}$. O pacote de informações é protocolado através de comunicação serial Modbus RTU, um dos mais utilizados na indústria (URREA; MORALES; KERN, 2016). O usuário estabelece as ordens de operação remotamente por um modelo de comunicação mestre-escravo. O aplicativo supervisório desenvolvido lê e escreve as informações na rede, enquanto a placa de aquisição mantém-se em estado ocioso até a solicitação de um pedido. 


\subsection{Validação da bancada automatizada de ensaios}

Uma interface gráfica do usuário (GUI) foi desenvolvida para condução dos ensaios de validação sob plataforma PC pelo ambiente de desenvolvimento integrado Microsoft ${ }^{\circledR}$ Visual Studio ${ }^{\circledR}$ 2017, em linguagem C\# (Figura 10). A GUI permite a execução e monitoramento de ensaios, sendo que os pontos em azul representam os dados sendo coletados e registrados no documento, depois do período de ajuste e estabilização (vermelho) do sistema.

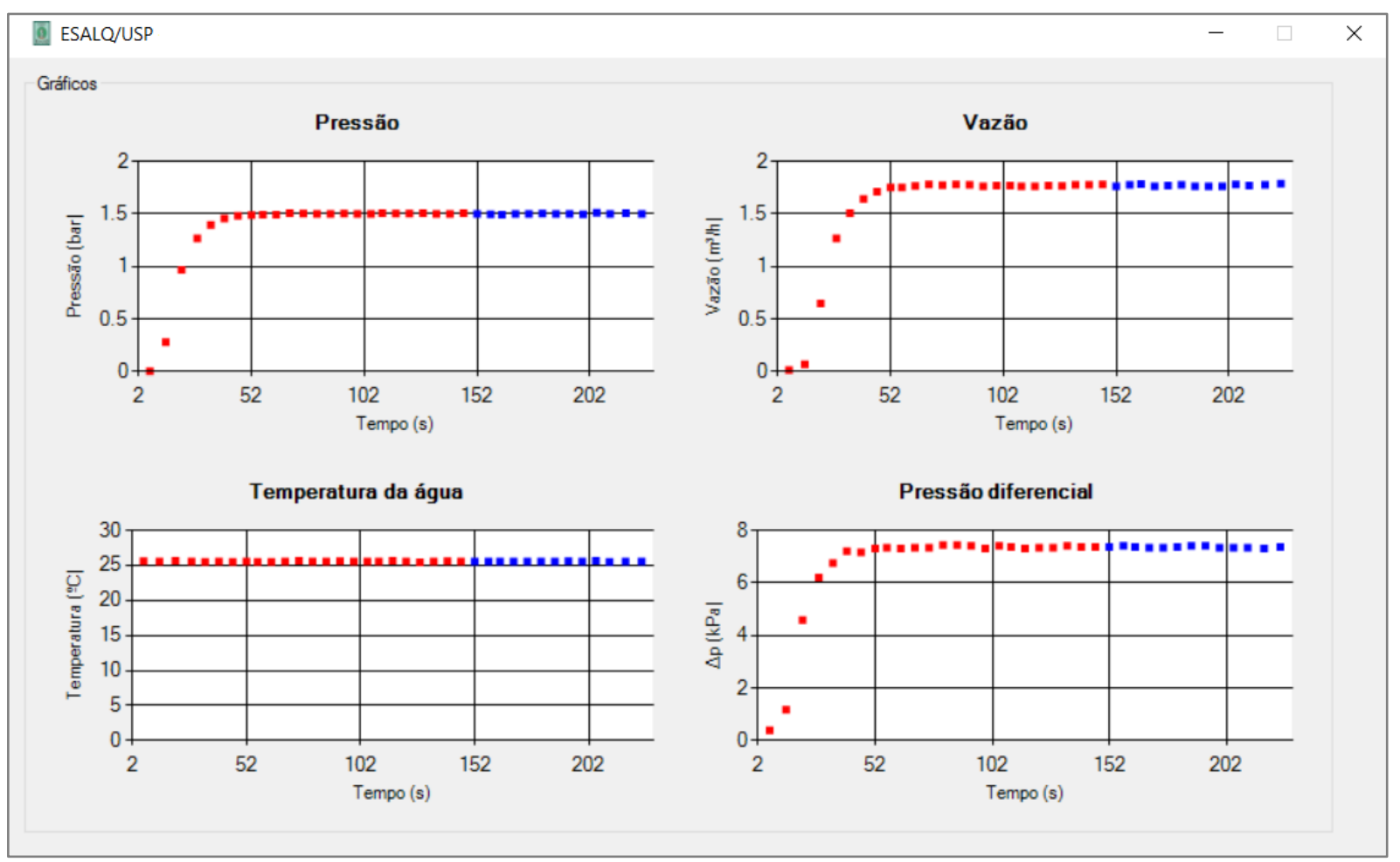

Figura 10. Representação da coleta de dados obtidas durante um ensaio para validação da bancada.

Os dados foram coletados sob a pressão de ensaio de $150 \mathrm{kPa}$ e sob vazão de 0,90 e 2,70 $\mathrm{m}^{3} \mathrm{~h}^{-1}$. Os ensaios de perda localizada de carga em peças, conexões e acessórios de microirrigação são conduzidos sob pressão de ensaio constante, sendo esse valor atribuído considerado como um valor usual. As vazões avaliadas representam limites práticos das condições de ensaio. O conjunto de dados utilizado para as análises considera um número de 50 amostras com uma única observação. Após o ajuste e estabilização das condições de ensaio, os dados foram coletados em intervalos de 5 segundos.

Gráficos de controle de Shewhart para observações individuais foram utilizados para o monitoramento da média e da variabilidade da pressão de ensaio. Os gráficos de controle foram gerados utilizando o aplicativo Action Stat Quality ${ }^{\circledR}$. Com base nas especificações da norma ISO 9644:2008, foram atribuídos os seguintes limites de especificação: (1) $\pm 2 \%$ em relação ao valor alvo ou médio para as variáveis pressão de ensaio, vazão e pressão diferencial; (2) $\pm 1^{\circ} \mathrm{C}$ em relação ao valor médio para a variável temperatura da água. As variáveis de interesse, ou seja, as características da qualidade avaliadas foram: pressão de ensaio, vazão, temperatura da água e pressão diferencial. 


\subsection{Aplicativo supervisório}

Após os testes de validação, a interface gráfica foi otimizada para condução dos ensaios de perda de carga. O aplicativo permite que o usuário configure os parâmetros de ensaio (Figura 11), tais como: pressão de ensaio controlada, abertura da válvula de retorno no início e seu incremento (passo), além do número de pontos coletados sob cada condição de vazão. O modo histerese está incluído na rotina para a coleta de pontos com decréscimo da vazão, após a abertura completa do registro de retorno. Com os valores definidos, pode-se iniciar a amostragem da peça.

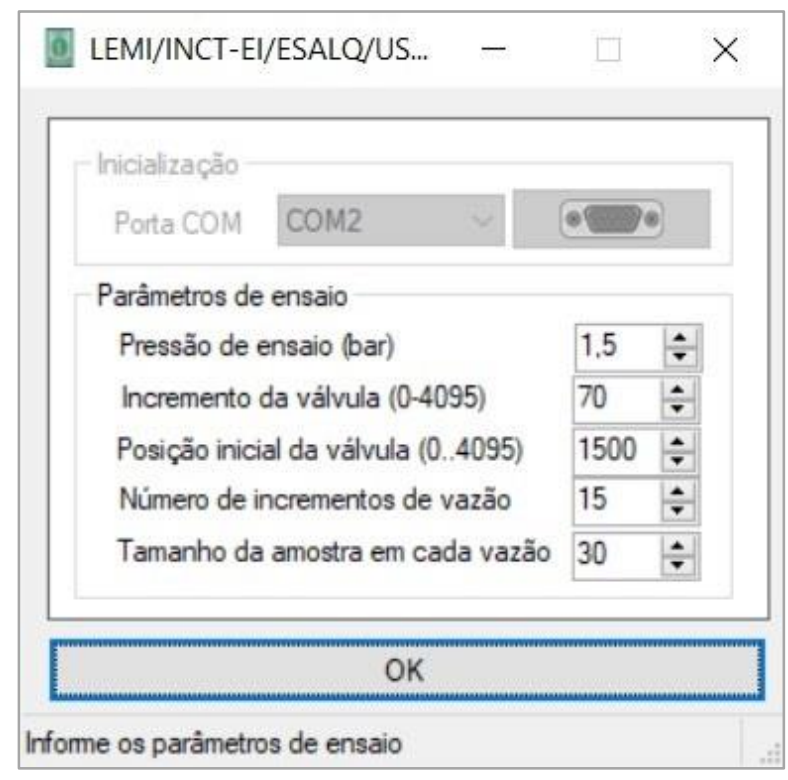

Figura 11. Janela inicial do aplicativo supervisório para configuração dos parâmetros de ensaio.

Os dados de coleta - tempo decorrido (s), pressão (bar), vazão $\left(\mathrm{m}^{3} \mathrm{~h}^{-1}\right)$, temperatura $\left({ }^{\circ} \mathrm{C}\right)$ e queda de pressão $(\mathrm{kPa})$ - são registrados e salvos num arquivo pré-nomeado pelo usuário em formato csv (comma-separated values). Uma interface de monitoramento permite acompanhar o sistema através de uma interface de monitoramento (Figura 12). No fim da amostragem se obtém o ajuste da curva potencial produzida pela paridade vazão-queda de pressão por meio do método dos mínimos quadrados. Uma vez que os pontos são coletados com o incremento e decréscimo da abertura da válvula, os gráficos de monitoramento da vazão e perda de carga no decorrer do tempo assumem uma forma com tendências simétricas. 


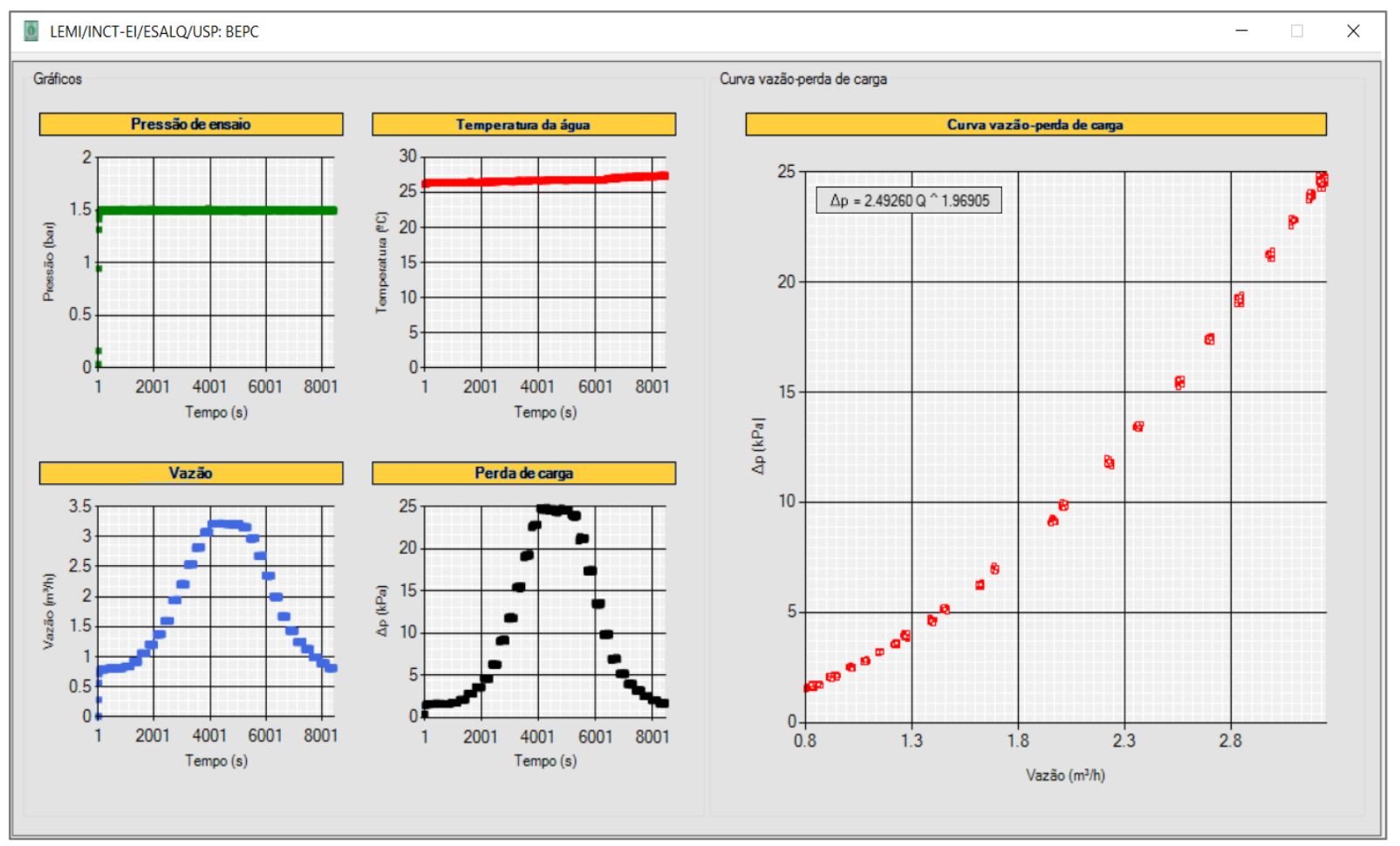

Figura 12. Tela parcial de monitoramento apresentada pelo aplicativo supervisório ao término de um ensaio.

\subsection{Material avaliado}

As conexões ensaiadas são produzidas pela empresa RSB Plásticos Ltda e são aplicáveis aos sistemas de microirrigação. Os modelos apresentados possuem diâmetro nominal para tubos de 13 a $16 \mathrm{~mm}$ e foram categorizados diante de sua aplicação, dentre eles: quatro uniões de linha, seis conectores iniciais, seis registros de união e cinco registros iniciais. Suas fotografias são apresentadas após a chamada de cada categoria.

\subsubsection{Modelos de união}

O diâmetro nominal de tubo para os modelos 0038, 0082 e 0083 é de $16 \mathrm{~mm}$ e o modelo 0081 é destinado para tubos de $13 \mathrm{~mm}$ (Figura 13). Há semelhança geométrica entre os modelos 0082 e 0083 , tendo apenas alterações no anél de fixação (anél garra e liso); nesses casos, valores próximos são esperados. Uma vantagem de se usar sistemas automatizados é a praticidade com que os ensaios são executados, então não há problema em se obter duplicidade de informação, haja visto que ainda podem servir para dar suporte a um modelo comum às características geométricas. 

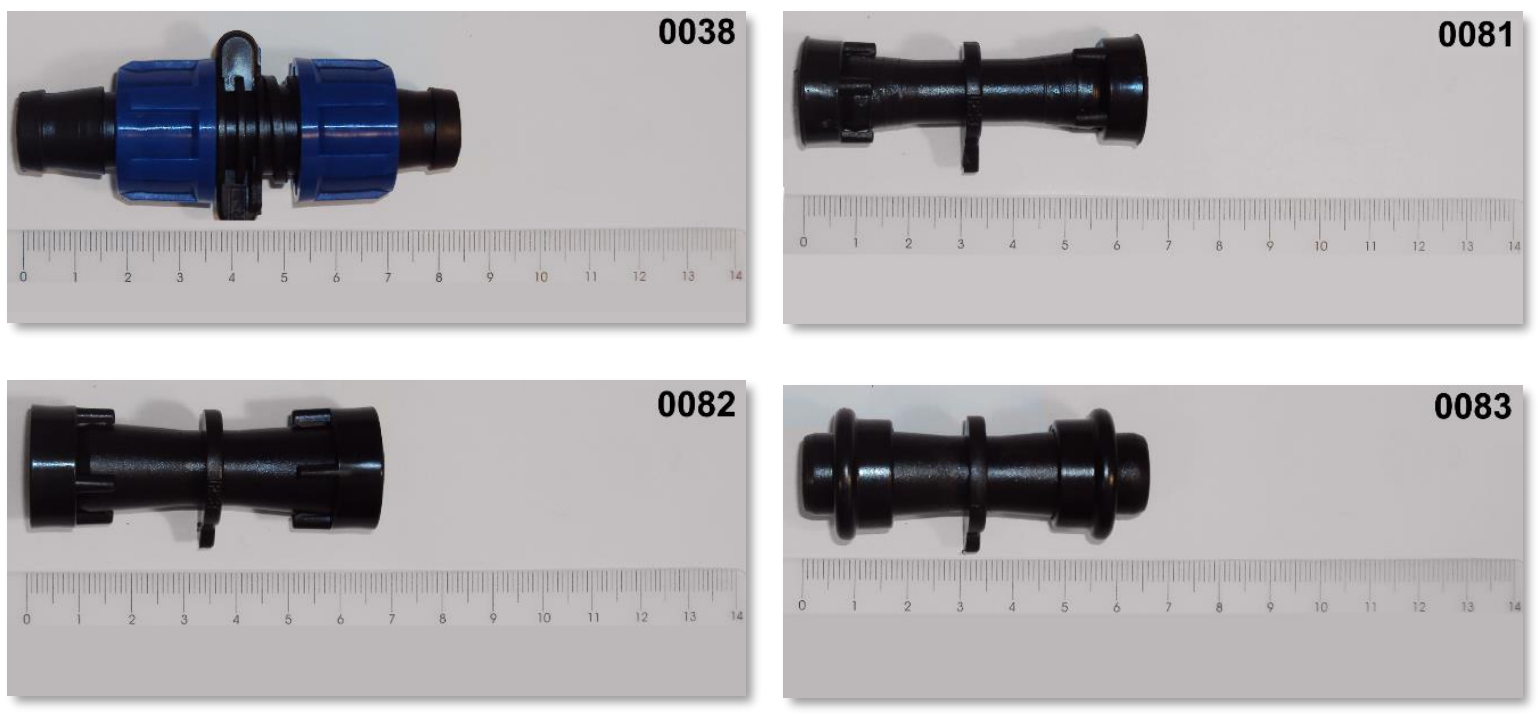

Figura 13. Modelos de união de ensaios.

\subsubsection{Modelos de conectores iniciais}

O diâmetro nominal de tubo para os modelos 0037, 0046, 0058, 0059 e 0186 é de 16 mm e o modelo 0057 é destinado para tubos de $13 \mathrm{~mm}$ (Figura 14). Os modelos 0058 e 0059 possuem semelhança geométrica, sendo alterado apenas o anél de fixação.
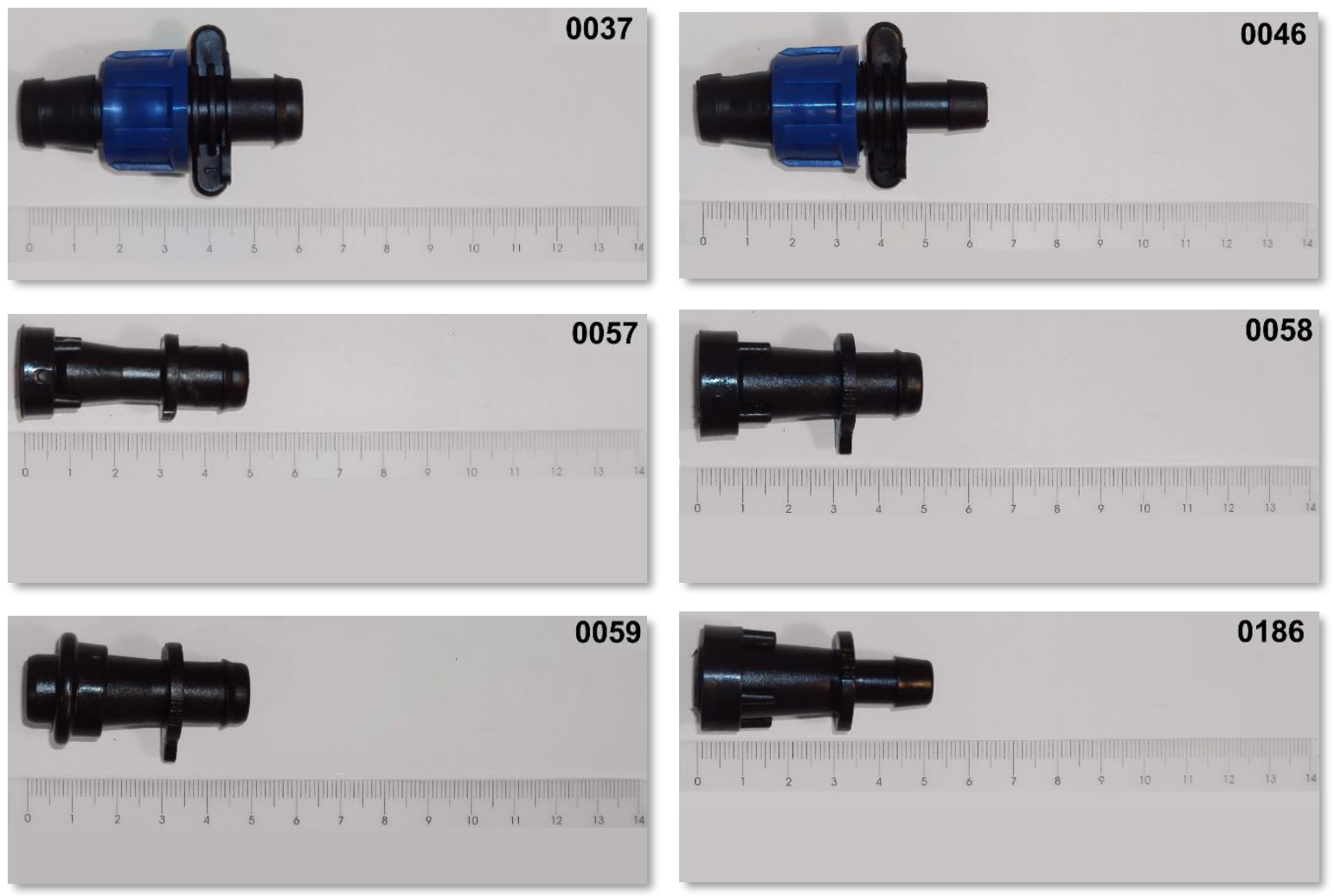

Figura 14. Modelos de conectores iniciais ensaiados. 


\subsubsection{Modelos de registros}

\subsubsection{Registros de união}

O diâmetro nominal de tubo para os modelos 0151, 212, 213, 214 e 223 é de 16 mm e o modelo 0153 é destinado para tubos de $13 \mathrm{~mm}$ (Figura 15). Há semelhança geométrica entre os modelos 0212, 0213 e 0223 ; alterando-se apenas o tipo de fixação (anél liso, garra e rosca).
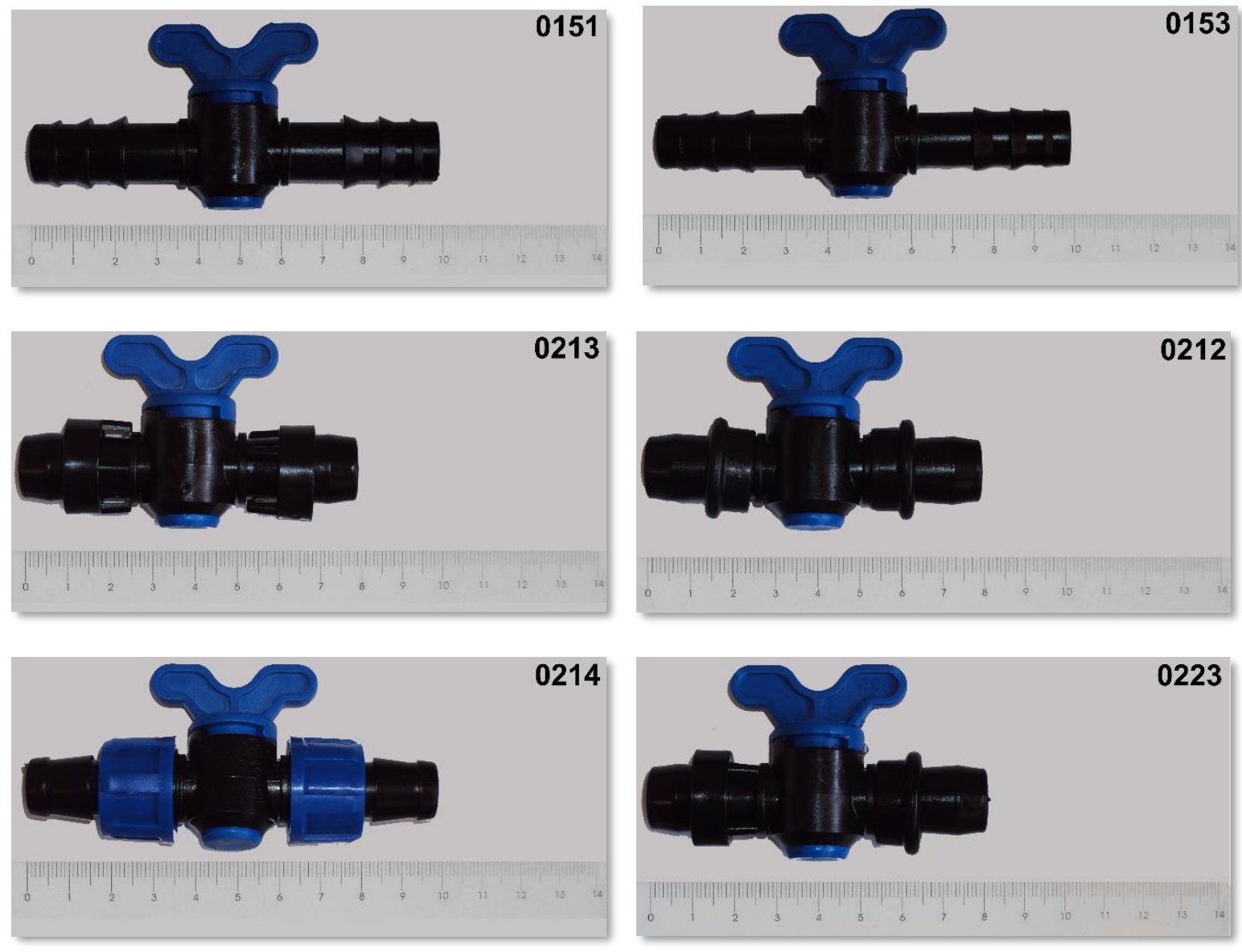

Figura 15. Modelos de registros de união ensaiados.

\subsubsection{Registros iniciais}

Esses componentes assumem papéis similares aos conectores iniciais, contudo permitem o controle manual de fluxo na linha lateral. O diâmetro nominal de tubo para os modelos 0150, 0182, 0183 e 0184 é de 16 mm e o modelo 0152 é destinado para tubos de $13 \mathrm{~mm}$ (Figura 16). Outra semelhança geométrica está presente entre os modelos 0182 e 0183. 

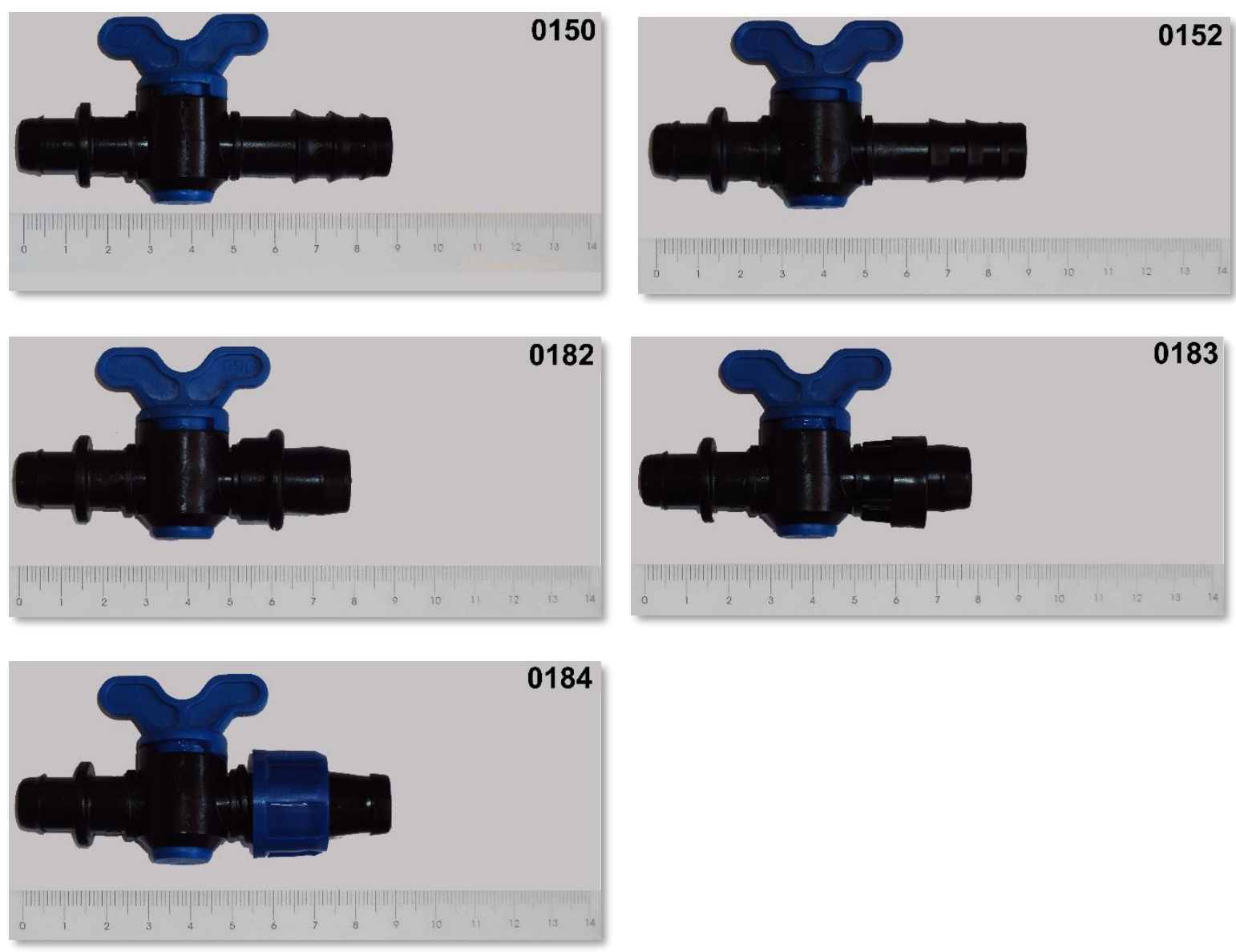

Figura 16. Modelos de registros inicias ensaiados.

\subsection{Características geométricas das peças}

A partir de um certo número de Reynolds, pode-se considerar que o efeito das forças viscosas é desprezível e o coeficiente de perda localizada de carga $\left(\mathrm{K}_{\mathrm{L}}\right)$ se torna quase que exclusivamente dependente das características geométricas da peça (RETTORE NETO et al., 2009). As dimensões dessas conexões foram extraídas por meio de um paquímetro digital, de marca Starett ${ }^{\circledR}$, com resolução de $0,01 \mathrm{~mm}$, faixa de medição de 0 a $150 \mathrm{~mm}$. Para cada modelo de conexão ensaiado foram extraídas 5 medidas por dimensão, obtendo-se um valor médio.

A Figura 17 contém o corte longitudinal dos modelos de união e conector inicial ensaiados, e as médias dos valores especificados para cada modelo são informadas, em milímetros, pela Tabela 2. 

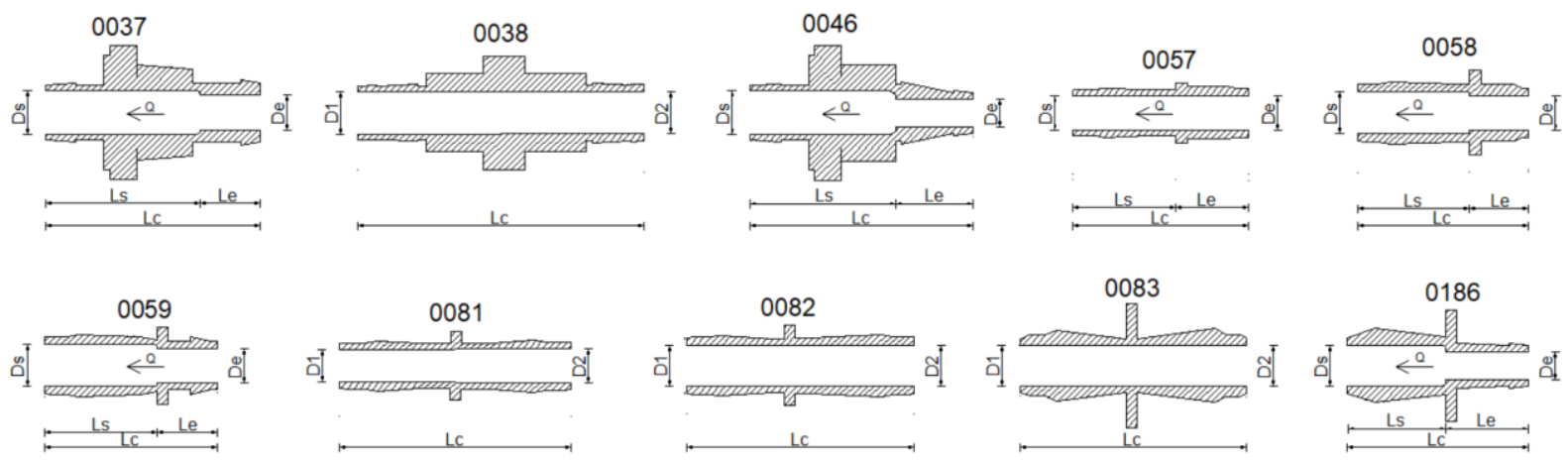

Figura 17. Corte longitudinal das uniões e conectores iniciais.

Tabela 2. Características dimensionais (médias e desvio padrão) das uniões e conectores iniciais, em milímetros.

\begin{tabular}{ccccccccccc}
\hline \multirow{2}{*}{ Código } & \multicolumn{2}{c}{$\mathrm{D}_{\mathrm{E}} \sim \mathrm{D}_{1}$} & \multicolumn{2}{c}{$\mathrm{D}_{\mathrm{S}} \sim \mathrm{D}_{2}$} & \multicolumn{2}{c}{$\mathrm{L}_{\mathrm{E}}$} & \multicolumn{2}{c}{$\mathrm{L}_{\mathrm{S}}$} & \multicolumn{2}{c}{$\mathrm{L}_{\mathrm{C}}$} \\
\cline { 2 - 11 } & $\bar{x}$ & $\pm \sigma$ & $\bar{x}$ & $\pm \sigma$ & $\bar{x}$ & $\pm \sigma$ & $\bar{x}$ & $\pm \sigma$ & $\bar{x}$ & $\pm \sigma$ \\
\hline 0037 & 9,79 & 0,04 & 12,24 & 0,03 & 16,83 & 0,17 & 43,28 & 0,16 & 60,11 & 0,05 \\
0038 & 11,74 & 0,06 & 12,17 & 0,05 & - & - & - & - & 79,99 & 0,10 \\
0046 & 7,95 & 0,03 & 12,36 & 0,03 & 21,63 & 0,23 & 40,83 & 0,27 & 62,46 & 0,07 \\
0057 & 9,64 & 0,02 & 9,66 & 0,03 & 18,47 & 0,22 & 30,77 & 0,26 & 49,24 & 0,10 \\
0058 & 9,69 & 0,03 & 11,65 & 0,03 & 16,43 & 0,36 & 31,43 & 0,35 & 47,86 & 0,08 \\
0059 & 9,72 & 0,03 & 11,68 & 0,04 & 16,83 & 0,41 & 31,37 & 0,41 & 48,20 & 0,04 \\
0081 & 9,66 & 0,05 & 9,19 & 0,02 & - & - & - & - & 64,68 & 0,12 \\
0082 & 11,23 & 0,05 & 11,63 & 0,03 & - & - & - & - & 63,46 & 0,15 \\
0083 & 11,60 & 0,03 & 11,17 & 0,03 & - & - & - & - & 63,48 & 0,14 \\
0186 & 7,82 & 0,03 & 11,60 & 0,03 & 22,93 & 0,58 & 27,56 & 0,33 & 50,49 & 0,41 \\
\hline
\end{tabular}

De metodologia semelhante, foi estimado as características dimensionais das classes de registros. Os cortes longitudinais dos registros ensaiados, tanto de união quanto inicial, são apresentados pela Figura 18.
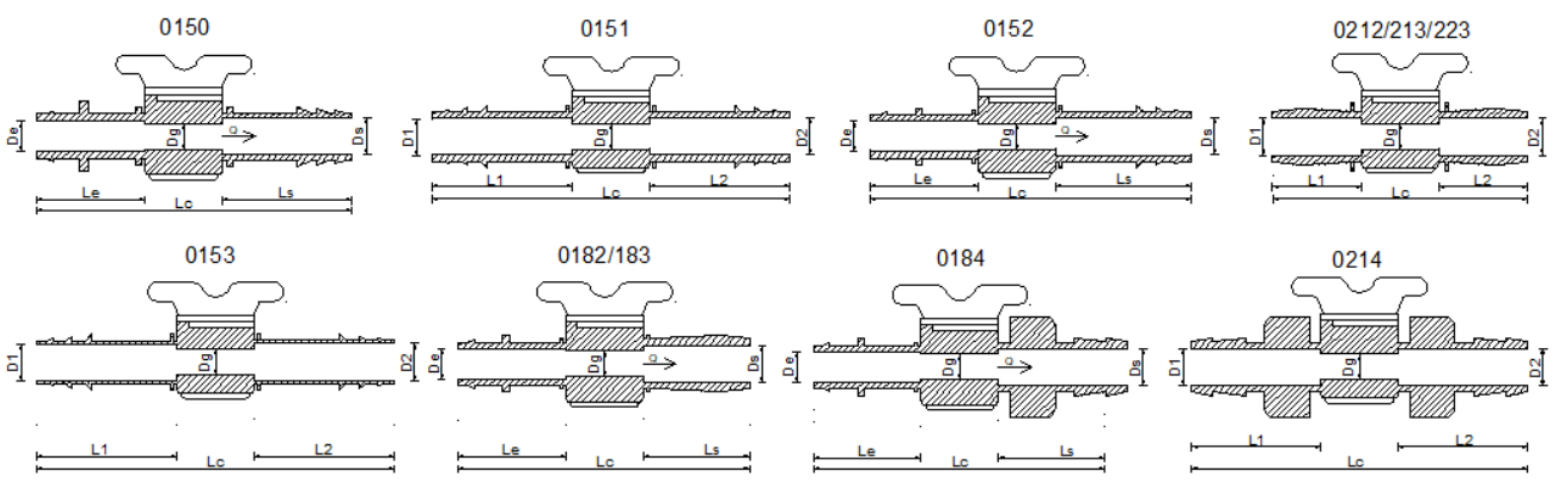

Figura 18. Corte longitudinal dos registros de união e registros iniciais ensaiados.

Haja visto o estreitamento na seção de articulação do registro, fez-se necessário estimar o seu diâmetro reduzido de garganta $\left(\mathrm{D}_{\mathrm{G}}\right)$ com uso de um projetor ótico Starrett ${ }^{\circledR}$ HB400 (Figura 19) disposto nas dependências do laboratório. O fenômeno da passagem na garganta é dado por uma contração e expansão brusca no escoamento. Os valores do diâmetro foram estimados pela média de cinco peças do mesmo modelo, os quais foram obtidos por meio de 8 pontos de coordenadas $\left(45^{\circ}\right)$. Possíveis peças irregulares (Figura 19B) foram descartadas do grupo de amostras e 
substituídas dos ensaios hidráulicos, de modo que o coeficiente de variação do diâmetro entre peças do mesmo modelo tenha atingido um máximo de 2,097\%. A média dessas dimensões obtidas é informada pela Tabela 3.

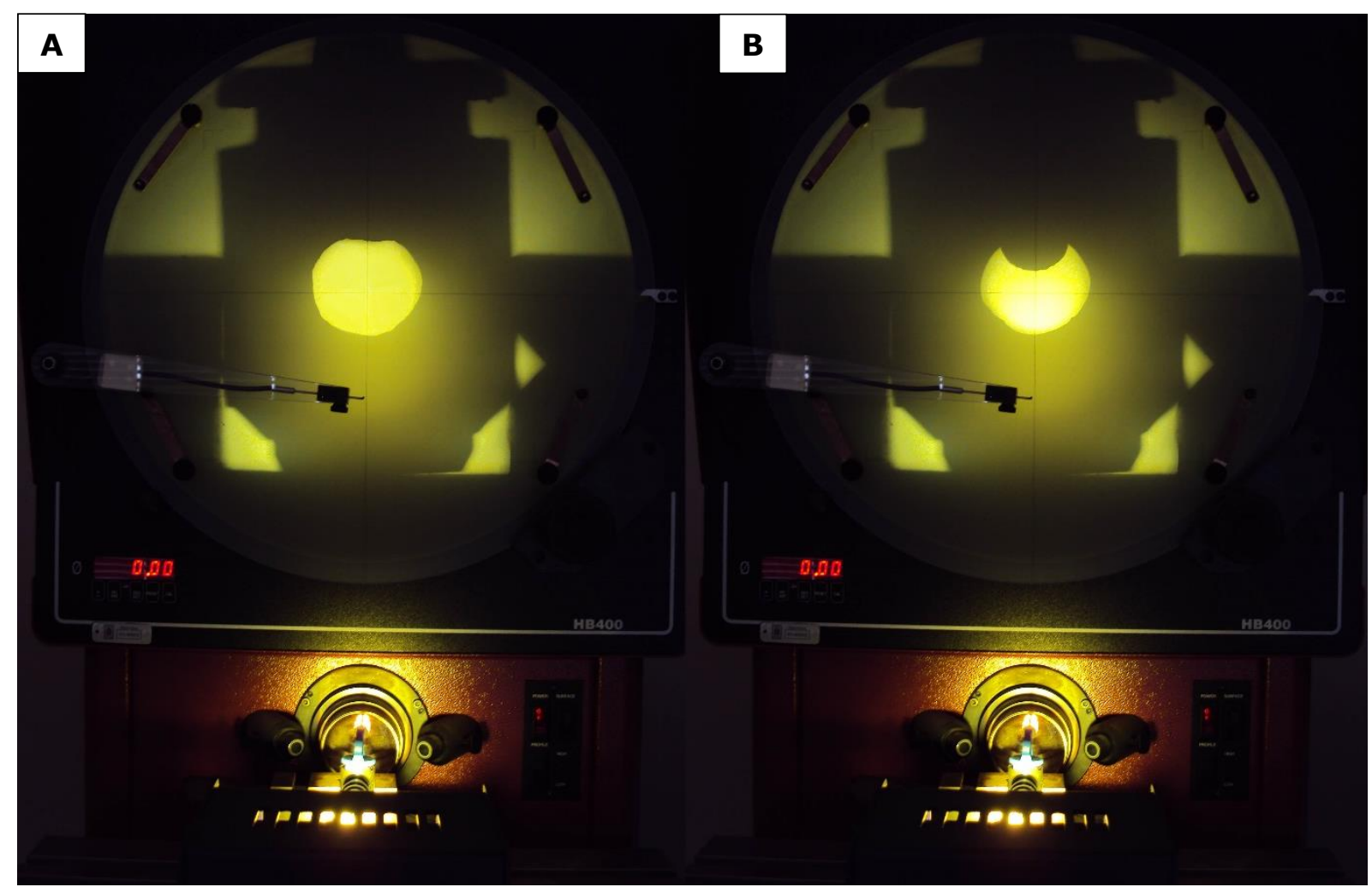

Figura 19. Projetor ótico Starret HB400 utilizado para determinação do diâmetro da garganta em registros sendo (a) peça regular caracterizada e (b) peça com irregularidade descartada do grupo.

Tabela 3. Características dimensionais (médias e desvio padrão) dos registros de união e registros iniciais, em milímetros.

\begin{tabular}{lcccccccccccc}
\hline \multirow{2}{*}{ Código } & \multicolumn{3}{c}{$\mathrm{D}_{\mathrm{E}} \sim \mathrm{D}_{1}$} & \multicolumn{2}{c}{$\mathrm{D}_{\mathrm{S}} \sim \mathrm{D}_{2}$} & \multicolumn{2}{c}{$\mathrm{D}_{\mathrm{G}}$} & \multicolumn{2}{c}{$\mathrm{L}_{\mathrm{E}}$} & \multicolumn{2}{c}{$\mathrm{L}_{\mathrm{S}}$} & \multicolumn{3}{c}{$\mathrm{L}_{\mathrm{C}}$} \\
\cline { 2 - 12 } & $\bar{x}$ & $\pm \sigma$ & $\bar{x}$ & $\pm \sigma$ & $\bar{x}$ & $\pm \sigma$ & $\bar{x}$ & $\pm \sigma$ & $\bar{x}$ & $\pm \sigma$ & $\bar{x}$ & $\pm \sigma$ \\
\hline 150 & 9,51 & 0,04 & 11,59 & 0,01 & 7,55 & 0,16 & 33,44 & 0,48 & 43,14 & 0,80 & 89,99 & 0,12 \\
151 & 11,53 & 0,04 & 11,64 & 0,01 & 7,65 & 0,39 & 43,67 & 0,97 & 43,17 & 1,41 & 100,56 & 0,09 \\
152 & 9,46 & 0,02 & 11,61 & 0,06 & 7,59 & 0,08 & 33,48 & 0,89 & 42,39 & 0,52 & 90,06 & 0,10 \\
153 & 11,50 & 0,12 & 11,58 & 0,11 & 7,98 & 0,11 & 43,16 & 0,62 & 43,35 & 0,65 & 100,37 & 0,05 \\
$0182 /$ & 9,51 & 0,03 & 11,51 & 0,02 & 7,57 & 0,05 & 33,57 & 0,81 & 33,18 & 0,91 & 79,66 & 0,03 \\
0183 & 9,48 & 0,05 & 11,51 & 0,08 & 7,62 & 0,12 & 33,88 & 0,32 & 42,97 & 1,80 & 90,37 & 0,50 \\
0184 & & & & & & & & & & & & \\
$0212 /$ & 11,48 & 0,02 & 11,48 & 0,12 & 7,95 & 0,17 & 32,68 & 1,10 & 32,82 & 1,01 & 79,62 & 0,10 \\
$0213 /$ & & & & & & & & & & & & \\
0223 & 11,58 & 0,06 & 11,60 & 0,03 & 7,56 & 0,29 & 42,98 & 0,46 & 43,30 & 0,77 & 99,79 & 0,03 \\
214 & & & & & & & & & & & &
\end{tabular}

\subsection{Módulos de ensaios}

Os módulos respeitam a ordem de 2D e 10D (montante e jusante). Uma medição do diâmetro interno dos tubos de polietileno foi realizada por meio do paquímetro digital. Os valores foram estimados numa média de 3 mensurações de dez trechos novos de tubo, sendo estimados no segmento com cuidado para não forçar um formato elíptico. Os diâmetros internos dos tubos comerciais da Plasnova ${ }^{\circledR}$ de $13 \mathrm{~mm}$ e $16 \mathrm{~mm}$ ficaram estimados pela média 
de 13,697 mm e 16,388 mm. Rocha (2014) utilizou um projetor ótico para medição do diâmetro interno, encontrando valores próximos a esses obtidos, sendo de 13,120 mm e 16,818 mm para esses diâmetros nominais correspondentes.

Uma mangueira de silicone promoveu o estanque para inserção das tomadas de pressão no tubo com resultado satisfatório. Posteriormente ao encaixe dos colares, foi realizado uma furação centralizada no tubo com uma broca de $2 \mathrm{~mm}$, estabelecido como um diâmetro mínimo de furo (ISO, 2008). Uma microretífica Dremel 3000 foi utilizada para o serviço de furo e acabamento no material, retirando possíveis resíduos do polietileno após a abertura de sua parede. Esse cuidado é importante para evitar zonas de baixa pressão durante o escoamento e, consequentemente, obter qualidade nos resultados.

\subsubsection{Módulos para união}

O espaçamento adequado para inserção das tomadas de pressão (Figura 20) foi determinado pelo diâmetro do tubo obtido anteriormente. O arranjo experimental de união foi construído para cada diâmetro e se instala retilineamente com a saída da bancada.

No tubo de $16 \mathrm{~mm}$ (Figura 20B) foi adotado um par de colares produzidos pela Irritec ${ }^{\circledR}$, fabricados para acoplamento de tubos com diâmetros de 20 milímetros. Um segmento de tubo PVC serrado ao meio contribuiu para suprir essa diferença dimensional junto com a espessura da mangueira de silicone. No tubo de 13 mm (Figura 20A) foi alocado um par de castanhas (semi-círculo) confeccionadas em poliamida náilon, tendo seu aperto fixado por uma dupla de abraçadeiras. A junção das castanhas foi desgastada suavemente até se obter um aperto adequado, sem estrangular o tubo e sem vazamentos.

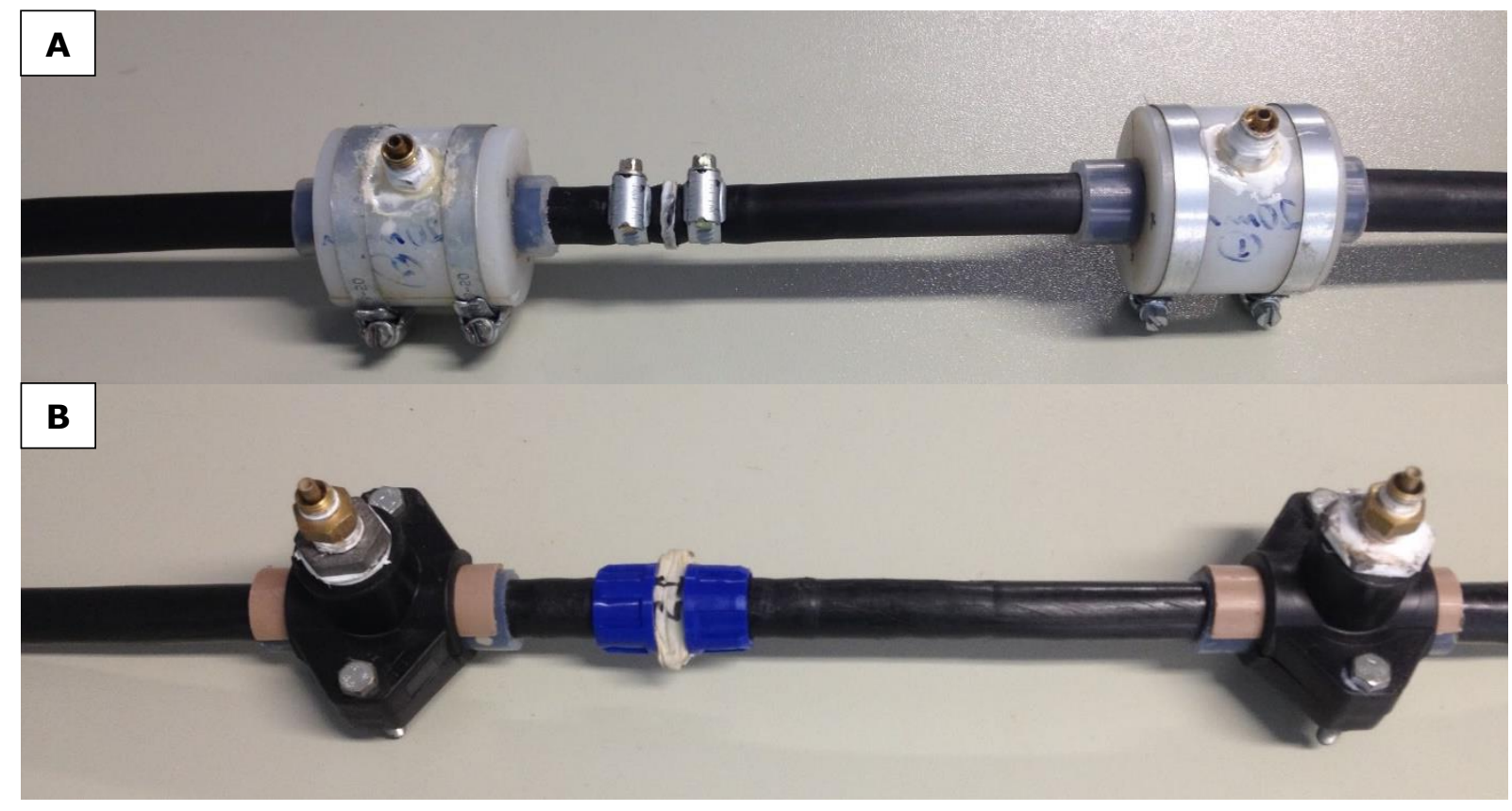

Figura 20. Arranjo dos trechos experimentais para uniões com diâmetros nominais de (a) 13 e (b) 16 milímetros; com sentido de fluxo da esquerda para direita. 


\subsubsection{Módulos para conectores iniciais}

Um tubo rígido PVC DN 50 foi alocado perpendicularmente com a saída da bancada para inserção dos conectores iniciais. De acordo com Vilaça (2012), a perda localizada de carga pela passagem lateral é diretamente proporcional a uma potência do diâmetro de saída e comprimento do conector, da velocidade de escoamento na entrada do conector e do tubo de polietileno; não tendo o diâmetro do tubo rígido maiores significâncias no cálculo. Conforme esse autor, a tubulação onde os conectores são inseridos pode ser imaginado como um reservatório, e por isso não interfere na perda localizada de carga. O conector inicial é inserido também após uma distância de 10 diâmetros do início do tubo rígido (50 centímetros) para assegurar a estabilização do fluxo no conduto. Uma ventosa foi instalada na extremidade do tubo rígido, a fim de evitar a permanência de um bolsão de ar durante o preenchimento da seção do tubo com água.

Os conectores iniciais são fixados e vedados com o tubo rígido por meio de um anel de vedação bilabial, de borracha, comumente denominado de "chula". Cada conector possui seu anel de vedação recomendado pelo fabricante. Os dois anéis empregados nos ensaios de tais conexões, são representados pela Figura 21.

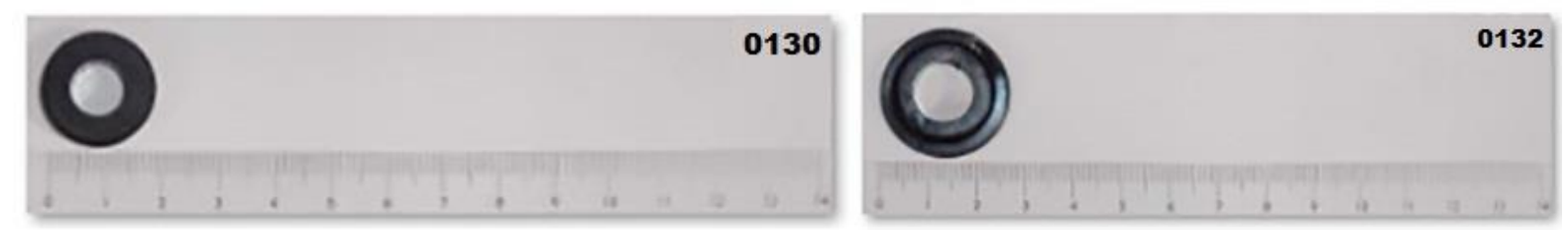

Figura 21. Anéis de vedação bilabiais empregados para alocação dos conectores iniciais na linha de derivação.

Os conectores iniciais com diâmetros inferiores de engate com a linha de derivação (0046 e 0186) fazem uso do código 0130. Já os que possuem diâmetros superiores $(0037,0057,0058,0059)$ adotam o modelo de código 0132. Os ensaios respeitaram a ordem crescente de perfuração do tubo rígido para inserção do anél de vedação, onde foram utilizadas brocas com diâmetros de guia de $12,70 \mathrm{~mm}(1 / 2$ ”) e 17,46 mm (11/16”) para a inserção, respectiva, dos modelos 0130 e 0132. O acompanhamento dessa informação pelo fabricante é bastante útil para promover seu uso eficiente.

Um maior detalhamento dos anéis de vedação bilabiais pode ser observado e analisado de acordo com a ilustração da Figura 22, na qual seguem os respectivos dimensionais por meio da Tabela 4. Muito embora, as geometrias desses anéis variem após sua inserção no tubo, sofrendo uma compressão desejada do material com a peça conectora. 


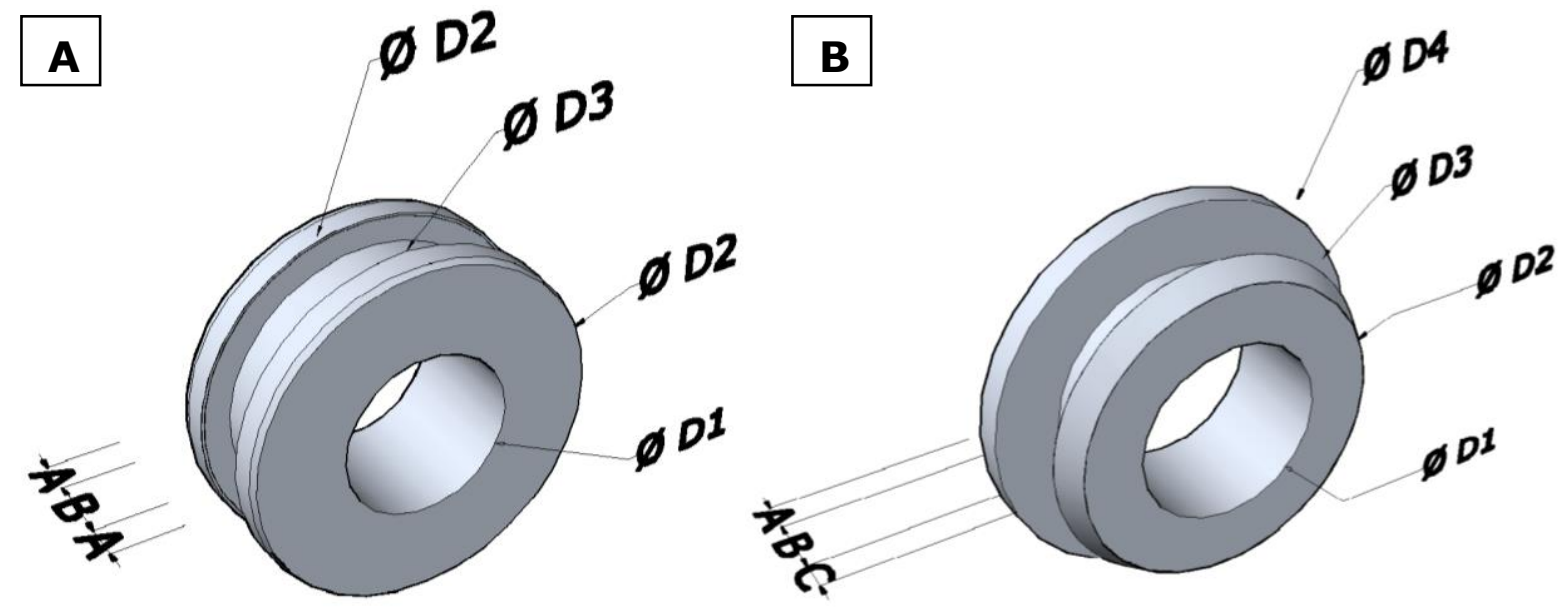

Figura 22. Características dimensionais dos anéis de vedação (a) 0130 e (b) 0132.

Os valores informados pela Tabela 4 foram extraídos de 5 leituras, obtidas por paquímetro digital, acima de uma única peça. Essas informações podem ser úteis para uma análise detalhada da área de protrusão na passagem direta pela linha de derivação.

Tabela 4. Indicação das características dimensionais (média e desvio padrão) dos anéis de vedação reportados, em milímetros.

\begin{tabular}{|c|c|c|c|c|c|c|c|c|c|c|c|c|c|c|}
\hline \multirow{2}{*}{ Código } & \multicolumn{2}{|c|}{ A } & \multicolumn{2}{|c|}{ B } & \multicolumn{2}{|c|}{$\mathrm{C}$} & \multicolumn{2}{|c|}{ D1 } & \multicolumn{2}{|c|}{ D2 } & \multicolumn{2}{|c|}{ D3 } & \multicolumn{2}{|c|}{ D4 } \\
\hline & $\bar{x}$ & $\pm \sigma$ & $\bar{x}$ & $\pm \sigma$ & $\bar{x}$ & $\pm \sigma$ & $\bar{x}$ & $\pm \sigma$ & $\bar{x}$ & $\pm \sigma$ & $\bar{x}$ & $\pm \sigma$ & $\bar{x}$ & $\pm \sigma$ \\
\hline 130 & 1,99 & 0,09 & 4,41 & 0,10 & - & - & 9,53 & 0,13 & 19,57 & 0,20 & 13,09 & 0,27 & - & - \\
\hline 132 & 2,84 & 0,13 & 3,80 & 0,11 & 1,95 & 0,18 & 12,88 & 0,15 & 20,98 & 0,13 & 17,53 & 0,15 & 26,53 & 0,16 \\
\hline
\end{tabular}

\subsection{Grupos adimensionais categorizados}

De acordo com Vilaça et al. (2017), a perda localizada de carga ocasionada na passagem lateral de um conector inicial pode ser descrita por ser função do escoamento através do conector, das propriedades do fluido e características geométricas da linha de derivação, conector e linha lateral. Os autores consideraram que nove variáveis $(k=9)$ possam influenciar no decréscimo da energia pela passagem do conector. Entretanto, o estudo acaba por mostrar que os dados observados de perda localizada apresentaram valores muito próximos dos ensaios com diâmetros de derivação diferente $(35,50$ e $75 \mathrm{~mm})$, sendo constatado que os efeitos geométricos da derivação podem ser negligenciados.

O processo físico envolve três grandezas básicas (MLT), e nesse caso será considerado o comprimento de segmentação dos diâmetros, assimiliado assim um grupo de nove fatores, sugerindo que possam ser extraídos até 6 grupos adimensionais. Inicialmente foram concebidos os termos Pi para os conectores inicias (eq. 30), os quais foram definidos combinando as variáveis repetitivas $\left(V_{L}, D_{L}\right.$ e $\left.\rho\right)$ com as demais variáveis. Os grupos adimensionais propostos foram baseados no que é exposto por Vilaça et al. (2017), mas mantém a diferença de usar o comprimento do conector segmentado pela entrada e saída. Acima disso, os fatores para modelos de união sofreram uma simplificação (eq. 31), sendo que os termos separados do diâmetro de entrada e saída do conector foram reduzidos a um único termo do diâmetro interno da peça (valor médio) pois não é esperado uma seção variada em sua fabricação, e assim será utilizado o comprimento total da peça. Já nos registros de união (eq. 32) se propôs sete 
grupos adimensionais, pois será incluído uma relação do diâmetro interno da garganta com o diâmetro do tubo $\left(\mathrm{D}_{\mathrm{G}} / \mathrm{D}_{\mathrm{T}}\right)$ e seu comprimento correspondente. Nos registros de conexões iniciais (eq. 33) foi considerado todos intervalos dimensionais, mantendo a expressão com oito termos. Se houver redundância de algum termo, pode-se optar por uma maior simplificação.

$$
\begin{gathered}
\frac{\Delta p_{c}}{\rho V_{L}^{2}}=\phi\left(\frac{\rho \mathrm{V}_{L} \mathrm{D}_{\mathrm{L}}}{\mu}, \frac{D_{E}}{\mathrm{D}_{\mathrm{L}}}, \frac{D_{S}}{\mathrm{D}_{\mathrm{L}}}, \frac{\mathrm{L}_{E}}{\mathrm{D}_{\mathrm{L}}}, \frac{\mathrm{L}_{S}}{\mathrm{D}_{\mathrm{L}}}\right) \\
\frac{\Delta p_{c}}{\rho V_{L}^{2}}=\phi\left(\frac{\rho \mathrm{V}_{L} \mathrm{D}_{\mathrm{L}}}{\mu}, \frac{D_{i}}{\mathrm{D}_{L}}, \frac{L_{c}}{\mathrm{D}_{L}}\right) \\
\frac{\Delta p_{c}}{\rho V_{L}^{2}}=\phi\left(\frac{\rho \mathrm{V}_{L} \mathrm{D}_{\mathrm{L}}}{\mu}, \frac{D_{i}}{\mathrm{D}_{\mathrm{L}}}, \frac{D_{G}}{\mathrm{D}_{\mathrm{L}}}, \frac{L_{E}}{\mathrm{D}_{\mathrm{L}}}, \frac{L_{S}}{\mathrm{D}_{\mathrm{L}}}, \frac{L_{G}}{\mathrm{D}_{\mathrm{L}}}\right) \\
\frac{\Delta p_{c}}{\rho V_{L}^{2}}=\phi\left(\frac{\rho \mathrm{V}_{L} \mathrm{D}_{\mathrm{L}}}{\mu}, \frac{D_{E}}{\mathrm{D}_{\mathrm{L}}}, \frac{D_{S}}{\mathrm{D}_{\mathrm{L}}}, \frac{D_{G}}{\mathrm{D}_{\mathrm{L}}}, \frac{L_{E}}{\mathrm{D}_{\mathrm{L}}}, \frac{L_{S}}{\mathrm{D}_{\mathrm{L}}}, \frac{L_{G}}{\mathrm{D}_{\mathrm{L}}}\right)
\end{gathered}
$$

Sendo padronizado a ordem $\prod_{1}=\prod_{2}, \prod_{3}, \ldots, \prod_{\mathrm{n}}$

Os dados experimentais foram utilizados para aproximação dos coeficientes de uma regressão múltipla do tipo potência (eq. 34) por meio de método dos mínimos quadrados entre os valores estimados pelo modelo desenvolvido com os valores observados do termo Pi dependente (número de Euler). Perboni (2015) fez uso dessa regressão múltipla do tipo potência para ajustar o modelo de perda de carga em linhas laterais, sendo também adotado por Vilaça et al. (2017) para predição de perda localizada na passagem lateral de conectores iniciais.

$$
\Pi_{1}=\beta_{1} \Pi_{2}^{\beta_{2}} \Pi_{3}^{\beta_{3}} \ldots \Pi_{n}^{\beta_{n}}
$$

Em que, $\beta$ i corresponde aos coeficientes aproximados.

\subsection{Determinações hidráulicas}

Os modelos foram ensaiados com cinco e dez peças uniformes de um mesmo lote. Recomenda-se uma curva vazão-queda de pressão que contenha, no mínimo, 5 condições de vazão (ISO, 2008). Nesse trabalho, as curvas relacionando vazão e queda de pressão foram elaboradas acima de 15 condições, submetidas sob uma constante pressão de entrada de $150 \mathrm{kPa}$ e construídas sob condição crescente e decrescente para incluir eventuais efeitos de histerese. O intervalo de vazão abrange a abertura do retorno para uma vazão mínima de operação até sua abertura máxima, retornando posteriormente até sua posição de origem em passos constantes. Para cada condição de 
abertura são coletados 30 pontos (vazão-queda de pressão) proporcionando que as médias amostrais se aproximassem de uma distribuição normal.

Adicionalmente, os valores da temperatura da água foram monitorados continuamente durante os ensaios. A partir dos dados obtidos, foram ajustadas equações potenciais para estimativa de perda localizada de carga. Para cada modelo de conexão avaliado apresentam-se as seguintes informações: regressão do tipo potência da perda localizada de carga em função de vazão, coeficiente de perda localizada de carga $\left(K_{L}\right)$ e comprimento equivalente da peça (Leq).

O comprimento equivalente (Leq) é relacionado com o diâmetro do tubo da linha lateral. Por critério de prática usual e conservacionista foi considerado o coeficiente de atrito $f$ determinado por Swamee (1993) através de um Reynolds estimado com velocidade média de escoamento de $1,50 \mathrm{~m} \mathrm{~s}^{-1}$ e temperatura da água a $20^{\circ} \mathrm{C}$. 


\section{RESULTADOS E DISCUSSÃO}

\subsection{Bancada de ensaios}

Uma bancada móvel (Figura 23) foi montada utilizando perfil em alumínio (45 mm x $45 \mathrm{~mm}$ ). Uma chapa perfurada de ferro, com pintura eletrostática, foi posta acima da superfície, para suspender o arranjo determinado pela natureza de ensaio, numa dimensão de 2,00 m de comprimento por 0,90 m de largura, e é elevada a 1,00 m do plano do solo. Sua mobilidade permite independência de espaço para condução de outros ensaios (como de perda distribuída de carga) e acoplamento com o reservatório desejado. A alocação das tomadas de pressão abaixo da cota da peça amostral evita que se faça necessário a retirada de ar dos microtubos após cada troca de peça.

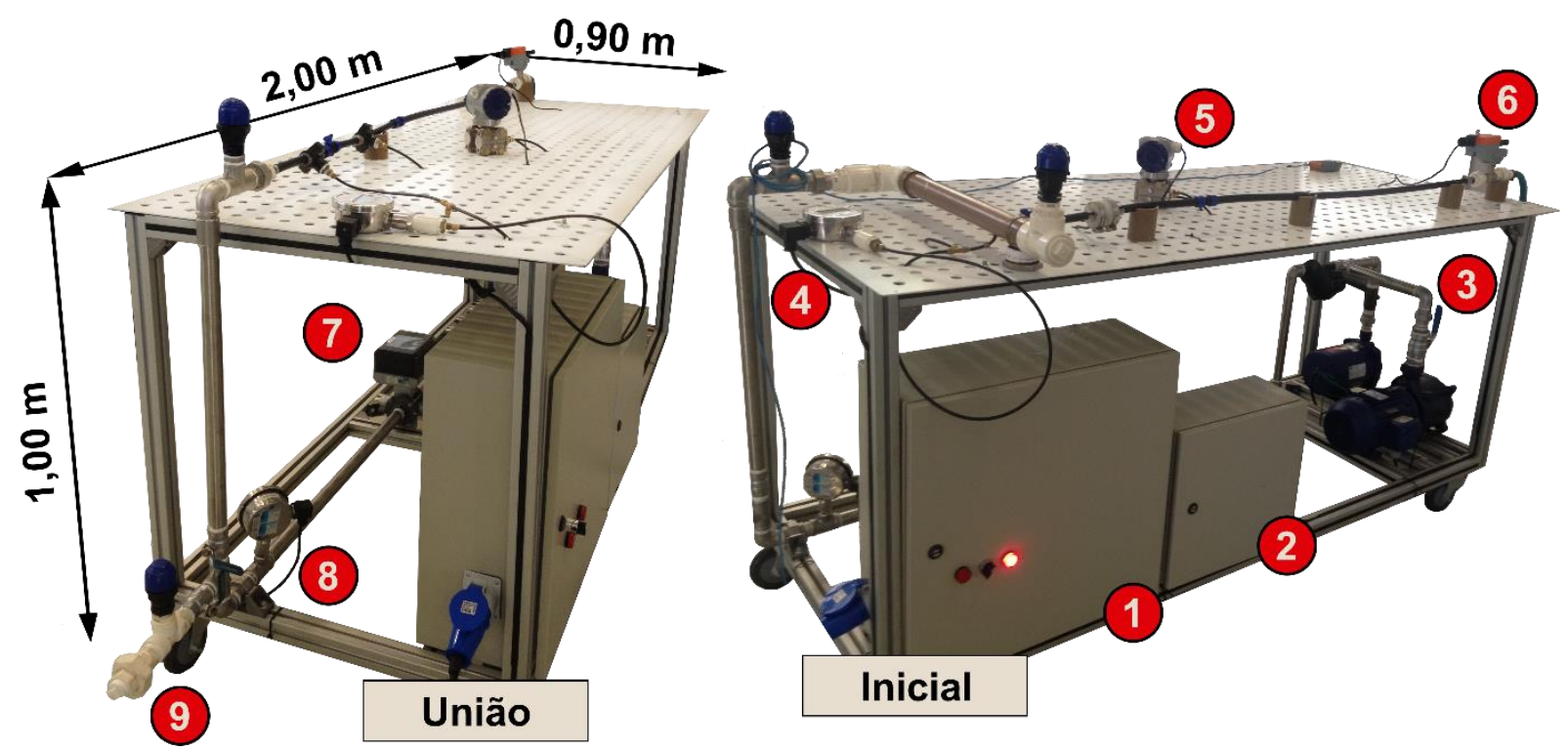

Figura 23. Arranjo experimental instalado na bancada para ensaios de conexões de união (esquerda) e conexões iniciais (direita); em que, (1) painel de potência, (2) painel de comando, (3) conjunto motobomba, (4) transmissor de pressão, (5) transmissor de pressão diferencial, (6) registro de retorno, (7) medidor de vazão eletromagnético, (8) transmissor de temperatura e (9) ramificação para ensaios de perda distribuída.

$\mathrm{Na}$ Figura 24 são detalhados os painéis elétricos abertos. O painel de potência (esquerda) contém dois inversores de frequência (de mesmo modelo) configurados com os parâmetros respectivos de cada bomba e programados para agir remotamente, os quais mantém sua energização condicionada por meio de uma chave seletora inclusa na parte externa do painel. Isso se oferece como uma opção facilitada para condicionamento de testes que demandem mais pressurização do sistema (como ensaios de resistência à pressão). 


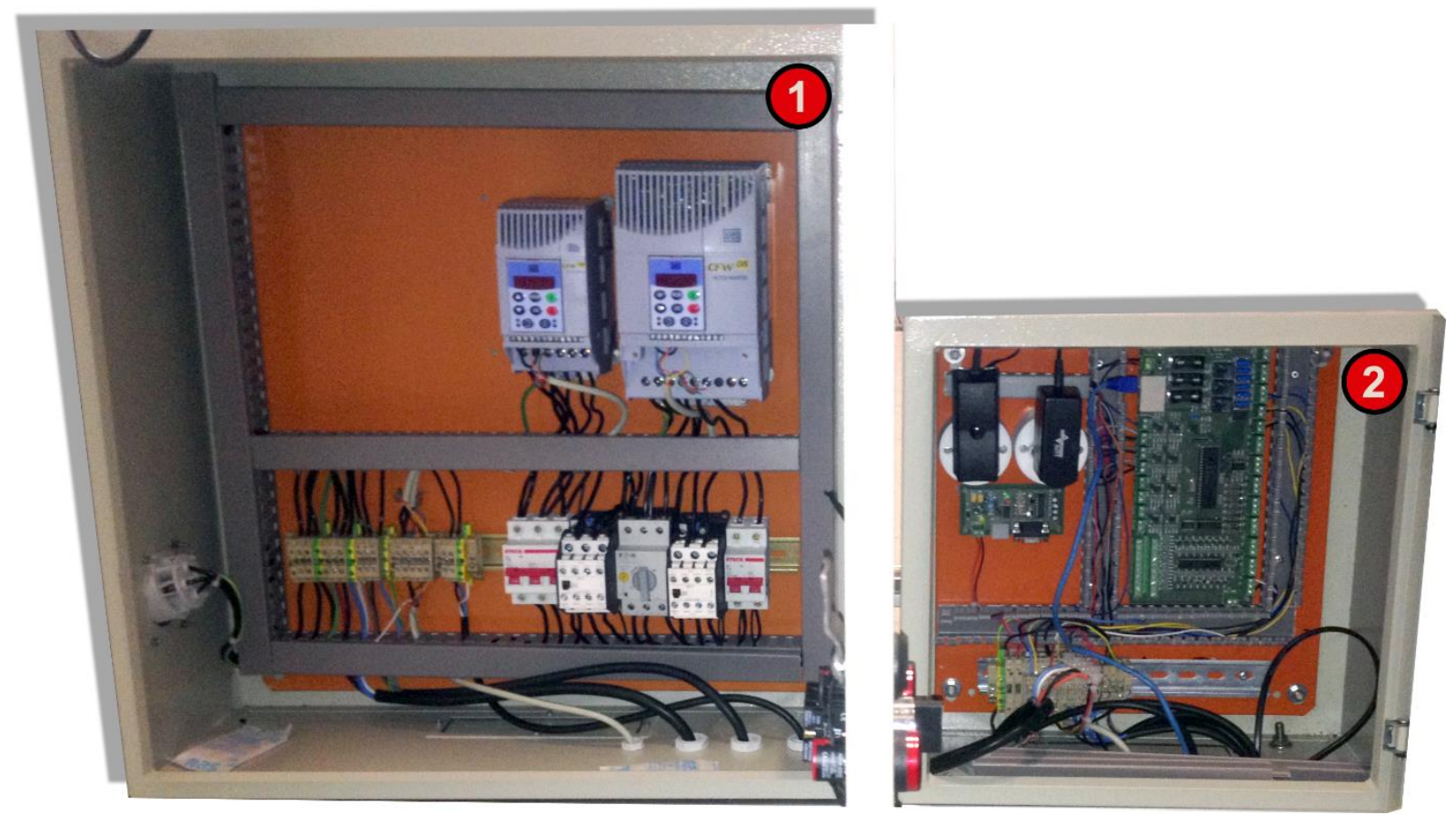

Figura 24. Disposição dos painéis elétricos de (1) potência e (2) comando, instalados na bancada.

Um disjuntor bipolar é responsável pelo controle das fontes de alimentação (placa e sensores) do painel de comando (direita). O painel de comando contém as fontes de 24 VCC, interface de comunicação (RS-485/PC) e placa de aquisição e controle.

\subsection{Ensaios preliminares de validação}

\subsubsection{Estabilidade}

A Figura 25 apresenta gráficos de controle utilizados para monitoramento da média e da variabilidade da pressão de ensaio. Dada a pressão de ensaio de 1,50 bar (150 kPa), estabelecida como alvo, os limites superior e inferior de especificação foram de 1,53 e 1,47 bar, respectivamente. Tanto a média quanto a variabilidade da pressão de ensaio mantiveram-se dentro dos limites de controle e de especificação, o que aponta para um processo sob controle em quaisquer das vazões avaliadas. Desse modo, o sistema utilizado para controle e monitoramento da pressão de ensaio mostrou-se apto a manter o valor dessa variável próximo do alvo desejado e sob variabilidade aceitável. Sobretudo, as observações indicam a pressão de ensaio manteve-se dentro dos limites de especificação estabelecidos na norma ISO 9644:2008. 

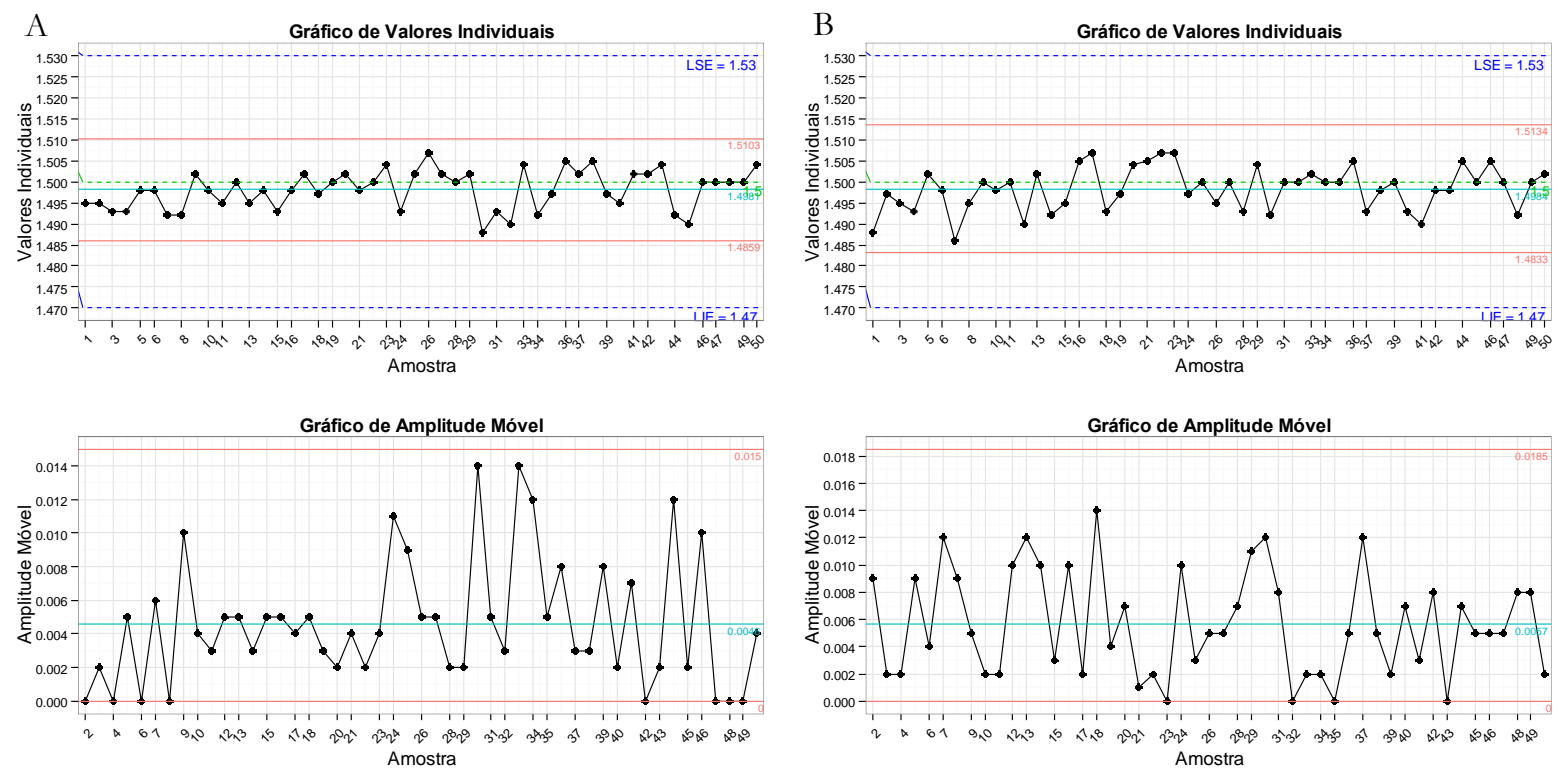

Figura 25. Gráficos de controle para monitoramento da média e da variabilidade da pressão de ensaio (valor alvo $=1,5$ bar) $\operatorname{sob}$ duas vazões: (A) vazão baixa, $0,90 \mathrm{~m}^{3} \mathrm{~h}^{-1}$; (B) vazão elevada, $2,70 \mathrm{~m}^{3} \mathrm{~h}^{-1}$.

A Figura 26 apresenta gráficos de controle utilizados para monitoramento da média e da variabilidade da vazão. A pressão de ensaio em ambos os testes foi mantida em 1,50 bar. Tanto a média quanto a variabilidade da pressão de ensaio apontam para um processo sob controle em quaisquer das vazões avaliadas. A Figura 26A apresenta limites de especificação mais estreitos que os limites de controle do processo. De qualquer modo, a vazão manteve-se dentro dos limites de controle e de especificação em quaisquer das condições avaliadas.

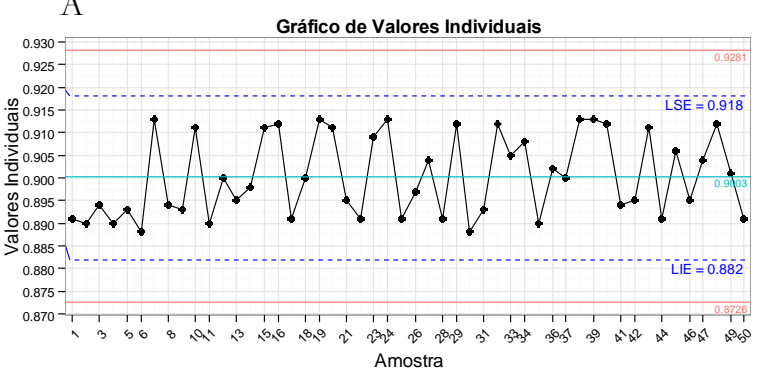

Gráfico de Amplitude Móvel

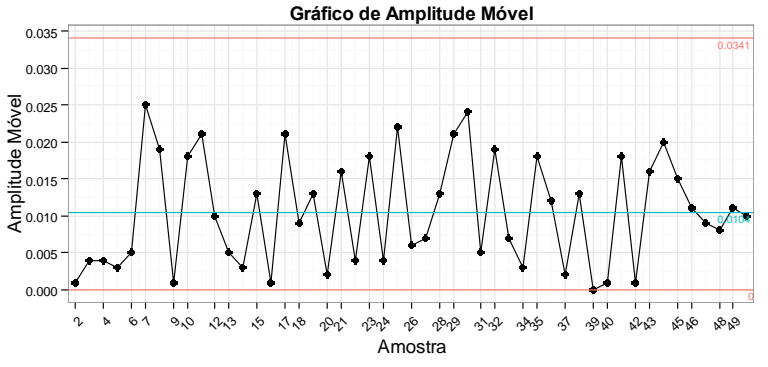

B
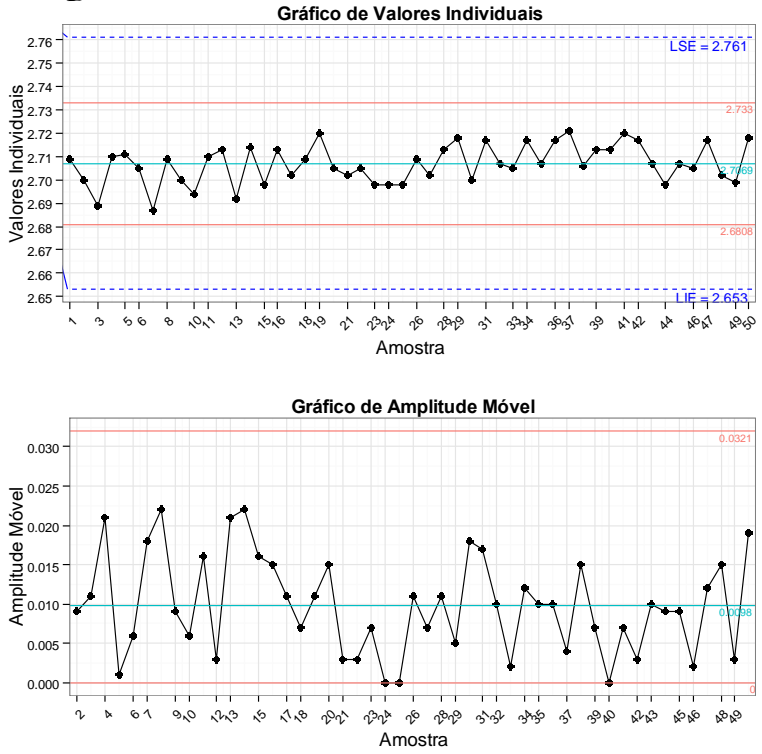

Figura 26. Gráficos de controle para monitoramento da média e da variabilidade da vazão: (A) vazão baixa, $0,90 \mathrm{~m}^{3} \mathrm{~h}^{-1}$; (B) vazão elevada, $2,70 \mathrm{~m}^{3} \mathrm{~h}^{-1}$.

A Figura 27 apresenta gráficos de controle utilizados para monitoramento da média e da variabilidade da temperatura da água. Na condição de ensaio sob baixa vazão, a temperatura da água se manteve também dentro dos 
limites de controle, indicando um processo sob controle. Entretanto, na condição de vazão elevada, tanto no gráfico de médias quanto de amplitude, observa-se pontos além dos limites de controle. Os valores mínimo e máximo observados na condição de vazão elevada foram 23.37 e $23.56{ }^{\circ} \mathrm{C}$, respectivamente. Em termos práticos, a variação de temperatura observada durante o ensaio pode ser considerada desprezível e indica que os limites de controle foram demasiadamente rigorosos para a análise dessa característica da qualidade. Adicionalmente, em ambas as condições de ensaio, a temperatura da água manteve-se dentro dos limites de especificação de $\pm 1{ }^{\circ} \mathrm{C}$ em relação ao valor médio, e portanto, a oscilação observada nos valores de temperatura estão dentro dos limites estabelecidos pela norma ISO 9644:2008.
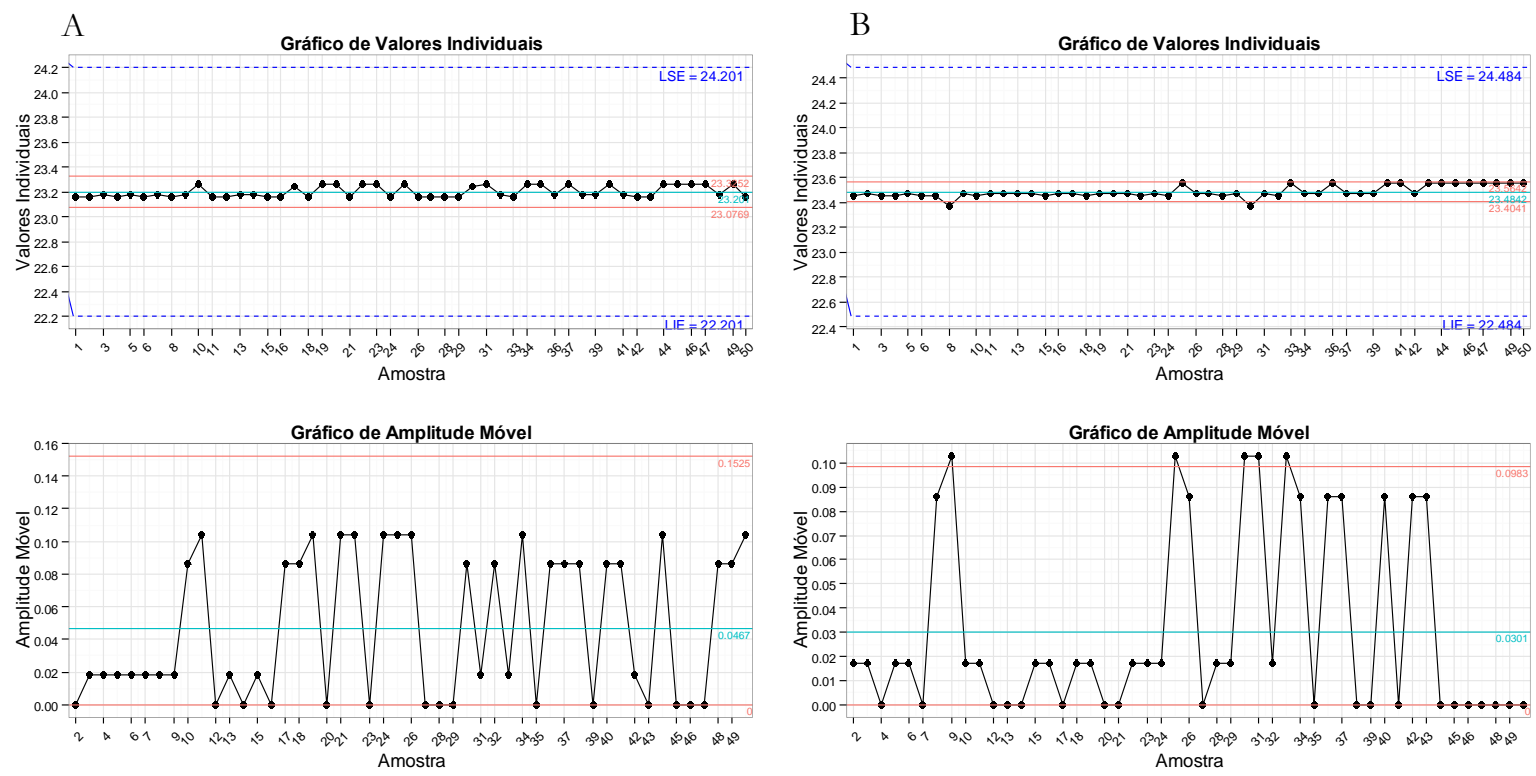

Figura 27. Gráficos de controle para monitoramento da média e da variabilidade da temperatura da água: (A) vazão baixa, 0,90 $\mathrm{m}^{3} \mathrm{~h}^{-1}$; (B) vazão elevada, $2,70 \mathrm{~m}^{3} \mathrm{~h}^{-1}$.

A Figura 28 apresenta gráficos de controle utilizados para monitoramento da média e da variabilidade da pressão diferencial. Tanto os gráficos de média quanto de amplitude apresentam pontos fora dos limites de controle e de especificação para a condição de baixa vazão. Para a condição de alta vazão, observou-se apenas um ponto fora dos limites de controle no gráfico de médias. Assim como foi observada para a análise de vazão, os limites de especificação são mais estreitos do que os limites de controle na condição de baixa vazão, sendo bastante provável que o critério adotado nesse trabalho para estabelecer os limites de especificação seja inadequado. Para a condição de baixa vazão os valores mínimo e máximo de pressão diferencial foram 2,036 e 2,208 kPa, resultando numa amplitude máxima de variação de $0,17 \mathrm{kPa}$. Em termos práticos, tais oscilações nas observações da pressão diferencial são aceitáveis, dadas as instabilidades inerentes a medições de perda de carga e provocadas pela turbulência associada ao escoamento. Embora pontos fora dos limites de controle evidenciem processo fora de controle, Montgomery (2013) alerta para a necessidade de interpretar resultados de gráficos de controle em conjunto com outros critérios técnicos a fim de evitar condenar erroneamente um processo que opera adequadamente. 

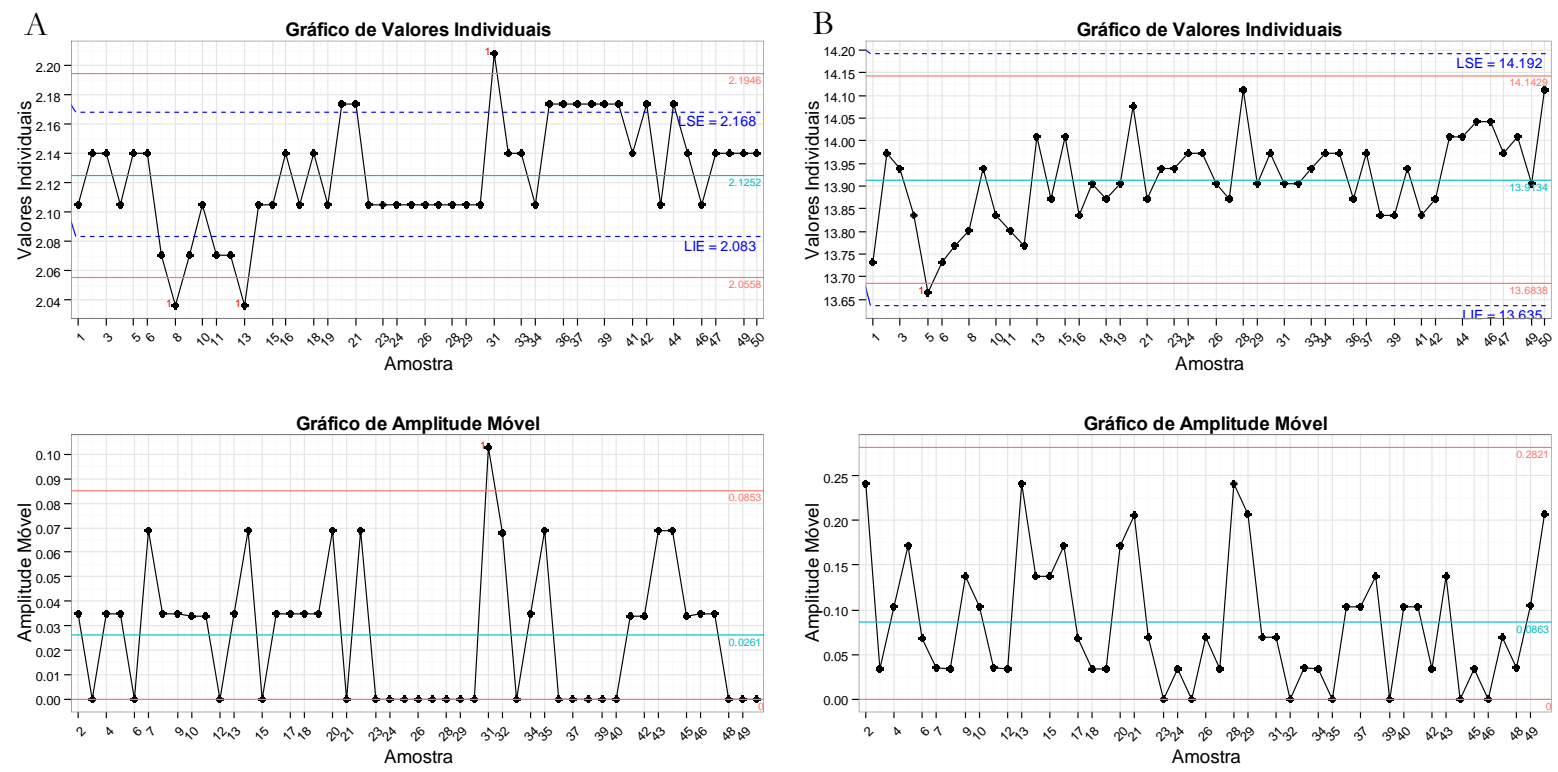

Figura 28. Gráficos de controle para monitoramento da média e da variabilidade da pressão diferencial: (A) vazão baixa, $0,90 \mathrm{~m}^{3}$ $\mathrm{h}^{-1}$; (B) vazão elevada, $2,70 \mathrm{~m}^{3} \mathrm{~h}^{-1}$.

\subsection{Ensaios de perda localizada de carga}

Os modelos são classificados categoricamente, e seus gráficos estão ordenados num padrão que está descrito nesse parágrafo. Será exposto o decréscimo da energia de pressão por unidade de vazão em séries singulares de peças ensaiadas de cada modelo de conexão, a fim de se identificar visualmente a peça com valores extremos de dispersão que possam vir a ter valores consideráveis (Gráfico A). Em seguida, é descontado a perda distribuída de carga no tubo e feito a transformação da pressão resultante numa coluna d'água, e essa correção em termo de perda localizada de carga está sob domínio da vazão e é ordenada como uma série única de todas as peças ensaiadas, possibilitando uma regressão do tipo potência considerando todos os pontos amostrais (Gráfico B). Sua relação com a carga cinética (energia cinética por peso) fornece uma reta, cujo coeficiente angular da regressão linear com início na origem nada mais é do que o coeficiente $\mathrm{K}_{\mathrm{L}}$, quantificando a proporção com que a perda localizada sofre acréscimo com o aumento da velocidade (Gráfico C). Também é verificado o comportamento de $\mathrm{K}_{\mathrm{L}}$ em função do número de Reynolds para visualização de sua constância, e são fornecidos os dados técnicos obtidos pelo modelo de conexão (Gráfico D). De acordo com Azevedo Netto \& Fernandez (2015), o coeficiente $K_{\mathrm{L}}$ assume valores praticamente constantes para números de Reynolds acima de $50 \cdot 10^{3}$. No campo da microirrigação, Cardoso e Klar (2014) notaram o estabelecimento logo após $20 \cdot 10^{3}$ para um conjunto tubo-conexão; outros autores reportam ainda que, para os gotejadores integrados, o coeficiente se mantém estabilizado com Reynolds a partir de 10·10³ (GOMES, 2009; RETTORE NETO et al., 2009). O comprimento equivalente foi considerado para uma condição de escoamento com velocidade de $1,50 \mathrm{~m} \mathrm{~s}^{-1} \mathrm{e}$ viscosidade cinemática da água à $20^{\circ} \mathrm{C}\left(1,01 \cdot 10^{-6} \mathrm{~m}^{2} \mathrm{~s}^{-1}\right)$. 


\subsubsection{Uniões}

\subsubsection{Diâmetro nominal de $13 \mathrm{~mm}$}

Na Figura 29 são apresentandos os resultados experimentais de uniões de $13 \mathrm{~mm}$. Esses ensaios do modelo 0081 atingem uma velocidade máxima de escoamento acima das demais conexões ensaiadas, dado o diâmetro reduzido da conexão de $13 \mathrm{~mm}$ e a baixa excentricidade de uma união. A velocidade de escoamento média vai de $0,95 \mathrm{~m} \mathrm{~s}^{-1}$ a $5,60 \mathrm{~m} \mathrm{~s}^{-1}$, o que seria bem acima do usual, mas que torna a curva mais expressiva além de comprovar visualmente o impacto que altas velocidades oferecem nos sistemas de irrigação. Os modelos de uniões e conectores iniciais contam com uma amostragem de 10 peças.
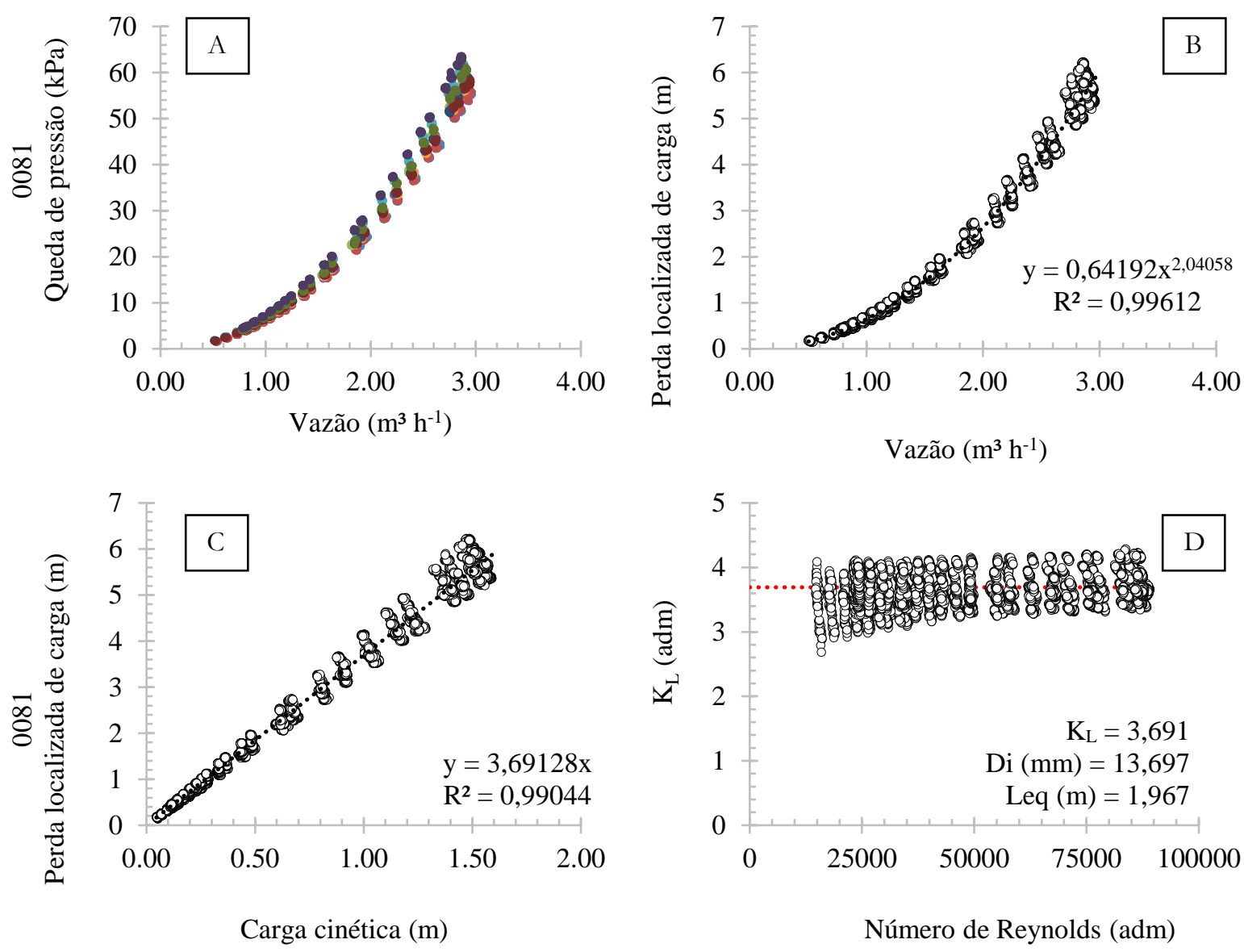

Figura 29. Resultados experimentais da união 0081: (a) curva de queda de pressão em função de vazão; (b) perda localizada de carga em função de vazão; (c) perda localizada de carga em função de carga cinética; (d) coeficiente $\mathrm{K}_{\mathrm{L}}$ em função de Reynolds.

\subsubsection{Diâmetro nominal de $16 \mathrm{~mm}$}

Na Figura 30, 31 e 32 são apresentandos respectivamente os resultados experimentais de uniões $16 \mathrm{~mm}$, do modelo de conexão 0038, 0082 e 0083. Percebe-se aqui um nítido estreitamento de $\mathrm{K}_{\mathrm{L}}$ atingindo sua constância com o aumento do número de Reynolds. 

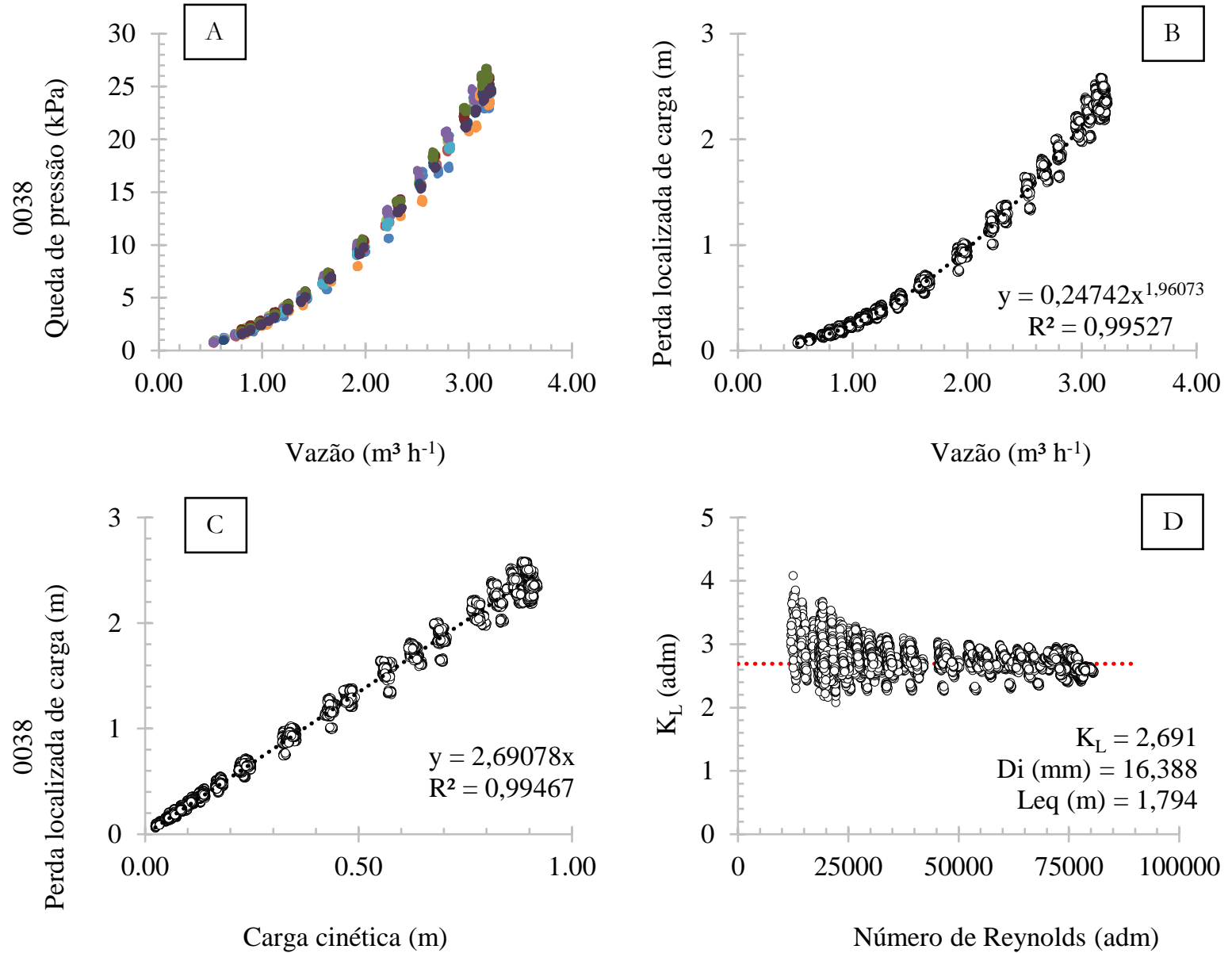

Figura 30. Resultados experimentais da união 0038: (a) curva de queda de pressão em função de vazão; (b) perda localizada de carga em função de vazão; (c) perda localizada de carga em função de carga cinética; (d) coeficiente $K_{L}$ em função de Reynolds. 

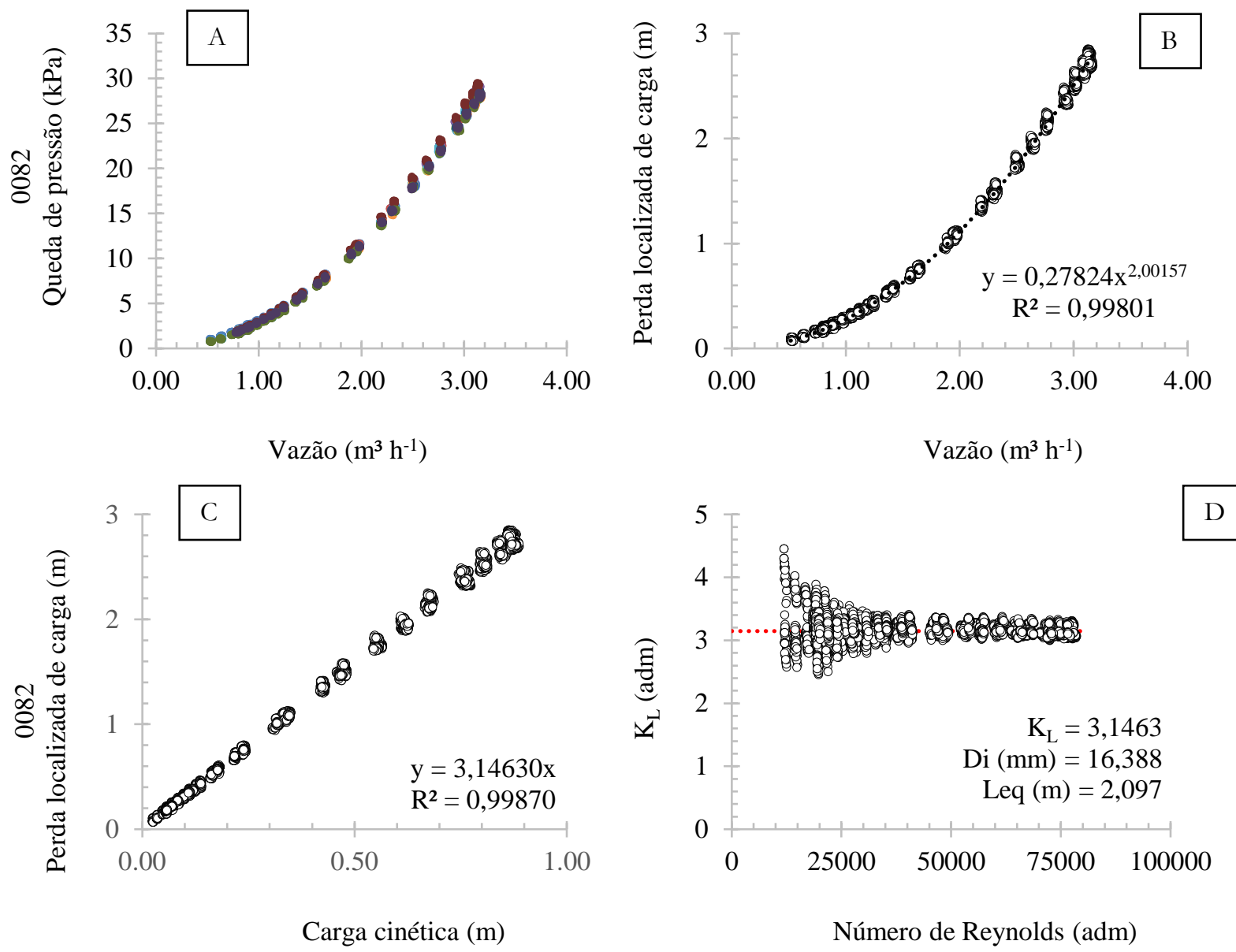

Carga cinética $(\mathrm{m})$

Figura 31. Resultados experimentais da união 0082: (a) curva de queda de pressão em função de vazão; (b) perda localizada de carga em função de vazão; (c) perda localizada de carga em função de carga cinética; (d) coeficiente $K_{L}$ em função de Reynolds. 

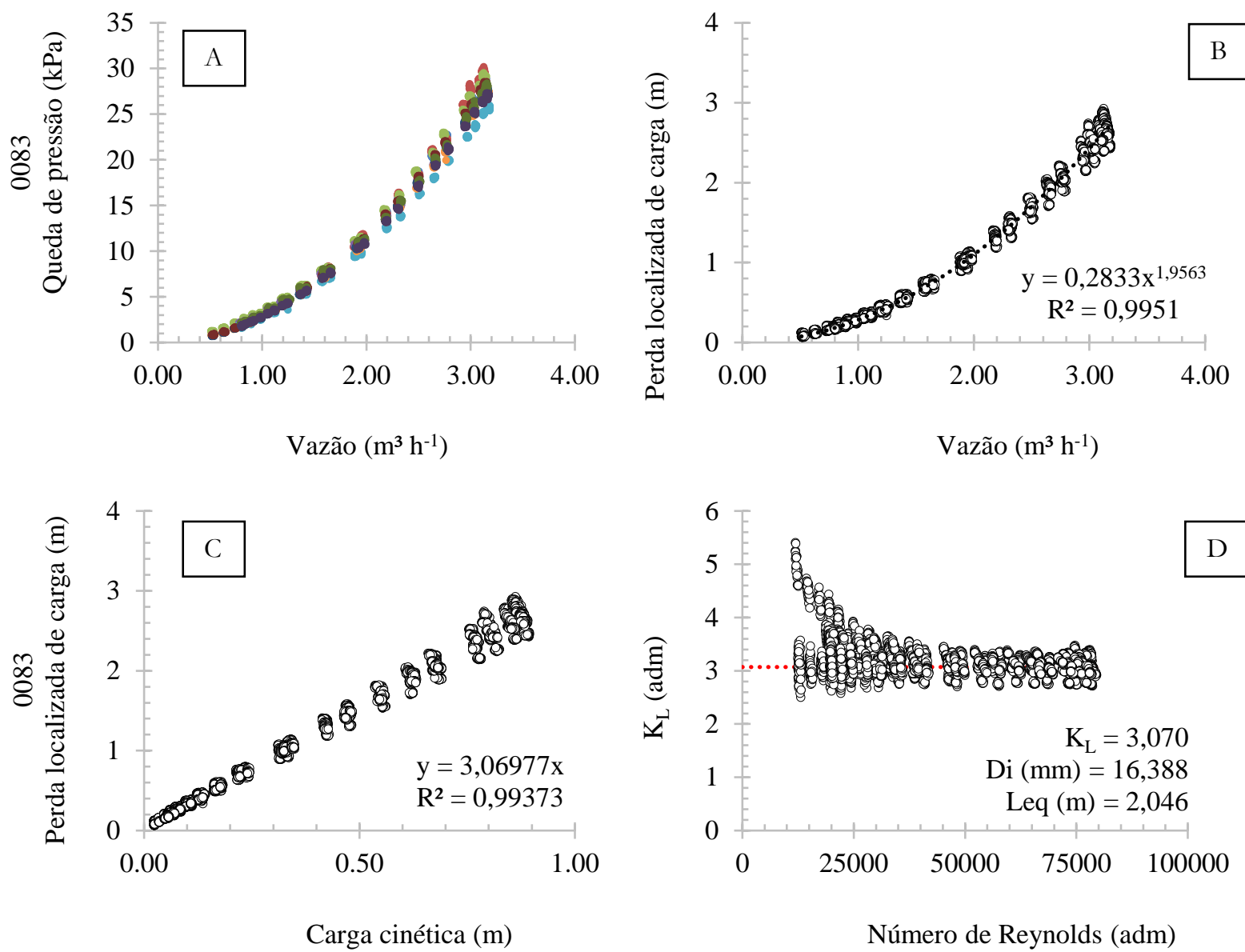

Figura 32. Resultados experimentais da união 0083: (a) curva de queda de pressão em função de vazão; (b) perda localizada de carga em função de vazão; (c) perda localizada de carga em função de carga cinética; (d) coeficiente $K_{L}$ em função de Reynolds.

\subsubsection{Conectores iniciais}

\subsubsection{Diâmetro nominal de $13 \mathrm{~mm}$}

Na Figura 33 é apresentado os resultados experimentais de conectores de $13 \mathrm{~mm}$ do modelo 0057. Espera-se valores superiores de $\mathrm{K}_{\mathrm{L}}$ para essa classe, pois o impacto na energia cinética é mais expressivo. Também é evidenciado a sensibilidade do coeficiente relacionada com a razão das seções internas nas conexões diante da expansão brusca no escoamento (relação de Borda-Bélanger), expresso pela amplitude de $\mathrm{K}_{\mathrm{L}}$ nos valores obtidos dessa classe. 

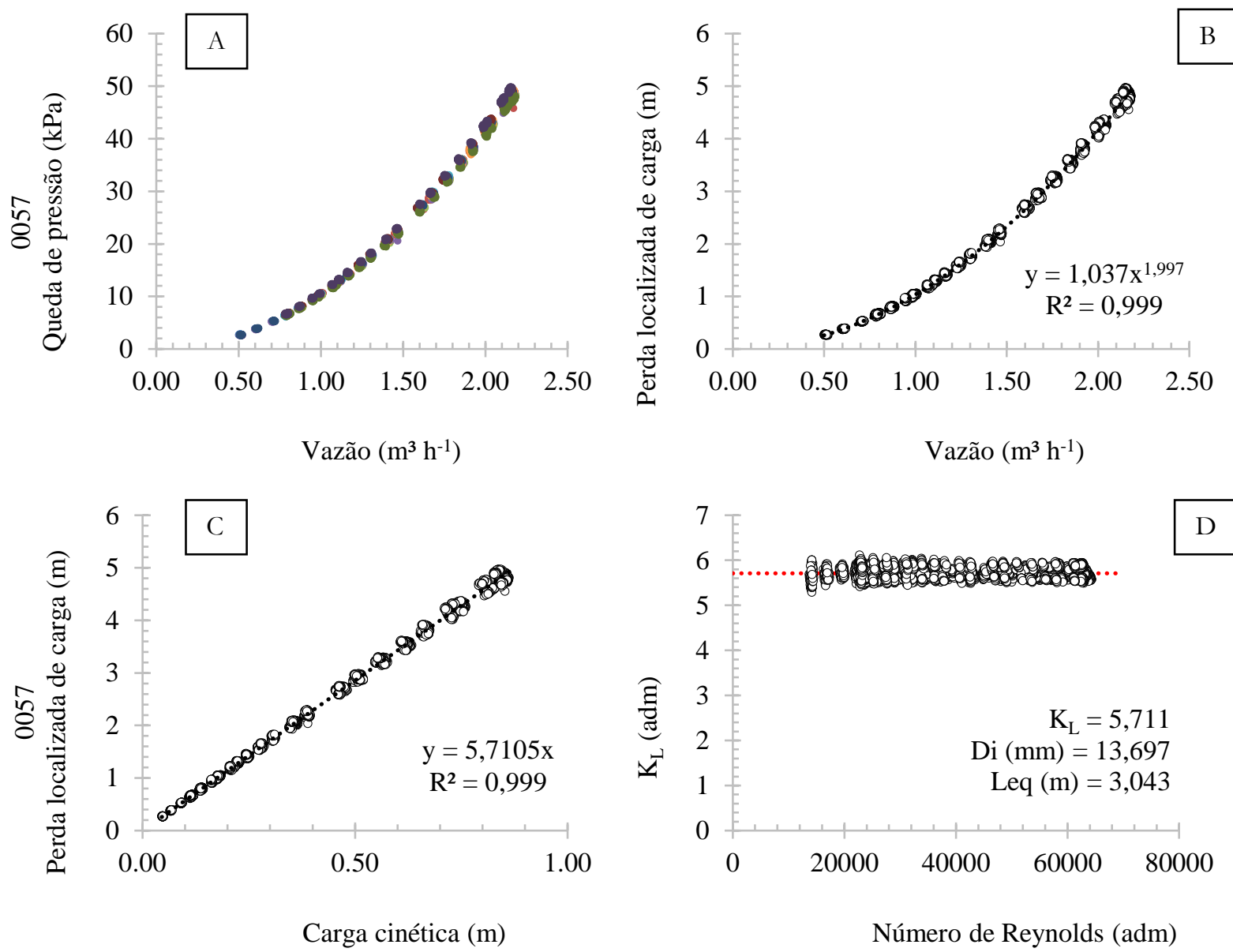

Figura 33. Resultados experimentais do conector inicial 0057: (a) curva de queda de pressão em função de vazão; (b) perda localizada de carga em função de vazão; (c) perda localizada de carga em função de carga cinética; (d) coeficiente $\mathrm{K}_{\mathrm{L}}$ em função de Reynolds.

\subsubsection{Diâmetro nominal de $16 \mathrm{~mm}$}

Nas Figura 34, 35, 36, 37 e 38 são apresentados respectivamente os resultados experimentais de conectores inicias de $16 \mathrm{~mm}$ dos modelos de conexão 0037, 0046, 0058, 0059 e 0186. Pequenas irregularidades foram constatadas na peça número 3 e 8 da conexão modelo 0046, mas suas interferências são redundantes pois a amostragem é uniformizada pela densidade de pontos coletados. O mesmo é válido para demais pontos fora do padrão de tendência. Percebe-se visualmente que o modelo 0186 apresentou mais dispersão nos dados entre peças dessa categoria. 

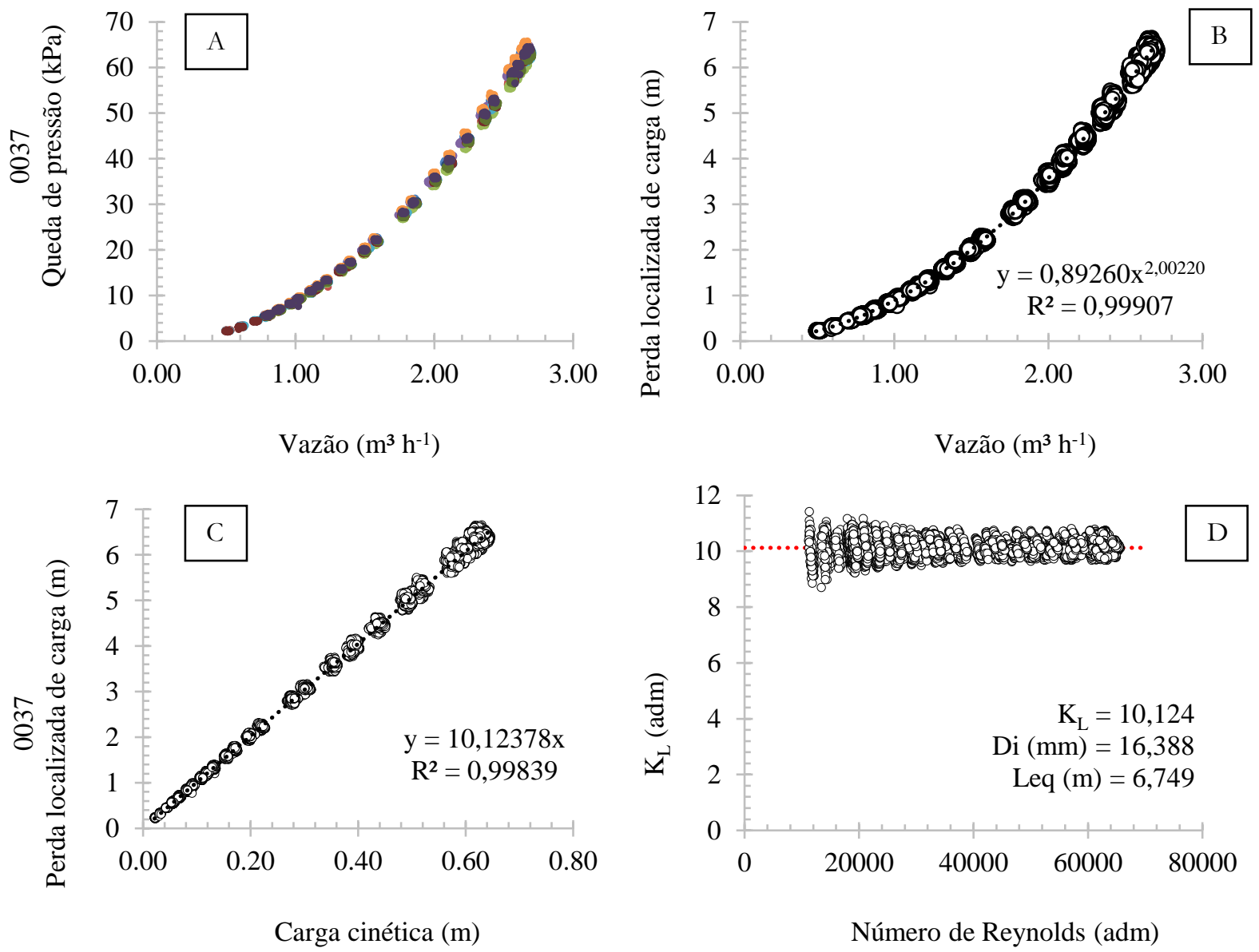

Figura 34. Resultados experimentais do conector inicial 0037: (a) curva de queda de pressão em função de vazão; (b) perda localizada de carga em função de vazão; (c) perda localizada de carga em função de carga cinética; (d) coeficiente $\mathrm{K}_{\mathrm{L}}$ em função de Reynolds. 

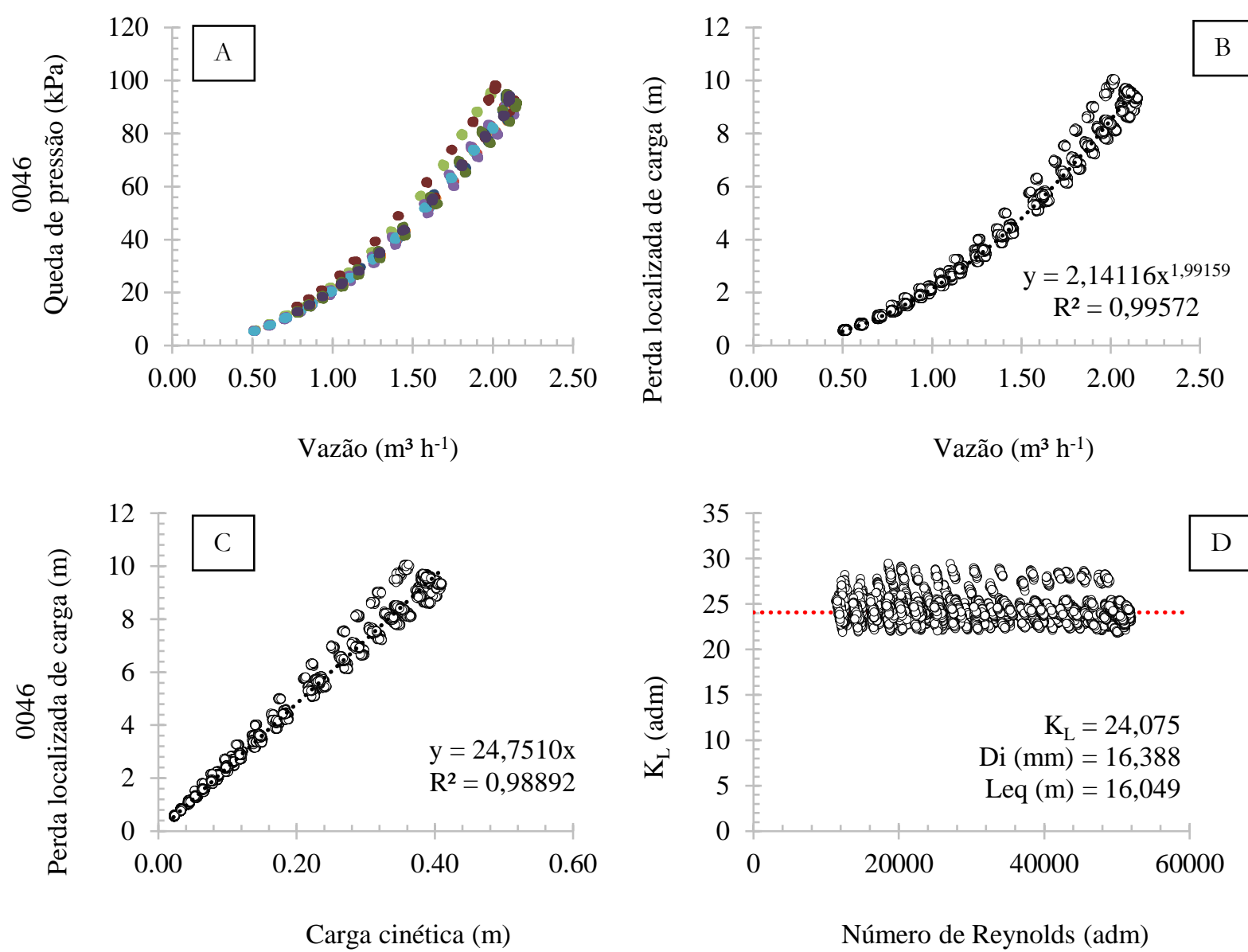

Figura 35. Resultados experimentais do conector inicial 0046: (a) curva de queda de pressão em função de vazão; (b) perda localizada de carga em função de vazão; (c) perda localizada de carga em função de carga cinética; (d) coeficiente $\mathrm{K}_{\mathrm{L}}$ em função de Reynolds. 

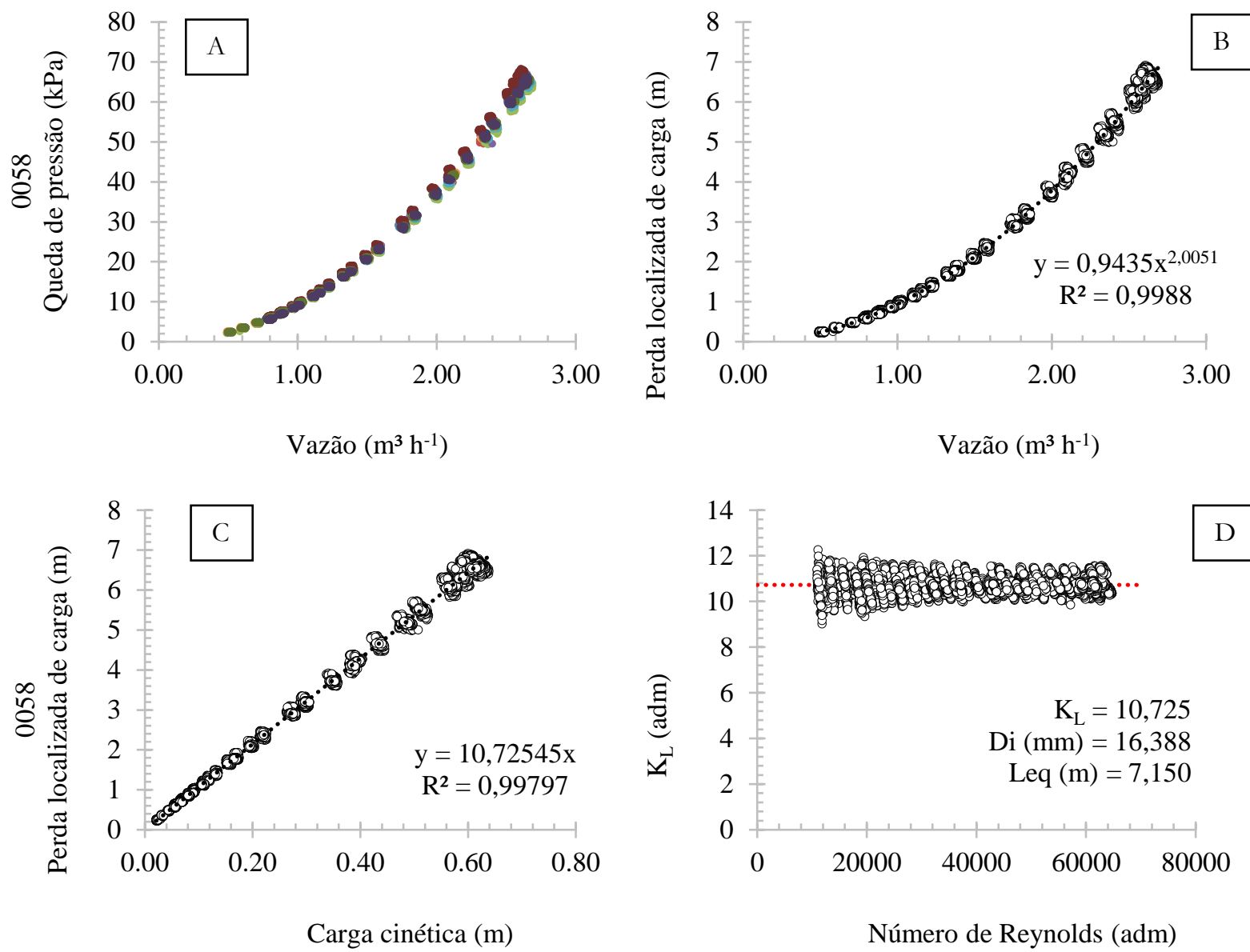

Figura 36. Resultados experimentais do conector inicial 0058: (a) curva de queda de pressão em função de vazão; (b) perda localizada de carga em função de vazão; (c) perda localizada de carga em função de carga cinética; (d) coeficiente $\mathrm{K}_{\mathrm{L}}$ em função de Reynolds. 

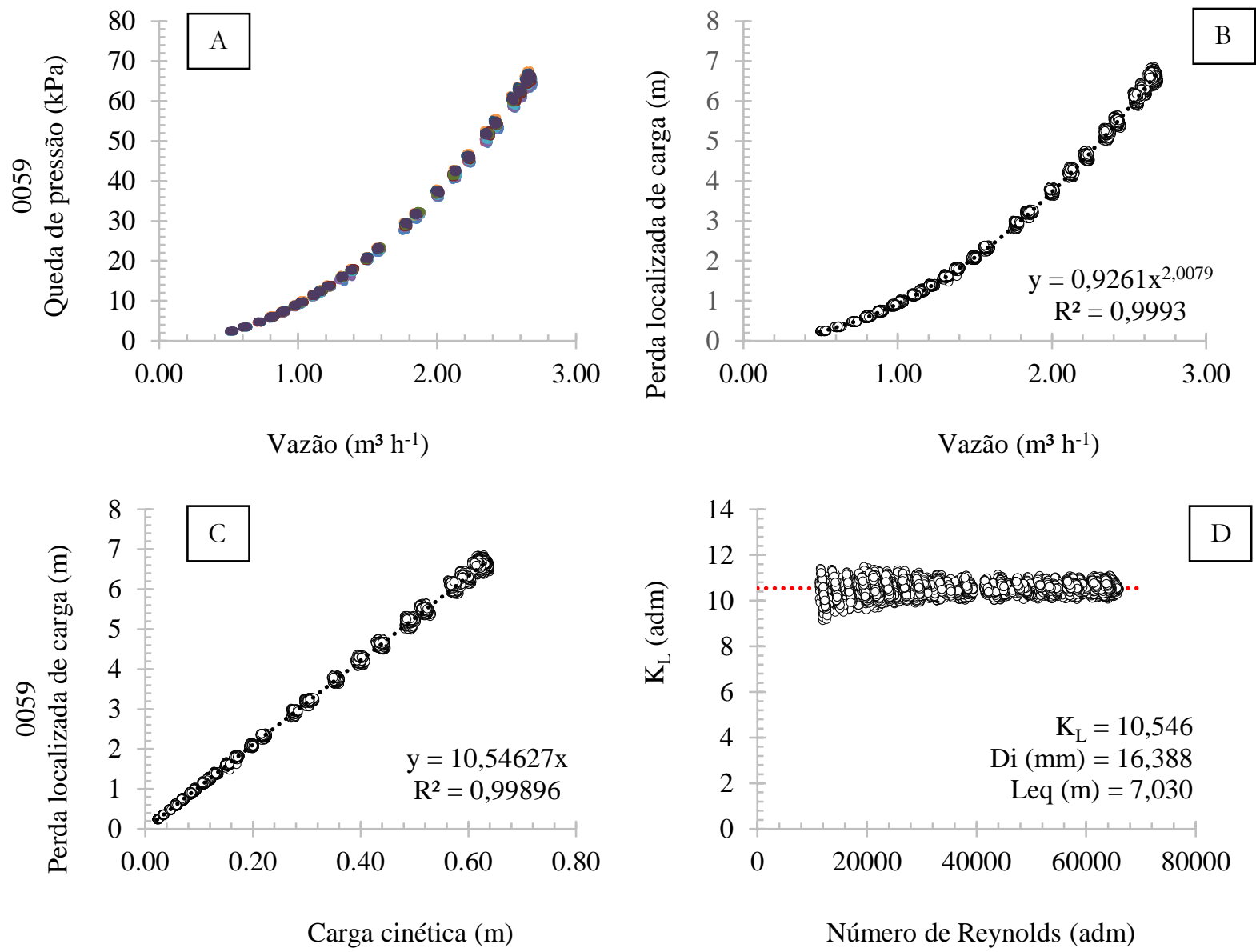

Figura 37. Resultados experimentais do conector inicial 0059: (a) curva de queda de pressão em função de vazão; (b) perda localizada de carga em função de vazão; (c) perda localizada de carga em função de carga cinética; (d) coeficiente $\mathrm{K}_{\mathrm{L}}$ em função de Reynolds. 

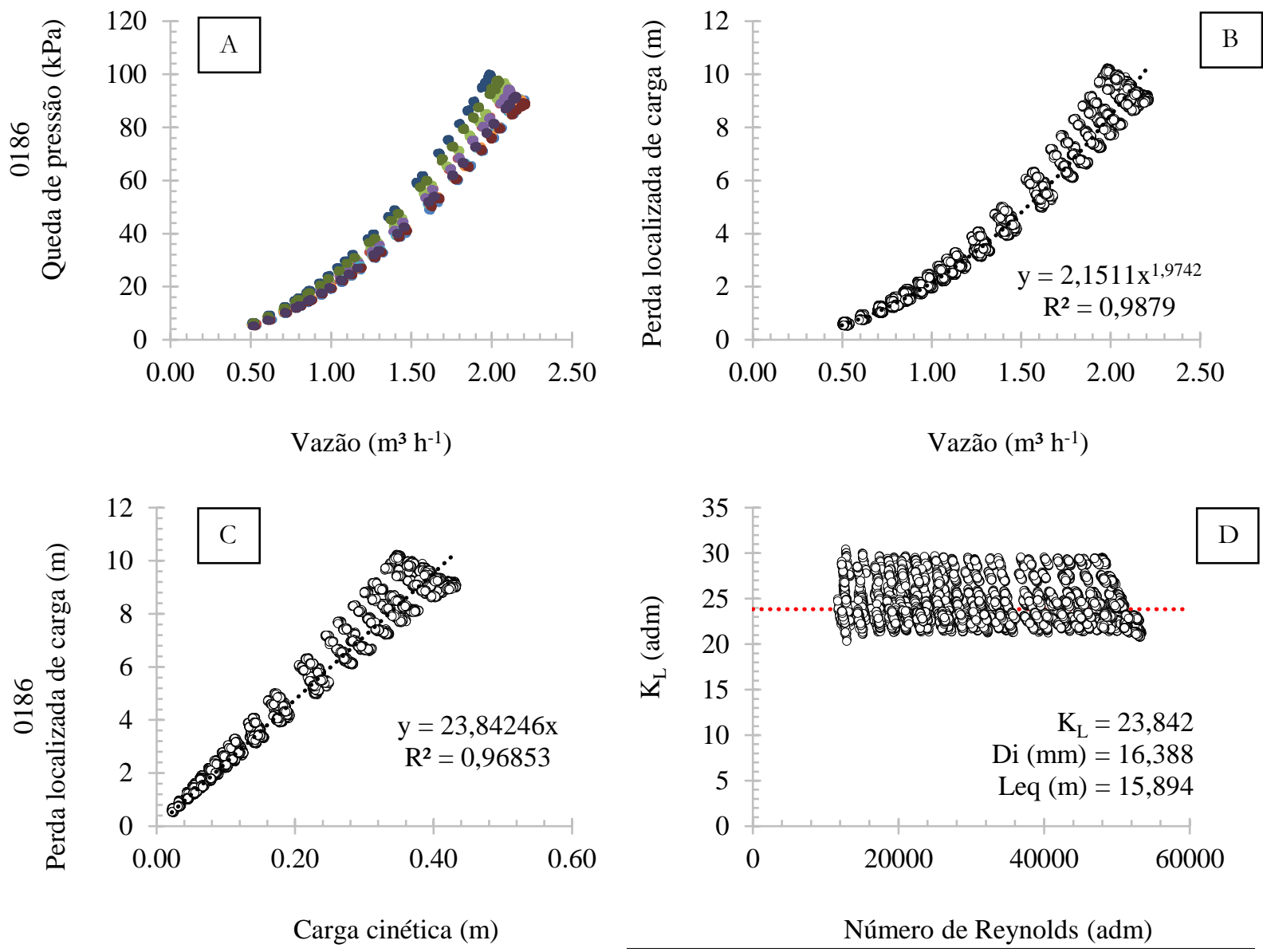

Figura 38. Resultados experimentais do conector inicial 0186: (a) curva de queda de pressão em função de vazão; (b) perda localizada de carga em função de vazão; (c) perda localizada de carga em função de carga cinética; (d) coeficiente $\mathrm{K}_{\mathrm{L}}$ em função de Reynolds.

Percebe-se que há uma maior dispersão dos pontos de perda localizada de carga com o acréscimo da carga cinética, o que é provocado pela presença de rebarbas decorrentes na produção da peça. O modelo 0186 apresentou-se como mais expressivo nesse quesito de variação entre a classe dos conectores iniciais, como demonstrado posteriormente na Tabela 5.

\subsubsection{Registros}

\subsubsection{Registros de união}

\subsection{Diâmetro nominal de $13 \mathrm{~mm}$}

Nos registros há uma resistência adicional oferecida por sua garganta, fato que diminui a vazão máxima atingida em relação aos componentes lisos (sem mais singularidades); os valores máximos de vazão foram próximos de $1,30 \mathrm{~m}^{3} \mathrm{~h}^{-1}$ e seu decréscimo de pressão pode causar uma falsa impressão de imediato por essa escala. Uma maneira clara de se comparar essa magnitude é através dos coeficientes $\mathrm{K}_{\mathrm{L}}$, que assumem valores consideráveis. Há uma dispersão dos valores bastante afetada pela variância de fabricação da garganta em cada peça, onde pequenas irregularidades tornam-se sensíveis pelo seu diâmetro de redução. Pela disponibilidade ocasional, os ensaios de todos 
modelos de registros contam com uma amostragem de cinco peças por modelo. Procurou-se separar cada grupo em peças mais uniformes possíveis a serem ensaiadas.

Na Figura 39 é apresentado os resultados experimentais de registro de união de $13 \mathrm{~mm}$ do modelo de conexão 0153.
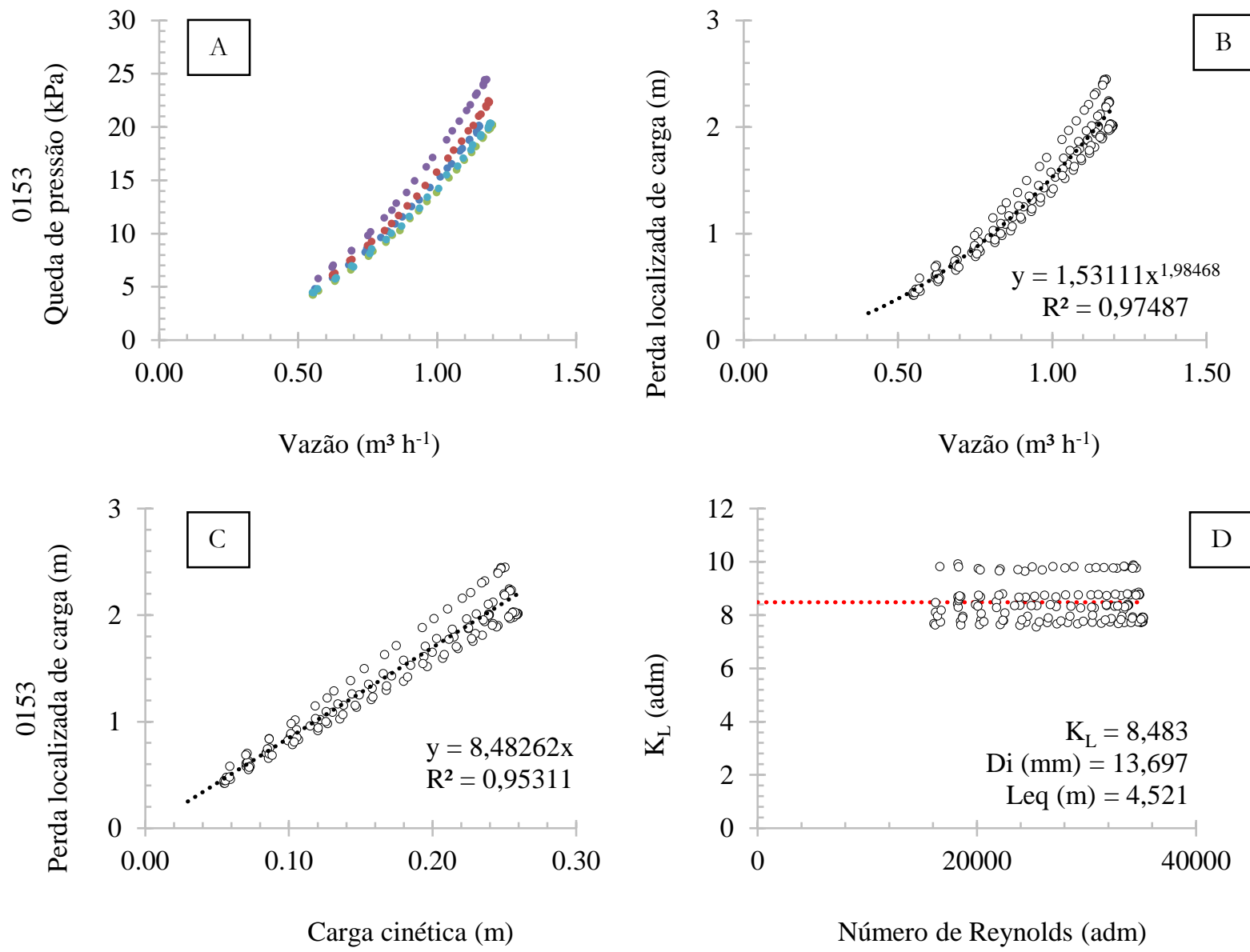

Figura 39. Resultados experimentais do registro de união 0153: (a) curva de queda de pressão em função de vazão; (b) perda localizada de carga em função de vazão; (c) perda localizada de carga em função de carga cinética; (d) coeficiente $\mathrm{K}_{\mathrm{L}}$ em função de Reynolds.

\subsection{Diâmetro nominal de $16 \mathrm{~mm}$}

Nas Figuras 40, 41 e 42 são apresentados os resultados experimentais de registro de união de 16 mm dos modelos de conexão 0151, 0212, 0213, 0214 e 0223. Os modelos 0212, 0213 e 0223 são apresentados juntos, uma vez que possuem semelhança geométrica. 

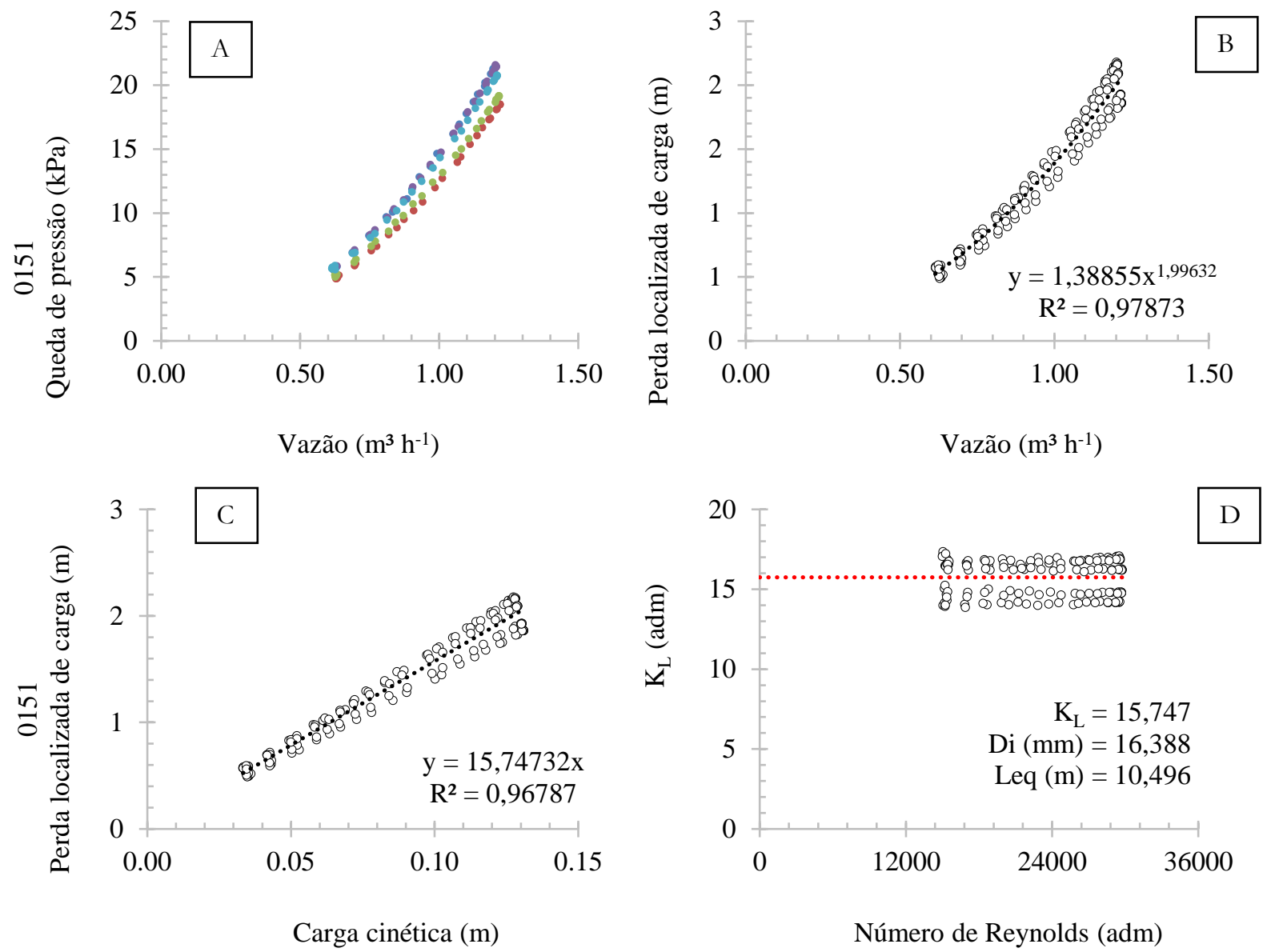

Figura 40. Resultados experimentais do registro de união 0151: (a) curva de queda de pressão em função de vazão; (b) perda localizada de carga em função de vazão; (c) perda localizada de carga em função de carga cinética; (d) coeficiente $\mathrm{K}_{\mathrm{L}}$ em função de Reynolds. 

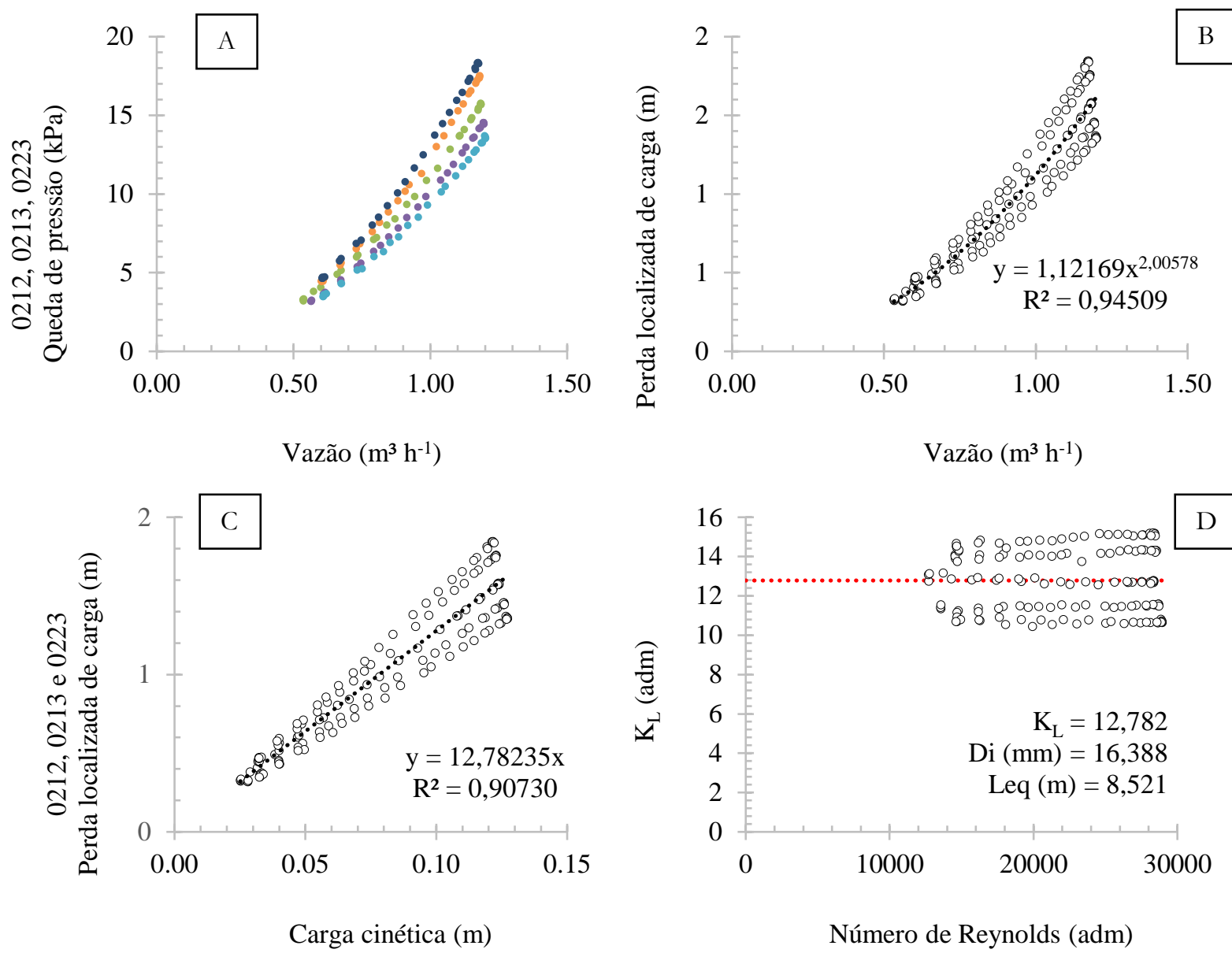

Figura 41. Resultados experimentais dos registros de união 0212, 0213 e 0223: (a) curva de queda de pressão em função de vazão; (b) perda localizada de carga em função de vazão; (c) perda localizada de carga em função de carga cinética; (d) coeficiente $\mathrm{K}_{\mathrm{L}}$ em função de Reynolds. 

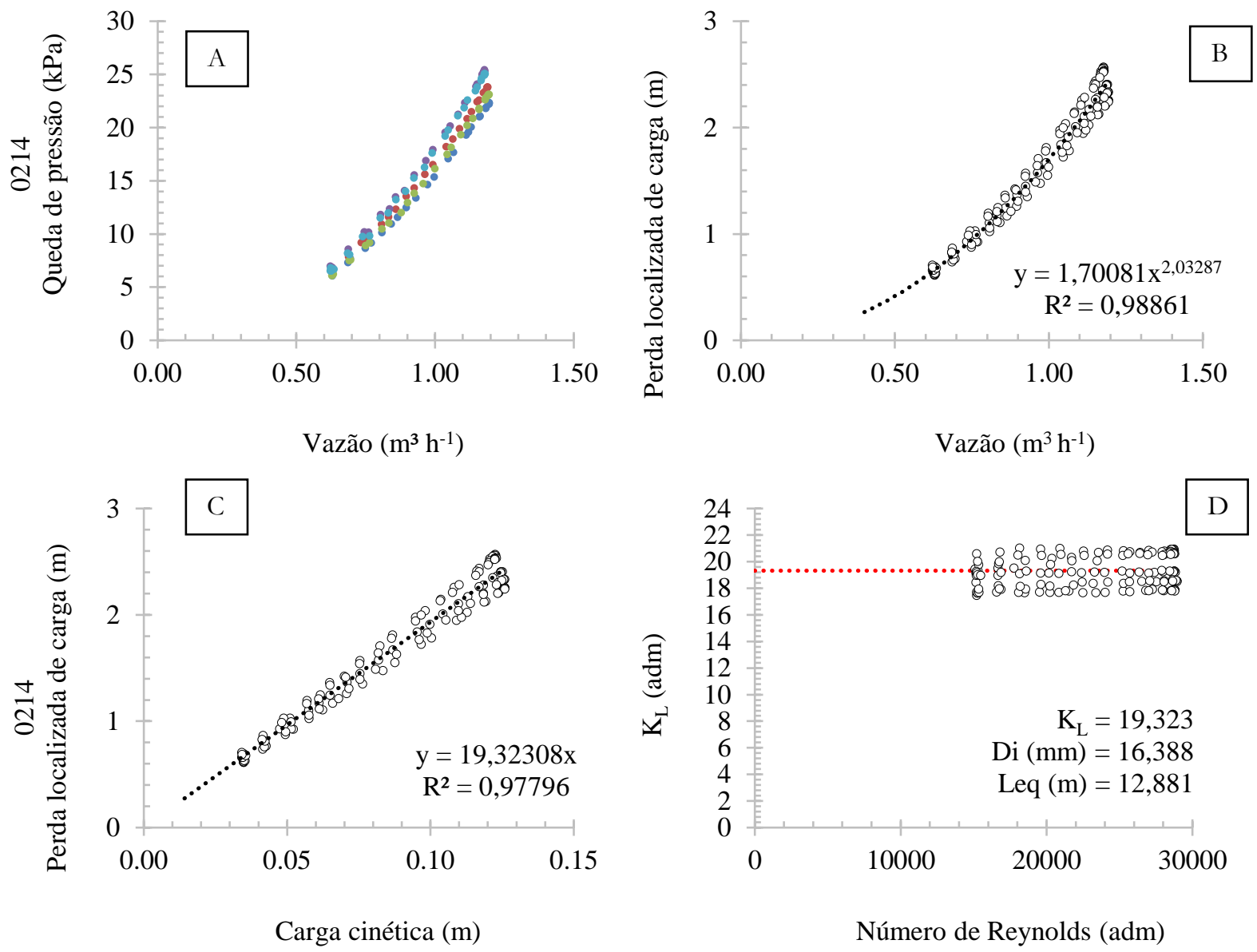

Figura 42. Resultados experimentais do registro de união 0214: (a) curva de queda de pressão em função de vazão; (b) perda localizada de carga em função de vazão; (c) perda localizada de carga em função de carga cinética; (d) coeficiente $\mathrm{K}_{\mathrm{L}}$ em função de Reynolds.

\subsubsection{Registros iniciais}

\subsection{Diâmetro nominal de $13 \mathrm{~mm}$}

Na Figura 43 é apresentado os resultados experimentais de registro inicial de $13 \mathrm{~mm}$ do modelo 0152. 

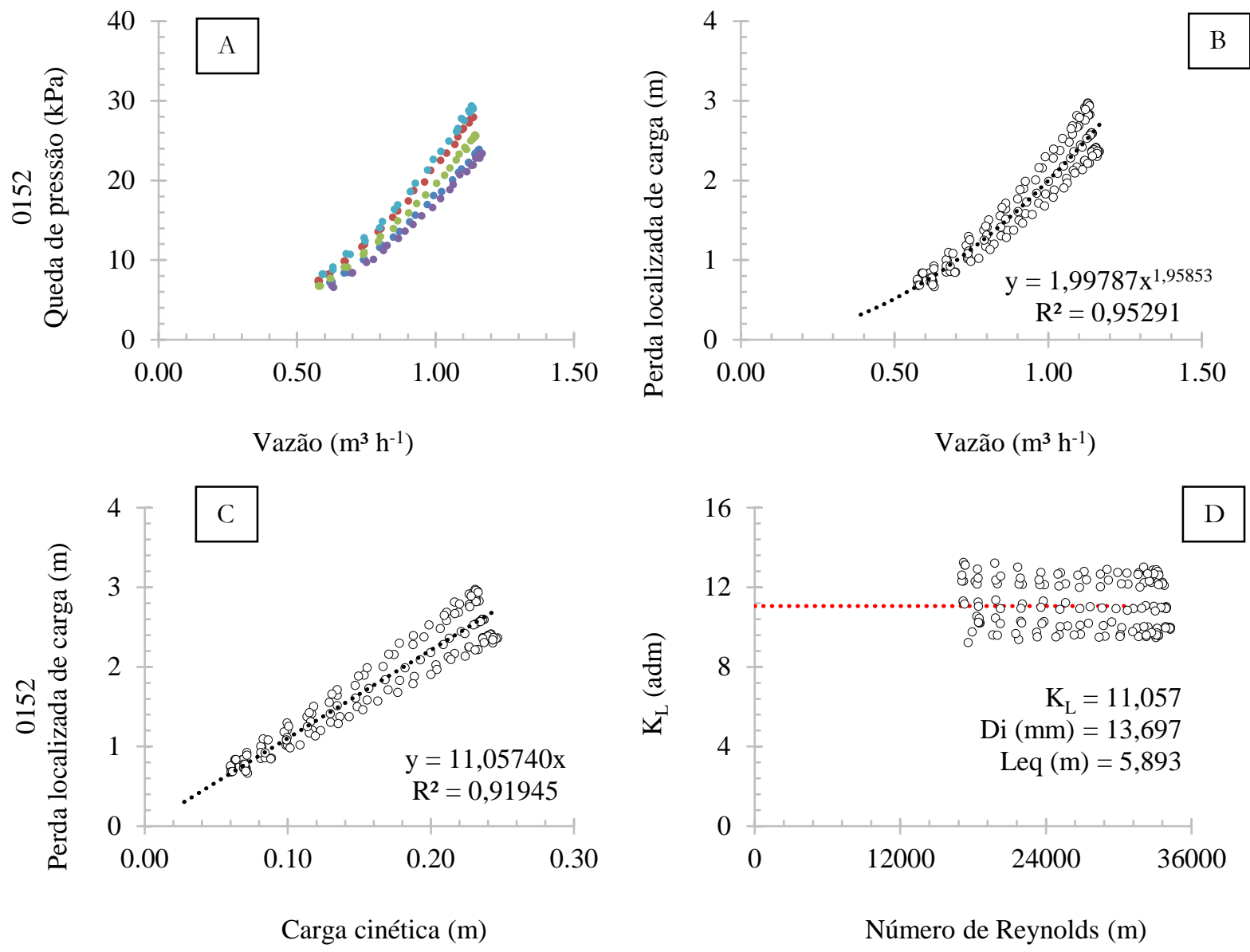

Figura 43. Resultados experimentais do registro inicial 0152: (a) curva de queda de pressão em função de vazão; (b) perda localizada de carga em função de vazão; (c) perda localizada de carga em função de carga cinética; (d) coeficiente $\mathrm{K}_{\mathrm{L}}$ em função de Reynolds.

\subsection{Diâmetro nominal de $16 \mathrm{~mm}$}

Nas Figuras 44, 45 e 46 são apresentados os resultados experimentais de registro de união de 16 mm dos modelos de conexão 0150, 0182, 0183 e 0184. Novamente, os modelos 0182 e 0183 são apresentados juntos. 

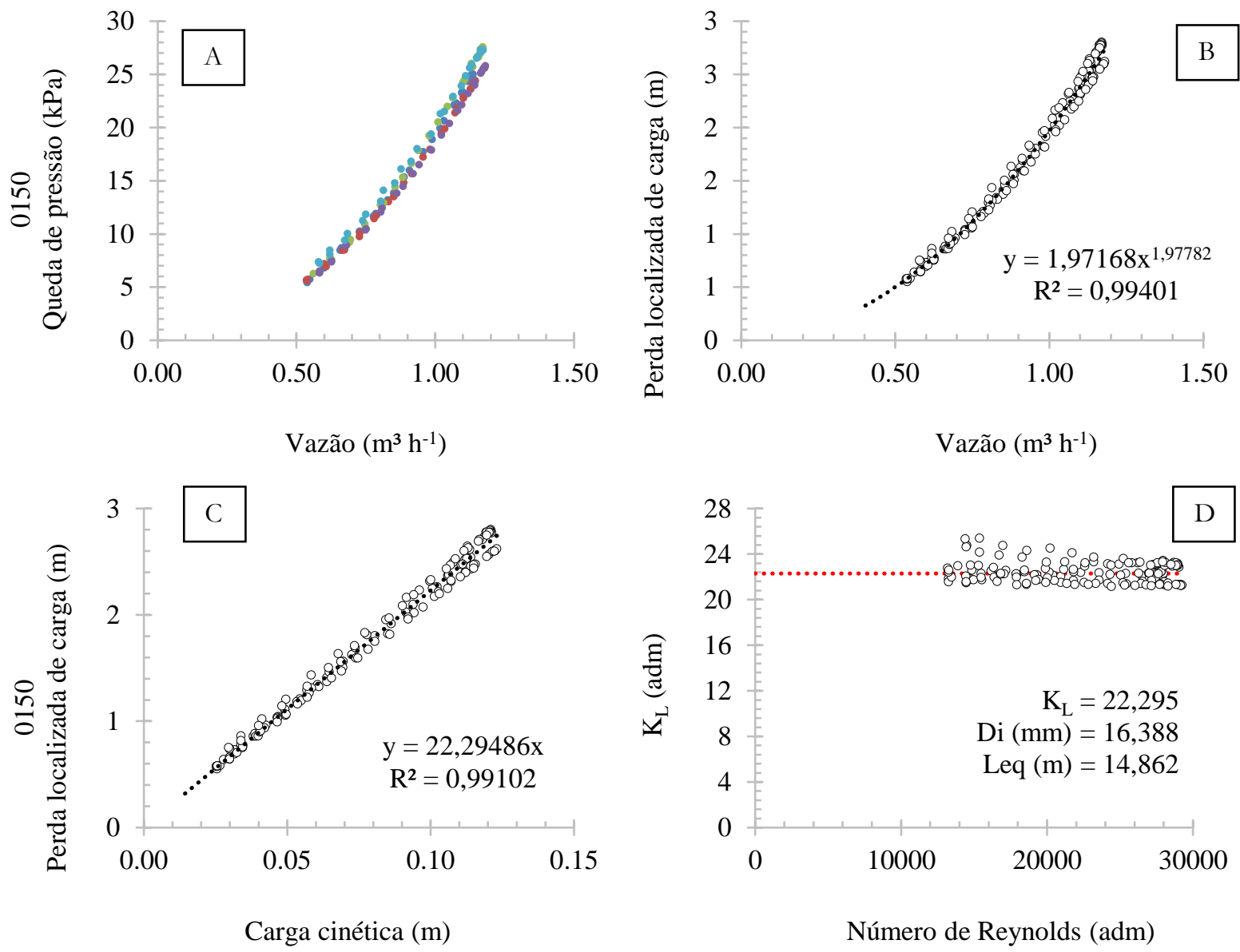

Figura 44. Resultados experimentais do registro inicial 0150: (a) curva de queda de pressão em função de vazão; (b) perda localizada de carga em função de vazão; (c) perda localizada de carga em função de carga cinética; (d) coeficiente $\mathrm{K}_{\mathrm{L}}$ em função de Reynolds. 

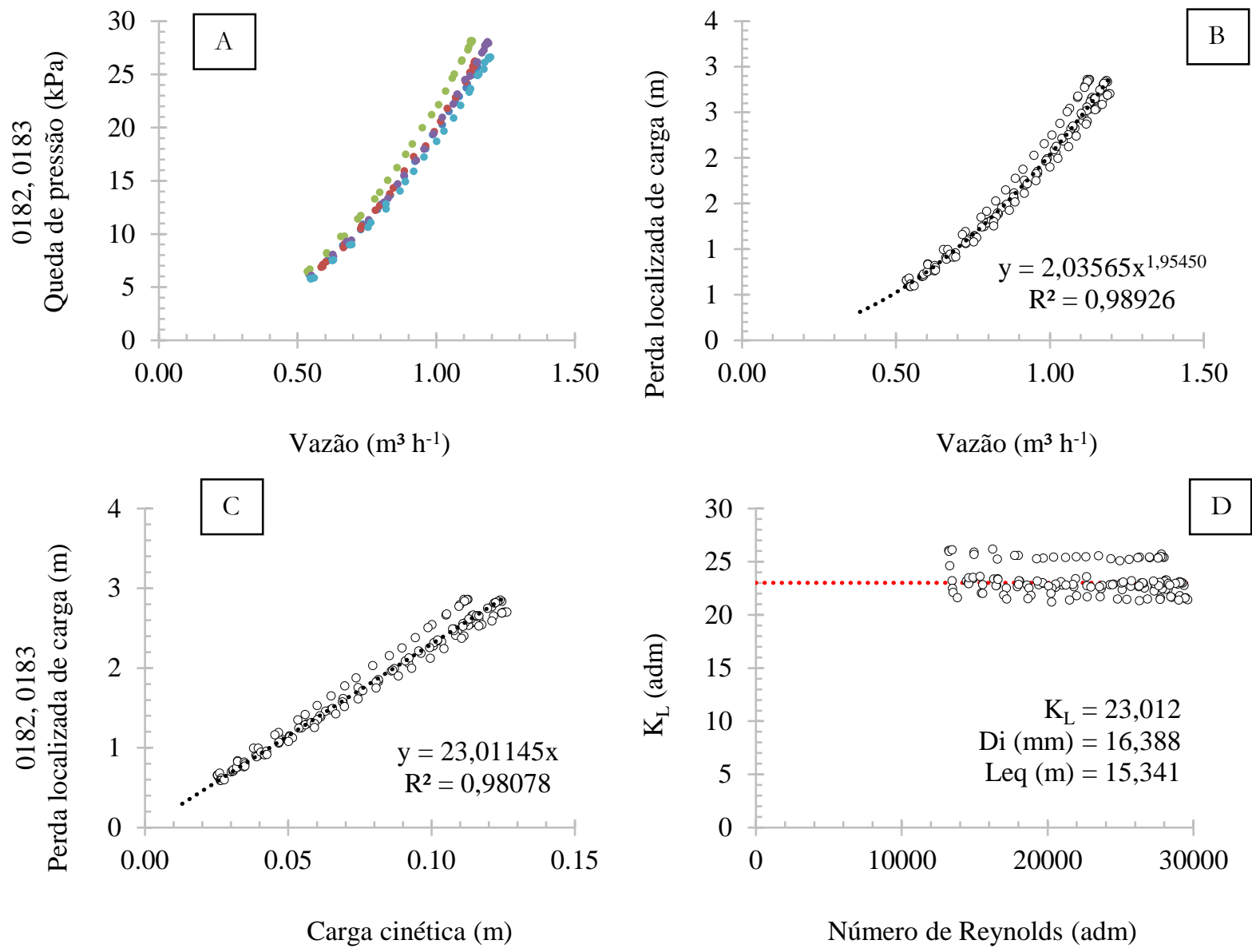

Figura 45. Resultados experimentais dos registros iniciais 0182 e 0183: (a) curva de queda de pressão em função de vazão; (b) perda localizada de carga em função de vazão; (c) perda localizada de carga em função de carga cinética; (d) coeficiente $\mathrm{K}_{\mathrm{L}}$ em função de Reynolds. 

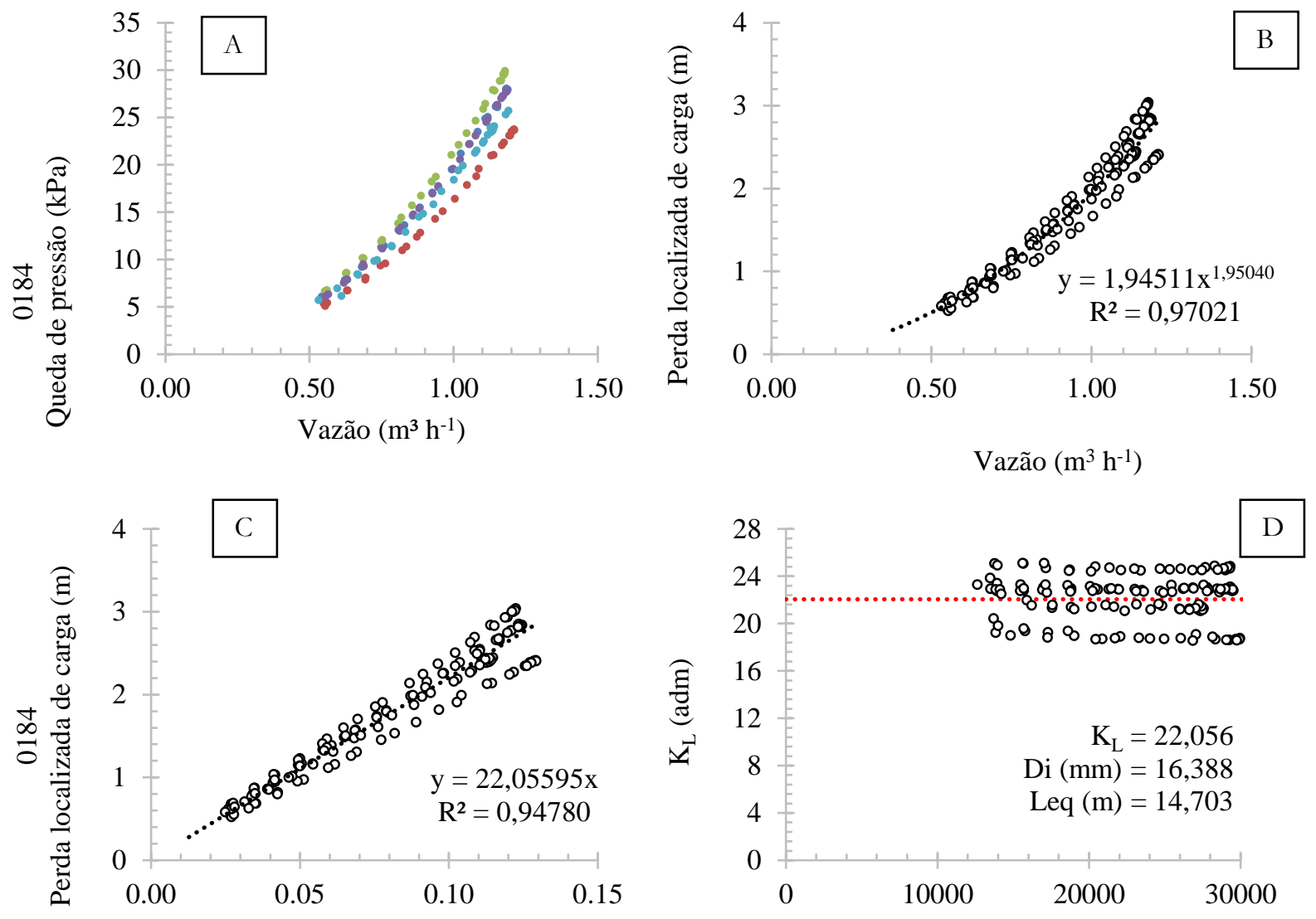

Carga cinética (m)

Número de Reynolds (adm)

Figura 46. Resultados experimentais do registro inicial 0184: (a) curva de queda de pressão em função de vazão; (b) perda localizada de carga em função de vazão; (c) perda localizada de carga em função de carga cinética; (d) coeficiente $\mathrm{K}_{\mathrm{L}}$ em função de Reynolds.

Salvo exceções dos modelos 0038, 0082 e 0083, o coeficiente $\mathrm{K}_{\mathrm{L}}$ apresentou estabilizado após um número de Reynolds de 10000. Os expoentes da vazão assumem valores próximos do que é aplicado pela equação de DarcyWeisbach $(\mathrm{m}=2)$. Os resultados obtidos podem contribuir com o desenvolvimento da microirrigação, e tornam-se úteis tanto para o projetista, quanto para com o fabricante. Para tanto, um estudo de aplicação pode ainda ser explorado para quantificar esse seu benefício.

\subsection{Uniformidade de fabricação}

Uma vez que $\mathrm{K}_{\mathrm{L}}$ se torna intimamente correlacionado com a característica geométrica da peça, os índices de uniformidade de fabricação podem ser analisados por estatística descritiva simples através das medidas de dispersão (desvio padrão e coeficiente de variação) entre cada uma das peças ensaiadas do modelo (Tabela 5). Os valores de $\mathrm{K}_{\mathrm{L}}$ que foram comparados consideram uma média das velocidades acima de 1,50 $\mathrm{m} \mathrm{s}^{-1} \mathrm{em}$ todas as classes, onde já era esperado o coeficiente tender a uma constância (um número de Reynolds acima de 20000). Essa velocidade foi definida por ser próximo da máxima alcançada por um modelo crítico de registro. 
Tabela 5. Média e medidas de dispersão dos dados obtidos do coeficiente $\mathrm{K}_{\mathrm{L}}$ entre peças dos modelos de conexão a partir de uma velocidade de referência acima de $1,50 \mathrm{~m} \mathrm{~s}^{-1}$.

\begin{tabular}{lcccc}
\hline \multirow{2}{*}{ Código } & Classe & & $\mathrm{K}_{\mathrm{L}}$ & \\
\cline { 3 - 5 } & & $\bar{x}(-)$ & $S_{x}(-)$ & $C V(\%)$ \\
\hline 0037 & Conector Inicial 16 mm & 10,118 & 0,254 & 2,512 \\
0038 & União $16 \mathrm{~mm}$ & 2,719 & 0,151 & 5,558 \\
0046 & Conector Inicial $16 \mathrm{~mm}$ & 24,164 & 1,420 & 5,875 \\
0057 & Conector Inicial $13 \mathrm{~mm}$ & 5,721 & 0,103 & 1,795 \\
0058 & Conector Inicial $16 \mathrm{~mm}$ & 10,718 & 0,296 & 2,762 \\
0059 & Conector Inicial $16 \mathrm{~mm}$ & 10,536 & 0,218 & 2,066 \\
0081 & União $13 \mathrm{~mm}$ & 3,625 & 0,240 & 6,624 \\
0082 & União $16 \mathrm{~mm}$ & 3,159 & 0,085 & 2,680 \\
0083 & União $16 \mathrm{~mm}$ & 3,103 & 0,171 & 5,510 \\
0186 & Conector Inicial $16 \mathrm{~mm}$ & 24,144 & 2,342 & 9,700 \\
0150 & Registro inicial $16 \mathrm{~mm}$ & 22,288 & 0,866 & 3,976 \\
0151 & Registro de união $16 \mathrm{~mm}$ & 15,776 & 1,131 & 7,167 \\
0152 & Registro inicial $13 \mathrm{~mm}$ & 11,086 & 1,220 & 1,009 \\
0153 & Registro de união $13 \mathrm{~mm}$ & 8,487 & 0,746 & 8,791 \\
0182,0183 & Registro inicial $16 \mathrm{~mm}$ & 22,305 & 0,646 & 2,894 \\
0184 & Registro inicial $16 \mathrm{~mm}$ & 22,166 & 2,213 & 9,984 \\
$0212,0213,0223$ & Registro de união $16 \mathrm{~mm}$ & 13,531 & 1,774 & 13,113 \\
0214 & Registro de união $16 \mathrm{~mm}$ & 19,439 & 1,172 & 6,031 \\
\hline & & & &
\end{tabular}

Classes de registros apresentam maiores dispersões de pontos, pois nesses há sensibilidade na fabricação de sua garganta de articulação que dificulta sua uniformidade. Nas demais categorias, a maior dispersão foi obtida no modelo 0186 de conector inicial, que também apresenta uma seção reduzida, atingindo um coeficiente de variação de $9,70 \%$ entre os resultados das peças ensaiadas.

\subsection{Aplicação da análise dimensional nos conectores ensaiados}

Os modelos simplificados das regressões múltiplas são apresentados a seguir, e consideram a aceleração gravitacional como sendo $9,81 \mathrm{~m} \mathrm{~s}^{-2}$ e temperatura da água a $20^{\circ} \mathrm{C}$. Todos modelos são considerados para o intervalo de diâmetro do tubo de 13,697 mm a 16,388 mm. O modelo ajustado para uniões (eq. 35) é válido desde que os intervalos de entrada sejam satisfeitos como $0,670 \leq \mathrm{V}_{\mathrm{T}} \leq 5,586 ; 63,459 \leq \mathrm{L}_{\mathrm{C}} \leq 79,994 ; 9,429 \leq \mathrm{Di} \leq 11,954$.

$$
h f_{L}=1,565 \cdot 10^{-2} \cdot V_{T}^{1,994} \cdot \frac{D_{T}^{4,522} \cdot L_{C}^{0,425}}{D_{i}^{4,953}}
$$


Em que, $\mathrm{hf}_{\mathrm{L}}$ é a perda de carga localizada $(\mathrm{m})$;

$\mathrm{V}_{\mathrm{T}}$ é a velocidade no tubo da linha lateral $\left(\mathrm{m} \mathrm{s}^{-1}\right)$;

$\mathrm{D}_{\mathrm{T}}$ é o diâmetro do tubo (mm);

LC é o comprimento da união (mm); e,

Di é o diâmetro interno médio da união (mm).

O modelo de conectores iniciais (eq. 36) é válido para os valores de: $0,643 \leq \mathrm{V}_{\mathrm{T}} \leq 4,113 ; 16,426 \leq \mathrm{L}_{\mathrm{E}} \leq$ 22,$931 ; 27,557 \leq \mathrm{L}_{\mathrm{S}} \leq 43,284 ; 7,816 \leq \mathrm{D}_{\mathrm{E}} \leq 9,791 ; 9,662 \leq \mathrm{D}_{\mathrm{S}} \leq 12,357$.

$$
h f_{L}=0,342 \cdot \frac{V_{T}^{1,994} \cdot D_{S}^{3,224} \cdot L_{E}^{0,228} \cdot D_{T}^{0,348}}{D_{E}^{3,436} \cdot L_{S}^{0,369}}
$$

Em que, $L_{E}$ é comprimento de entrada (mm);

$\mathrm{D}_{\mathrm{E}}$ é o diâmetro interno de entrada $(\mathrm{mm})$;

Ls é o comprimento de saída (mm);

$\mathrm{D}_{\mathrm{S}}$ é o diâmetro interno de saída (mm);

O modelo válido para registros de união (eq. 37) apresenta o intervalo de uso entre: $0,528 \leq \mathrm{V}_{\mathrm{T}} \leq 2,257$; $32,683 \leq \mathrm{L}_{\mathrm{E}} \leq 43,667 ; 13,507 \leq \mathrm{L}_{\mathrm{G}} \leq 14,114 ; 32,820 \leq \mathrm{L}_{\mathrm{S}} \leq 43,350 ; 11,482 \leq \mathrm{Di} \leq 11,587 ; 7,561 \leq \mathrm{D}_{\mathrm{G}} \leq 7,977$.

$$
h f_{L}=0,146 \cdot \frac{V_{T}^{2,004} \cdot D_{i}^{0,964} \cdot L_{S}^{7,012} \cdot D_{T}^{3,518}}{D_{G}^{1,328} \cdot L_{E}^{6,542} \cdot L_{G}^{3,621}}
$$

Em que, $\mathrm{D}_{\mathrm{G}}$ é o diâmetro interno da garganta $(\mathrm{mm})$;

$\mathrm{L}_{\mathrm{G}}$ é o comprimento da garganta $(\mathrm{mm})$.

Por fim, o modelo desenvolvido para registros inicias (eq. 38) possui os limites: $0,499 \leq \mathrm{V}_{\mathrm{T}} \leq 2,200$; $33,437 \leq \mathrm{L}_{\mathrm{E}} \leq 33,880 ; 12,901 \leq \mathrm{L}_{\mathrm{G}} \leq 14,196 ; 33,183 \leq \mathrm{LS}_{\mathrm{S}} \leq 43,143 ; 9,460 \leq \mathrm{D}_{\mathrm{E}} \leq 9,513 ; 7,550 \leq \mathrm{D}_{\mathrm{G}} \leq 7,618$; $11,507 \leq \mathrm{D}_{\mathrm{S}} \leq 11,610$.

$$
h f_{L}=0,591 \cdot V_{T}^{1,978} \cdot \frac{D_{T}^{3,606}}{D_{E}^{0,768} \cdot D_{S}^{1,134} \cdot D_{G}^{0,283} \cdot L_{E}^{0,648} \cdot L_{S}^{0,009} \cdot L_{G}^{0,786}}
$$

Os coeficientes ajustados para a modelagem completa são apresentados pela Tabela 6, juntamente com os respectivos erros quadráticos médios (RMSE) das equações simplificadas. O índice representa a acurácia dos valores observados com os estimados pelos modelos matemáticos. De modo geral, o modelo com menor erro quadrático médio deve ser escolhido (BATES; WATTS, 1988). 
Tabela 6. Coeficientes ajustados para a modelagem da perda localizada de carga para as categorias de (1) união; (2) conectores iniciais; (3) registros de união, e; (4) registros de conexões iniciais.

\begin{tabular}{cccccccccc}
\hline$\#$ & $\beta_{1}$ & $\beta_{2}$ & $\beta_{3}$ & $\beta_{4}$ & $\beta_{5}$ & $\beta_{6}$ & $\beta_{7}$ & $\beta_{8}$ & $\begin{array}{c}\text { RMSE } \\
\left(\mathrm{hf}_{\mathrm{LOC}}\right)\end{array}$ \\
\hline 1 & 0,16337 & $-0,00980$ & 0,42475 & $-4,95281$ & - & - & - & - & 0,12353 \\
2 & 3,63846 & $-0,01019$ & $-3,43619$ & 3,22370 & 0,22761 & $-0,36949$ & - & - & 0,29872 \\
3 & 1,34941 & 0,00642 & 0,96397 & $-1,32774$ & $-6,54166$ & 7,012498 & $-3,62144$ & - & 0,13074 \\
4 & 7,85250 & $-0,03681$ & $-0,76810$ & $-1,13418$ & $-0,28289$ & $-0,64843$ & $-0,00876$ & $-0,78617$ & 0,15164 \\
\hline
\end{tabular}

O modelo aplicado nos conectores iniciais foi a classe que mais apresentou discrepância com os valores observados. Muito embora esse erro quadrático médio aproxima-se do que foi obtido por Vilaça et al. (2017), onde os autores atingiram um RMSE de 0,2818 através de um modelo simplificado para predição da perda localizada de carga na passagem lateral de conectores iniciais. A Figura 47 apresenta a análise gráfica dos erros entre os dados estimados com os observados. O erro relativo dos dados estimados pela frequência acumulada de 100\%, 90\% e 50\% dos valores obtidos pelo modelo pode ser observado pela Figura 47B. Por exemplo, erros relativos de até 10\% foram observados em aproximadamente $91,31 \%$ da frequência acumulada dos valores estimados.

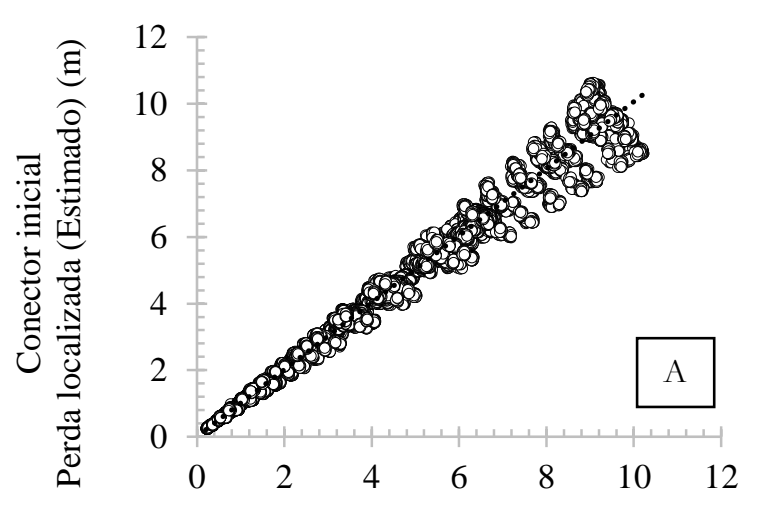

Observado (m)

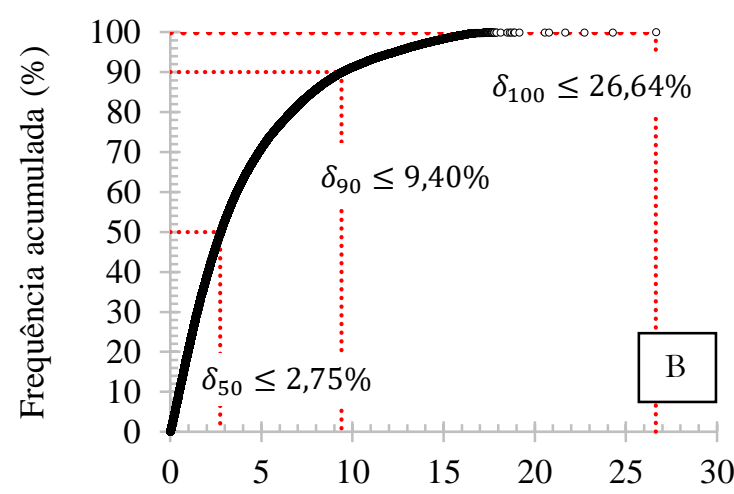

Erro relativo - $\delta(\%)$

Figura 47. Representação do desvio entre valores estimados e observados através do modelo desenvolvido para conectores iniciais, em que (a) valores estimados versus observado, e (b) análise gráfica do erro confrontando o erro relativo presente em dada frequência acumulada.

O mesmo processo de análise gráfica de erros foi efetuado para as classes de união, registros de união e registros iniciais. Sendo que, respectivamente, os erros relativos de até $10 \%$ foram observados em aproximadamente $85,77 \%, 65,35 \%$ e $77,52 \%$ da frequência acumulada dos valores estimados. Os gráficos podem ser visualizados nas Figuras 48, 49 e 50. 


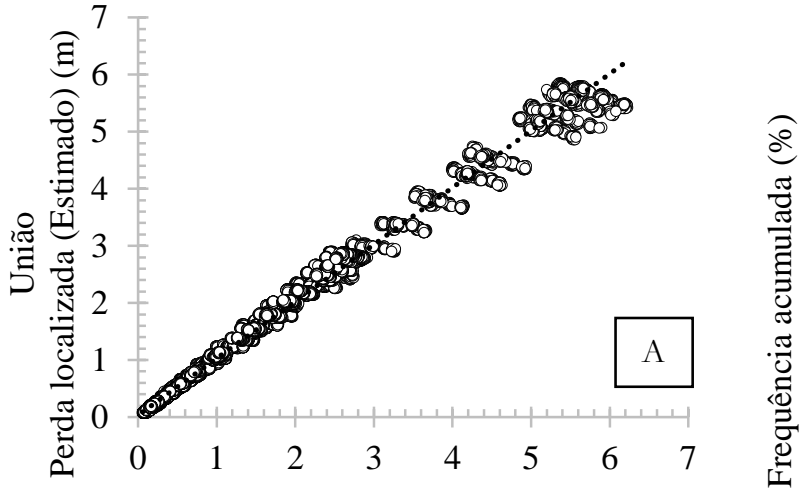

Observado (m)

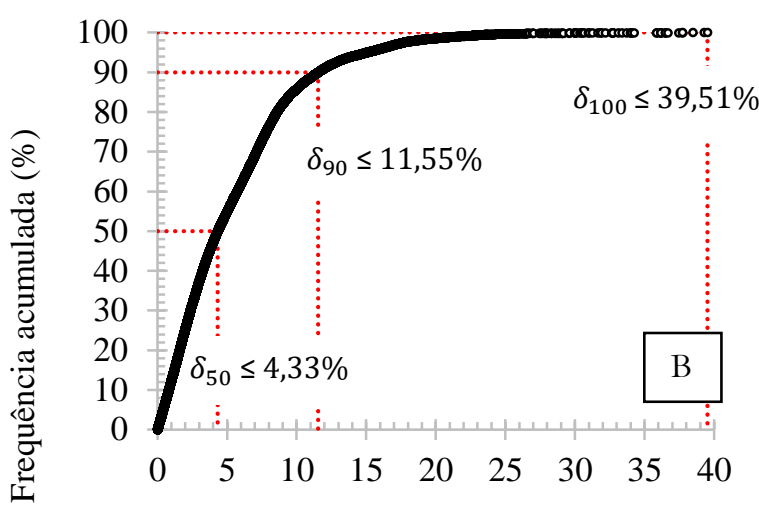

Erro relativo $-\delta(\%)$

Figura 48. Representação do desvio entre valores estimados e observados através do modelo desenvolvido para uniões, em que (a) valores estimados versus observado, e (b) análise gráfica do erro confrontando o erro relativo máximo por frequência acumulada.

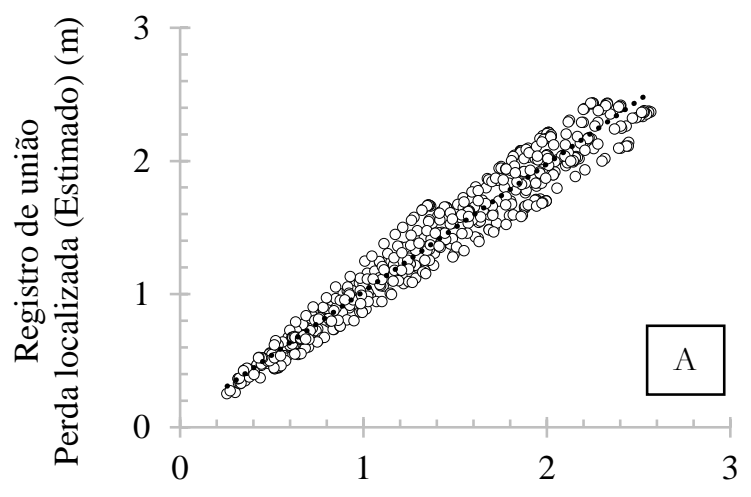

Observado (m)

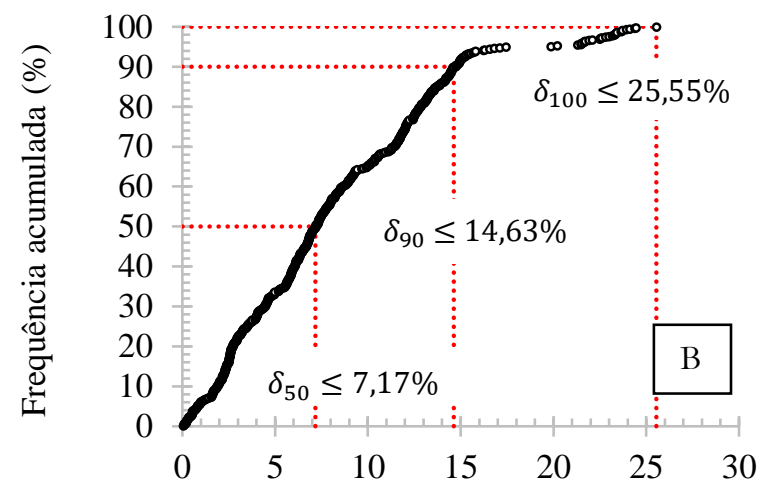

Erro relativo $-\delta(\%)$

Figura 49. Representação do desvio entre valores estimados e observados através do modelo desenvolvido para registros de união, em que (a) valores estimados versus observado, e (b) análise gráfica do erro confrontando o erro relativo máximo por frequência acumulada.
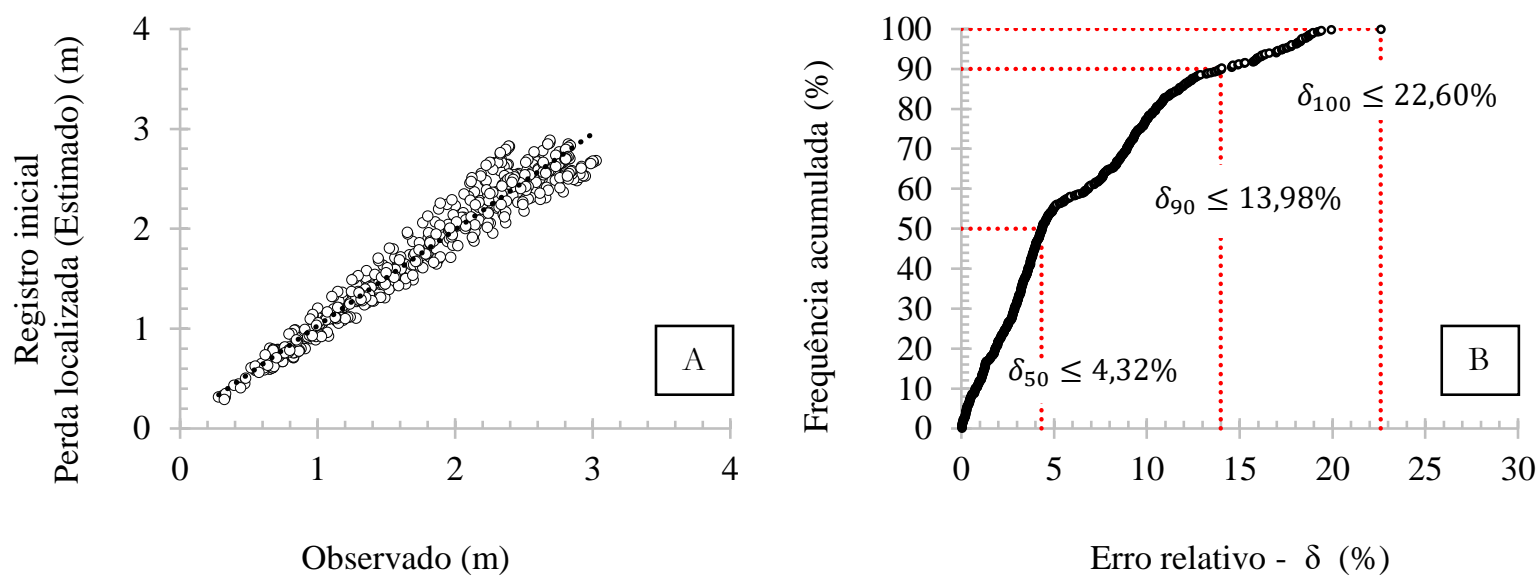

Figura 50. Representação do desvio entre valores estimados e observados através do modelo desenvolvido para registros iniciais, em que (a) valores estimados versus observado, e (b) análise gráfica do erro confrontando o erro relativo máximo por frequência acumulada. 
O modelo simplificado para conectores iniciais obtido nessa pesquisa foi comparado com o modelo simplificado proposto (eq. 39) por Vilaça et al. (2017), sendo obtido uma dispersão de pontos como apresentada pela Figura 51 juntamente com uma reta identidade assimilando seu desvio.

$$
h f_{L}=0,0190 \cdot \frac{V_{L}^{2,0632} D_{L}^{4,5565}}{v^{0,0632} D_{E}^{4,4933}}
$$

O modelo apresentado por Vilaça et al. (2017) é válido para $3026 \leq \operatorname{Re} \leq 94536 ; 0,4147 \leq \mathrm{D}_{\mathrm{E}} / \mathrm{D}_{\mathrm{L}} \leq$ 0,$7672 ; 0,5721 \leq \mathrm{D}_{\mathrm{S}} / \mathrm{D}_{\mathrm{L}} \leq 0,8538 ; 1,9435 \leq \mathrm{L}_{\mathrm{C}} / \mathrm{D}_{\mathrm{L}} \leq 4,3765$. O conjunto de dados de entrada é satisfeito para os intervalos condicionados de ambos modelos.
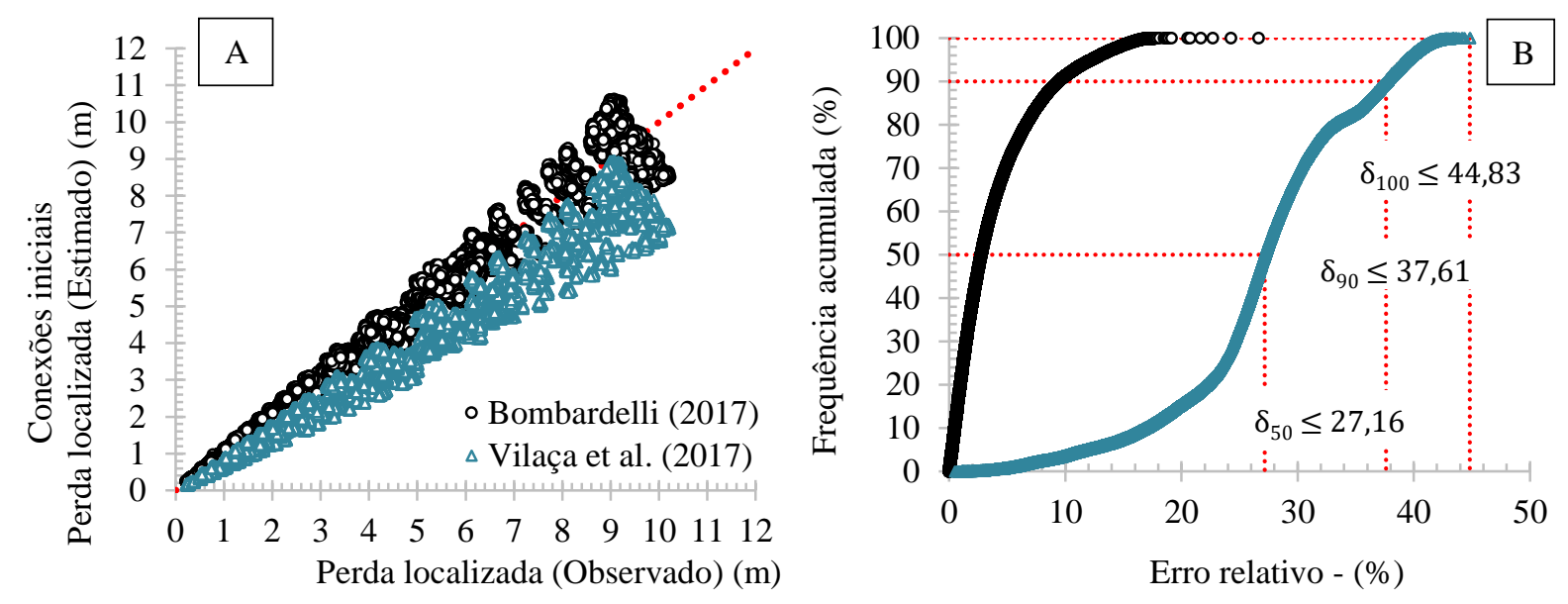

Figura 51. Representação da (a) perda localizada de carga nos conetores iniciais, estimado pelo modelo desse estudo e pelo modelo de Vilaça et al. (2017), com a perda localizada observada, e; (b) análise gráfica do erro confrontando o erro relativo máximo por frequência acumulada

O modelo proposto por Vilaça et al. (2017) subestimou as perdas localizadas de carga provocadas pelos conectores iniciais avaliados na presente pesquisa. O conjunto de dados de entrada utilizado nessa análise corresponde ao mesmo conjunto de dados empregado para o ajuste do modelo proposto e, portanto, é esperado que o modelo proposto apresente melhor acurácia do que aquele descrito por Vilaça et al. (2017). O desvio máximo absoluto verificado entre os pontos dos dois modelos foi de 2,088 $\mathrm{m}$ e os máximos atingindos por ambos modelos apresentaram um desvio percentual de $15,71 \%$.

Nesse caso, todos os dados foram usados para calibração do modelo. Entretanto, uma forma possivelmente mais apropriada para tal tipo de comparação, consistiria em separar os dados obtidos experimentalmente em dois grupos: dados para calibração do modelo e dados para validação do modelo. 


\section{CONCLUSÃO}

i. Os sistemas de controle e aquisição desenvolvidos para a bancada de ensaios operaram adequadamente, sendo capazes de atender os requisitos estabelecidos em normas técnicas.

ii. Os coeficientes de perda localizada de carga $\left(\mathrm{K}_{\mathrm{L}}\right)$ apresentaram valores de 2,691 até 24,075. De modo majoritário, esses coeficientes apresentaram constância após um número de Reynolds de 10000. Os expoentes da vazão assumem valores próximos do que é aplicado pela equação de Darcy-Weisbach ( $\mathrm{m}=2)$.

iii. Os modelos desenvolvidos a partir do teorema de Buckingham apresentaram um desempenho satisfatório para cada intervalo estabelecido. 


\section{REFERÊNCIAS}

AL-AMOUD, A. I. Significance of Energy Losses Due to Emitter Connections in Trickle Irrigation Lines. Journal of Agricultural Engineering Research, v. 60, n. 1, p. 1-5, 1995.

ALVES, D. G.; PINTO, M. F.; SALVADOR, C. A.; ALMEIDA, A. C. S.; ALMEIDA, C. D. G. C. De; BOTREL, T. A. Modelagem para o dimensionamento de um sistema de microirrigação utilizando microtubos ramificados. Revista Brasileira de Engenharia Agrícola e Ambiental, v. 16, n. 2, p. 125-132, 2012.

ANDRADE, L.; CARVALHO, J. de A. Análise da equação de Swamee-Jain para cálculo do fator de atrito. Revista Brasileira de Engenharia Agrícola e Ambiental, v. 316, n. 1, p. 554-557, 2001.

AZEVEDO NETTO, J. M.; FERNANDEZ Y FERNANDEZ, M. Manual de Hidráulica. 9 ed. São Paulo: Edgard Blucher, 2015.

BATES, D. M.; WATTS, D. G. Nonlinear Regression Analysis and Its Applications. Journal of the American Statistical Association, v. 85, n. 410, p. 594, 1988.

BOMBARDELLI, F. A.; GARCÍA, M. H. Hydraulic Design of Large-Diameter Pipes. Journal of Hydraulic Engineering, v. 129, n. 11, p. 839-846, 2003.

BRUNETTI, F. Mecânica dos Fluídos. 2. ed. São Paulo: Pearson Prentice Hall, 2008.

BUCKINGHAM, E. On physically similar systems: illustrations of the use of dimensional equations. Physical Review, v. 4, n. 4, p. 345-376, 1914.

CARDOSO, G. G. de G.; KLAR, A. E. Índice Geométrico E Perda De Carga Localizada Em Conexões De Emissores “Online”. Engenharia Agrícola, v. 34, n. 6, p. 1114-1127, 2014.

COLEBROOK, C. F.; WHITE, C. M. Experiments with fluid friction in roughened pipes. Proceedings of the Royal Society of London. Series A, Mathematical and Physical Sciences, v. 161, n. 906, p. 367-381, 1937.

EVANS, R. G.; WU, I.-P.; SMAJSTRALA, A. G. . Design and operation of farm irrigation systems. In: Microirrigation Systems. p. 632-683. St. Joseph: ASABE, 2007.

FISCHER, G. R.; WALLENDER, W. W. Collector size and test duration effects on sprinkler water distribution measurement. Transactions of the ASAE, v. 31, n. 2, p. 538-542, 1988.

FRIZZONE, J. A.; FREITAS, P. S. L.; REZENDE, R.; FARIA, M. A. Microirrigação: Gotejamento e microaspersão. 1. ed. Maringá: EDUEM, 2012.

GOMES, A. W. A. Perda localizada de carga em gotejadores integrados em tubos de polietileno. Dissertação: Irrigação e Drenagem. ESALQ/USP, 2009.

INTERNATIONAL ORGANIZATION FOR STANDARDIZATION. ISO TR 15155 - Test facilities for agricultural irrigation equipments. Genebra, 2005.

INTERNATIONAL ORGANIZATION FOR STANDARDIZATION. ISO 9644 - Pressure losses in irrigation valves - Test method. Genebra, 2008.

KELLER, J. .; BLIESNER, R. D. Sprinkle and trickle irrigation. New York: Champman \& Hall, 1990.

KOTOWSKI, A.; SZEWCZYK, H.; CIEZAK, W. Entrance loss coefficients in pipe hydraulic systems. Environment Protection Engineering, v. 37, n. 4, p. 105-117, 2011.

LIKHACHEV, E. R. Dependence of Water Viscosity on Temperature and Pressure. Technical Physics, v. 48, n. 4, p. 514-515, 2003.

MANTOVANI, E. C.; BERNARDO, S.; PALARETTI, L. F. Irrigação: princípios e métodos. 3. ed. Viçosa: UFV, 2012.

MONTGOMERY, D. C. Introdução ao Controle Estatístico da Qualidade. 4. ed. LTC: 2013.

MUNSON, B. R.; YONG, D. F.; OKIISHI, T. H. Fundamentos da mecânica dos fluidos. 4. ed. São Paulo: Edgard Blucher, 2004.

NIU, W.; LIU, L.; CHEN, X. Influence of fine particle size and concentration on the clogging of labyrinth emitters. Irrigation Science, 2012.

PERBONI, A. Sensibilidade de gotejadores à obstrução por partículas de areia. Tese: Engenharia de Sistemas Agrícolas. ESALQ/USP, 2016. 
PERBONI, A.; FRIZZONE, J. A.; CAMARGO, A. P. de; PINTO, M. F. Modelling head loss along emitting pipes using dimensional analysis. Journal of the Brazilian Association of Agricultural Engineering, v. 35, n. 3, p. 442457, 2015.

PERES, J. G. Hidráulica Agrícola. 1. ed. Araras: EDUFSCAR, 2015.

PINTO, M. F.; CAMARGO, A. P. De; NETO, O. R.; FRIZZONE, J. A. Caracterização hidráulica de tubos porosos oriundos de pneus reciclados utilizados em irrigação subsuperficial. Revista Brasileira de Engenharia Agrícola e Ambiental, v. 18, n. 11, p. 1095-1101, 2014.

PORTO, R. de M. Hidráulica Básica. 4 ed. São Carlos: EESC/USP, 2006.

PRADO, G. do. Decréscimo da energia de pressão devido a instalação de conexões e peças especiais nas tubulações. Enciclopédia Biosfera, v. 11, n. 21, p. 2542-2555, 2015.

PROVENZANO, G.; PUMO, D. Experimental Analysis of Local Pressure Losses for Microirrigation Laterals. Journal of Irrigation and Drainage Engineering, v. 130, n. 4, p. 318-324, 2004.

RETTORE NETO, O. Metodologia para determinação da perda de carga localizada em emissores não coaxiais integrados a tubos de polietileno. Dissertação: Irrigação e Drenagem. ESALQ/USP, 2008.

RETTORE NETO, O. Modelo para determinação da perda de carga contínua em tubos elásticos. Tese: Irrigação e Drenagem. ESALQ/USP, 2011.

RETTORE NETO, O.; BOTREL, T. A.; FRIZZONE, J. A.; PINTO, M. F.; CAMARGO, A. P. Quantificação do erro na determinação da perda contínua de carga em tubos elásticos. Engenharia Agrícola, v. 33, n. 6, p. 13121321, 2013.

RETTORE NETO, O.; FRIZZONE, J. A.; MIRANDA, J. H. de; BOTREL, T. A. Perda de carga localizada em emissores não coaxiais integrados a tubos de polietileno. Engenharia Agrícola, v. 29, n. 1, p. 28-39, 2009.

ROCHA, H. S.; MARQUES, P. A. A.; CAMARGO, A. P.; FRIZZONE, J. A.; SARETTA, E. Internal surface roughness of plastic pipes for irrigation. Bras. Eng. Agríc. Ambiental, v. 2121, n. 33, p. 143-149, 2017.

ROCHA, H. S. da. Rugosidade superficial interna de tubos para irrigação. Dissertação: Engenharia de Sistemas Agrícolas. ESALQ/USP, 2014.

ROCHA, H. S. da. Controle estatístico de qualidade aplicado a ensaios de material de irrigação. Tese: Engenharia de Sistemas Agrícolas. ESALQ/USP, 2016.

ROMEO, E.; ROYO, C.; MONZÓN, A. Improved explicit equations for estimation of the friction factor in rough and smooth pipes. Chemical Engineering Journal, v. 86, n. 3, p. 369-374, 2002.

SARETTA, E. Análise de incerteza de um sistema automatizado para ensaios de aspersores de irrigação. Tese: Engenharia de Sistemas Agrícolas. ESALQ/USP, 2014.

SCALOPPI, E. J. Critérios básicos para seleção de sistemas de irrigação. Informe agropecuário, v. 12, n. 139, p. 54-63, 1986.

SEGINER, I.; KAIITZ, D.; NIR, D.; VON BERNUTH, R. D. Indoor measurement of single-radius sprinkler patterns. Transactions of the ASAE, v. 35, n. 2, p. 523-533, 1992.

SONNAD, J. R.; GOUDAR, C. T. Using a Mathematically Exact Alternative to the Colebrook - White Equation. Journal of Hydraulic Engineering, v. 132, n. 8, p. 863-867, 2006.

SWAMEE, P. K. Design of a Submarine Oil Pipeline. Journal of Transportation Engineering, v. 119, n. 1, p. 159-170, 1993.

SWAMEE, P. K.; JAIN, A. K. Explicit equations for pipe-flow problems. Journal of Hydraulics Division ASCE, v. 102, n. HY5, p. 8, 1976.

TANAKA, M.; GIRARD, G.; DAVIS, R.; PEUTO, A.; BIGNELL, N. Recommended table for the density of water between $0{ }^{\circ} \mathrm{C}$ and $40^{\circ} \mathrm{C}$ based on recent experimental reports. Metrologia, v. 38, n. 4, p. 301, 2001.

TARJUELO, J. M.; MONTERO, J.; VALIENTE, M.; HONRUBIA, F. T.; ORTIZ, J. Irrigation Uniformity with Medium Size Sprinklers Part I: Characterization of Water Distribution in No-Wind Conditions. Transactions of the ASAE, v. 42, n. 3, p. 665-675, 1999.

TSAKIRIS, G.; TSAKIRIS, V. Pipe technologies for urban water conveyance distribution systems. Water Utility Journal, v. 3, n. 1, p. 29-36, 2012.

URREA, C.; MORALES, C.; KERN, J. Implementation of error detection and correction in the Modbus-RTU serial protocol. International Journal of Critical Infrastructure Protection, v. 15, p. 27-37, 2016. 
VALLE, F. R. El nacimiento de la Hidráulica Experimental. Ing. Hidráulica Y Ambiental, v. 36, n. 3, p. 48-60, 2015.

VILAÇA, F. N. Perda de carga em conectores iniciais da irrigação localizada. Dissertação: Irrigação e Drenagem. ESALQ/USP, 2012.

VILAÇA, F. N.; DE CAMARGO, A. P.; FRIZZONE, J. A.; MATEOS, L.; KOECH, R. Minor losses in start connectors of microirrigation laterals. Irrigation Science, v. 35, n. 3, p. 227-240, 2017.

VILELA, L. A. A.; SOCCOL, O. J.; GERVÁSIO, E. S.; FRIZZONE, J. A.; BOTREL, T. A. Alteração no diâmetro e na perda de carga em tubos de polietileno submetidos a diferentes pressões. Revista Brasileira de Engenharia Agrícola e Ambiental, v. 7, n. 1, p. 182-185, 2003.

VON BERNUTH, R. D. Simple and Accurate Friction Loss Equation for Plastic Pipe. Journal of Irrigation and Drainage Engineering, v. 116, n. 2, p. 294-298, 1990.

YILDIRIM, G. An assessment of hydraulic design of trickle laterals considering effect of minor losses. Irrigation and Drainage, v. 56, n. 1, p. 399 - 421, 2007.

YILDIRIM, G.; AGIRALIOGLU, N. Comparative Analysis of Hydraulic Calculation Methods in Design of Microirrigation Laterals. Journal of Irrigation and Drainage Engineering, v. 130, n. 3, p. 201-217, 2004.

YOO, D. H.; SINGH, V. P. Two Methods for the Computation of Commercial Pipe Friction Factors. Journal of Hydraulic Engineering, v. 131, n. 8, p. 694-704, 2005.

ZANON, E. R.; TESTEZLAF, R.; MATSURA, E. J. A data acquisition system for sprinkler uniformity testing. Applied Engineering in Agriculture, v. 16, n. 2, p. 123-127, 2000. 